\title{
Características Operacionais de Praças de Arrecadação de Pedágio
}

\author{
Juliana J erônimo de Araújo
}

Dissertação apresentada à Escola de Engenharia de São Carlos da Universidade de São Paulo, como parte dos requisitos para obtenção do título de Mestre em Engenharia Civil com ênfase em Transportes.

Orientador: Prof. Dr. J osé Reynaldo A. Setti 


\section{SUMÁRIO}

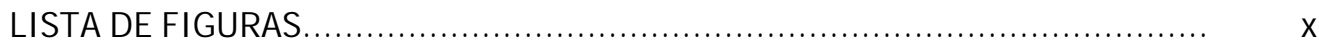

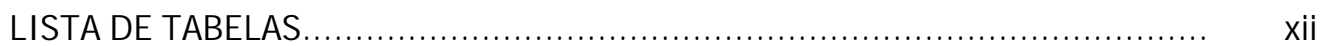

LISTA DE ABREVI ATURAS E SIGLAS ............................................... xiv

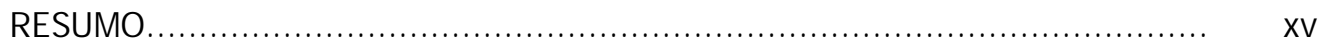

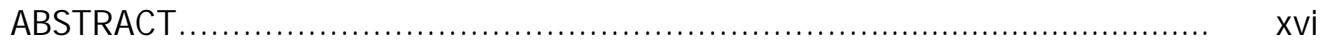

1 I NTRODUÇÃO.................................................................................... 1

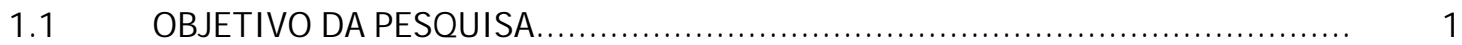

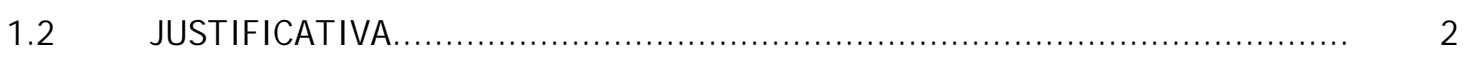

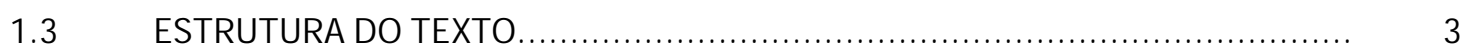

$2 \quad$ OPERAÇÃO DE PRAÇAS DE PEDÁGI O................................................ 5

2.1 CAPACIDADE DE PRAÇAS DE PEDÁGI O......................................... 7

2.2 NÍ VEL DE SERVIÇO DE PRAÇAS DE PEDÁGI O............................................. 9

2.3 COLETA ELETRÔNICA DE PEDÁGI O....................................................... 11

2.4 TÉCNI CAS OPERACIONAIS PARA MELHORIA DO NÍVEL DE SERVIÇO EM PRAÇAS DE PEDÁGI O...................................................................... 13

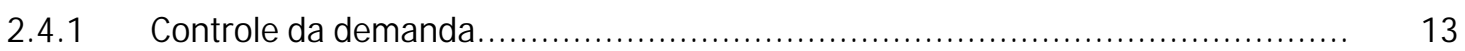

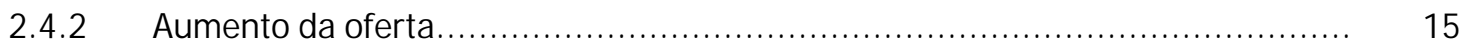

3 MODELAGEM DA OPERAÇÃO DE PRAÇAS DE PEDÁGI O....................... 18

C.1 CLASSI FICAÇÃO DOS MODELOS............................................................ 18 
3.2 MODELOS ANALÍTICOS DE PRAÇAS DE PEDÁGI O..................................... 19

M.3 MODELOS DE SI MULAÇÃO.......................................................... 22

3.3.1 Vantagens e desvantagens da simulação........................................... 23

3.3.2 Modelos de simulação de praças de pedágio............................................... 24

ANÁLISE DO NÍVEL DE SERVIÇO EM PRAÇAS DE PEDÁGIO...................................... 24

AVALIAÇÃO DO NÚMERO ÓtIMO DE CABI NES EM PRAÇAS DE PEDÁGIO......................... 26

ANÁLISE DO IMPACTO DA IMPLANTAÇÃO DE COLETA ELETRÔNICA DE PEDÁGIO.................. 29

AVALIAÇÃO DA OPERAÇÃO DE PRAÇAS COM COLETA ELETRÔNI CA DE PEDÁGIO.................. 30

4 CARACTERI ZAÇÃO OPERACI ONAL DE PRAÇAS DE ARRECADAÇÃO DE PEDÁGIO........................................................................................... 34

4.1 DEFINIÇÃO DOS PARÂMETROS E DAS PRAÇAS ESTUDADOS........................ 34

4.2 TÉCNI CAS E EQUI PAMENTOS UTILIZADOS NAS COLETAS DOS DADOS.......... 36

4.2.1 Câmeras de vídeo......................................................................... 36

4.2.2 Sensores para coleta automática de dados............................................. 37

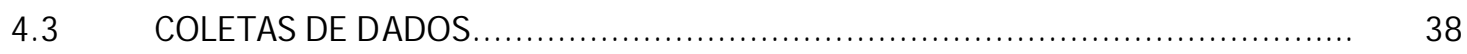

4.4 ANÁLISE DOS DADOS COLETADOS.................................................... 40

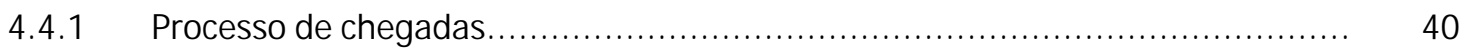

4.4.2 Perfis da desaceleração e da aceleração................................................. 43

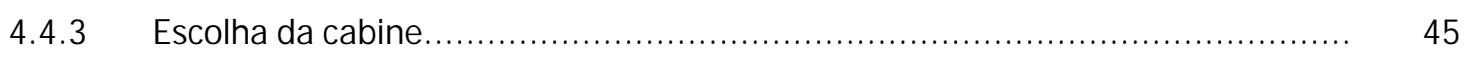

4.4.4 Tempos de atendimento......................................................... 46

EFEITO DAS CLASSES VEICULARES SOBRE O TEMPO DE ATENDIMENTO.......................... 48

EFEITO DA PRAÇA SOBRE O TEMPO DE ATENDIMENTO......................................... 50

EFEITO DO VALOR DA TARI FA SOBRE O TEMPO DE ATENDI MENTO........................... 52

EFEITO DO FLUXO DE TRÁFEGO DA PRAÇA SOBRE O TEMPO DE ATENDIMENTO.................. 53

EFEITO DO SENTIDO DE FLUXO SOBRE O TEMPO DE ATENDIMENTO......................... 55

EFEITO DO TIPO DE USUÁRI O SOBRE O TEMPO DE ATENDIMENTO............................ 56

EFEITO DA FORMA DE PAGAMENTO SOBRE O TEMPO DE ATENDIMENTO......................... 57

4.4.5 Coleta eletrônica de pedágio.................................................... 58 
5 ESTUDO DE CASO: AVALI AÇÃO DO NÍ VEL DE SERVI ÇO ATRAVÉS DE UMA MODELO DE SI MULAÇÃO........................................................... 64

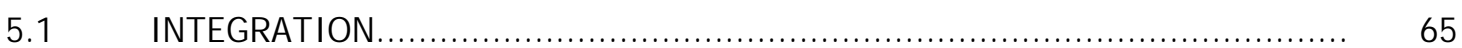

5.1.1 Estrutura básica do INTEGRATION......................................................... 65

5.1.2 Lógicas fundamentais do INTEGRATION............................................... 67

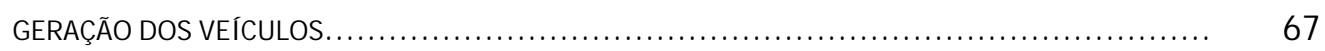

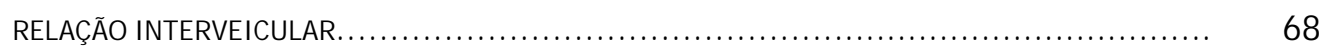

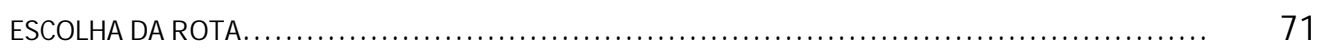

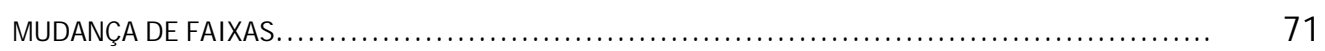

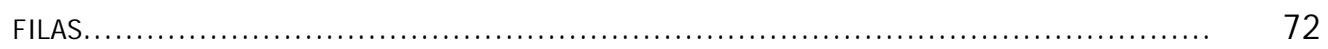

5.2 DESCRIÇÃO DO MODELO PROPOSTO............................................. 72

5.2.1 Dados de entrada do modelo de simulação.............................................. 74

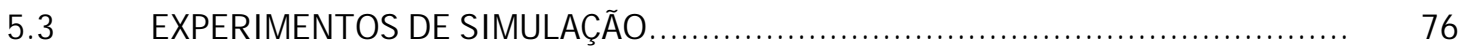

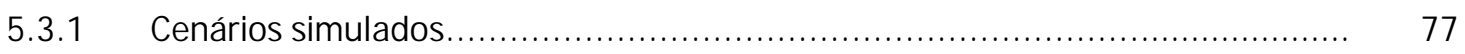

5.3.2 Discussão dos resultados obtidos na simulação..................................... 79

5.4 ANÁLISE DE CRITÉRIOS PARA AVALIAÇÃO DO NÍVEL DE SERVIÇO DE PRAÇAS DE PEDÁGI O.................................................................. 81

5.4.1 Tempo médio no sistema......................................................... 81

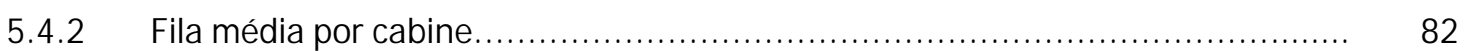

5.4.3 Um método para estabelecimento de critérios para avaliação do nível de serviço de praças de pedágio.......................................................... 83

6 CONCLUSÕES E RECOMENDAÇÕES............................................. 86

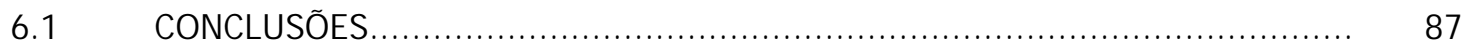

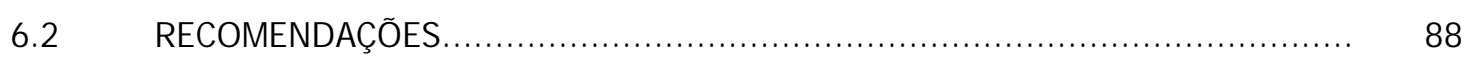

ANEXO A: ARQUI VOS DO INTEGRATI ON......................................... 91

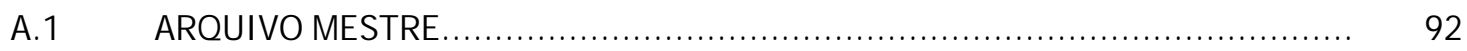

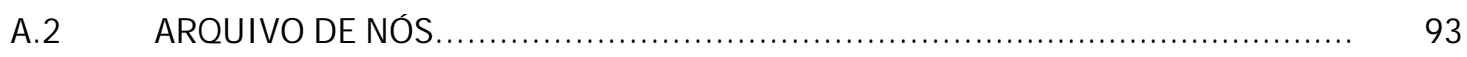

A.3 ARQUIVO DE TRAMOS .................................................................. 94 


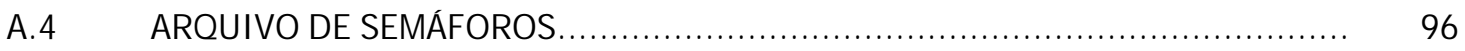

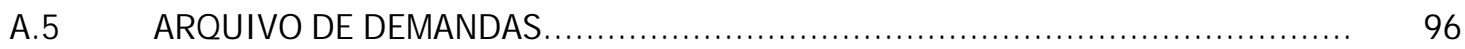

A. 6 ARQUIVO DE INCIDENTES........................................................ 96

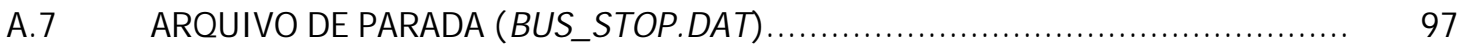

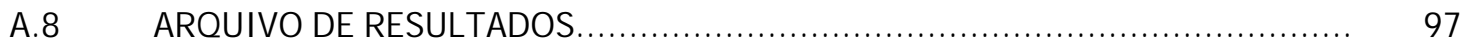

A. 9 ARQUIVO DE ESTATÍSTICAS DA SIMULAÇÃO (RUNERR.OUT)..................... 98

REFERÊNCI AS BLI OGRÁFI CAS....................................................... 100 


\section{LISTA DE FI GURAS}

2.1 Cabines de pedágio ramificadas.......................................................... 15

2.2 Layout da praça com cobrança unidirecional para automóveis e bidirecional para caminhões e ônibus..................................................................... 16

2.3 Praça de pedágio exclusiva para caminhões e ônibus.................................... 17

2.4 Cabines de pedágio em tandem..................................................... 17

4.1 Mapa de São Paulo com a localização das praças estudadas......................... 36

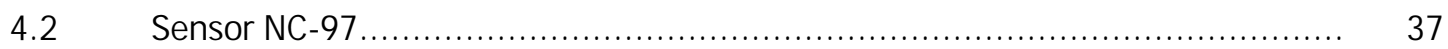

4.3 Sensor instalado no pavimento......................................................... 37

4.4 Posicionamento da câmera para coleta de tempo de atendimento................. 40

4.5 Posicionamento da câmera para coleta de perfil de aceleração....................... 40

4.6 Fluxos horáriso observados e fatores de hora pico, praça de Araraquara......... 41

4.7 Distribuições teórica e observada de headways para o período 11:00$12: 00 \mathrm{~h}$.

4.8 Distribuição dos tempos de atendimento dos veículos por classe veicular.

4.9 Distribuição dos tempos de atendimento dos veículos nas praças, sem estratificação por tipo de veículo.

4.10 Distribuição dos tempos de atendimento em função da forma de pagamento.

4.11 Distribuição dos tempos de atendimento nas cabines AVI .......................... 59

4.12 Distribuição dos tempos de atendimento.................................................. 60 
5.1 Relações entre as variáveis de tráfego [Van Aerde, 2000]............................ 69

$5.2 \quad$ Tela do INTEGRATION e rede simulada (sem escala)................................ 73

5.3 Resultados obtidos na simulação para o tempo médio gasto no sistema......... 80

5.4 Resultados obtidos na simulação para o comprimento médio de fila por cabi-

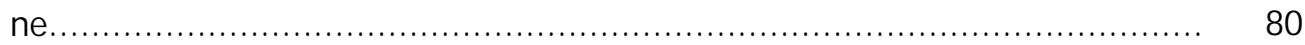

5.5 Níveis de serviço para critérios do tempo médio no sistema......................... 85

5.6 Níveis de serviço para critérios da fila média.............................................. 85

A.1 Rede simulada (sem escala) .......................................................... 95 


\section{LISTA DE TABELAS}

2.1 Valores encontrados na literatura para capacidade de cabines de pedágio

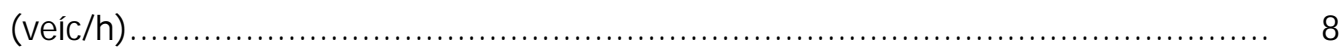

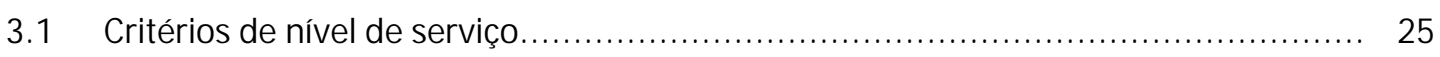

4.1 Exemplo de planilha contendo os dados obtidos pelos sensores NC-97............... 38

4.2 Dados coletados e equipamentos utilizados............................................ 39

4.3 Testes de aderência da distribuição exponencial negativa aos headways observa-

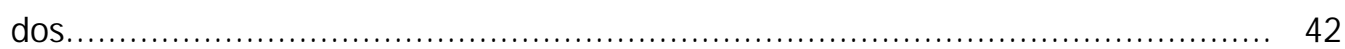

4.4 Parâmetros médios observados na desaceleração e na aceleração...................... 45

4.5 Parâmetros relativos aos tempos de atendimento (em segundos), em função da

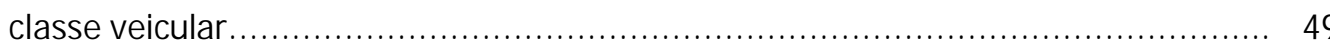

4.6 Médias dos tempos de atendimento (em segundos), em função da praça de pe-

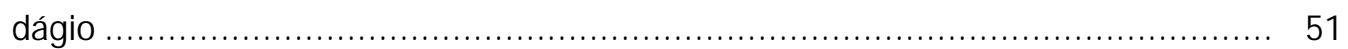

4.7 Classificação das praças em função do fluxo de tráfego................................ 54

4.8 Classificação das praças em função do tipo de usuário..................................... 56

4.9 Parâmetros relativos aos tempos de atendimento (em segundos), em função da forma de pagamento.............................................................................. 60

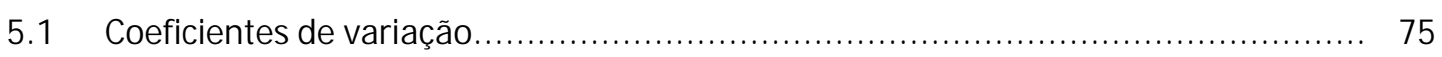

5.2 Descrição dos cenários simulados............................................................... 78

5.3 Descrição dos cenários adicionais simulados................................................ 79

5.4 Critérios de nível de serviço adotados por Lin e Su [1994] e Gulewicz e Danko [1995] 
5.5 Fluxos de tráfego limites para critérios baseados no tempo médio no sistema (veíc/h) 82

5.6 Fluxos de tráfego limites para critérios baseados na fila média (veíc/h)............... 83

5.7 Correlação entre as medidas de desempenho usadas para avaliar o nível de serviço de praças de pedágio.

A.1 Descrição dos dados do arquivo mestre..................................................... 93

A.2 Descrição dos dados contidos no arquivo de nós......................................... 94

A.3 Descrição dos dados contidos no arquivo de tramos...................................... 95

A.4 Descrição dos dados contidos no arquivo de demanda.................................... 96

A.5 Descrição dos dados contidos no arquivo de parada (bus_stop.dat)................... 97

A.6 Descrição dos resultados gerados no arquivo file16. out.................................. 98

A.7 Descrição das estatísticas apresentadas no arquivo runerr.out........................... 99 


\title{
LISTA DE ABREVI ATURAS E SI GLAS
}

\author{
ANOVA - Analysis of Variance \\ ASCII - American Standard Code for Information Interchange \\ AVI - Automatic Vehicle Identification \\ DERSA - Desenvolvimento Rodoviário S.A. \\ DER-SP - Departamento de Estradas de Rodagem de São Paulo \\ ETC - Electronic Toll Collection \\ FHP - Fator de Hora-Pico \\ GPS - Global Positioning System \\ HCM - Highway Capacity Manual \\ HOV - High Occupancy Vehicle \\ VMI - Vehicle Magnetic Imaging
}




\section{RESUMO}

ARAÚJ O, J J J . (2001). Características operacionais de praças de arrecadação de pedágio. São Carlos, 2001. 104 p. Dissertação (Mestrado) - Escola de Engenharia de São Carlos, Universidade de São Paulo.

O objetivo desta pesquisa foi analisar a operação de praças de arrecadação de pedágio, a fim de fornecer subsídios para o seu projeto e para o estabelecimento de parâmetros e procedimentos para avaliação do nível de serviço. Os dados foram coletados em cinco praças de pedágio do Estado de São Paulo, localizadas fora do meio urbano. Os aspectos operacionais estudados foram: o processo de chegadas dos veículos às praças; o perfil da velocidade durante a desaceleração dos veículos na entrada da praça; o processo de escolha da cabine pelos motoristas; o processo de atendimento dos veículos nas cabines (incluindo a forma de pagamento da tarifa); o perfil da velocidade durante a aceleração dos veículos na saída da praça; e as velocidades desenvolvidas nas cabines AVI, que são cabines que atendem somente veículos portadores da tecnologia de cobrança eletrônica de pedágio. As conclusões principais da análise dos dados coletados são: o processo de chegadas dos veículos à praças de pedágio pode ser representado por uma distribuição exponencial negativa (para intervalos curtos); modelos lineares são uma aproximação razoável para a representação do perfil da velocidade durante a desaceleração e a aceleração dos veículos nas praças; a maioria dos motoristas escolhe a cabine no mesmo lado em que chega à praça de pedágio e, uma vez selecionado o lado, se dirige à cabine com menor fila; caminhões e ônibus tendem a usar as cabines do lado direito da praça; alguns motoristas se dirigem a uma cabine com fila mesmo quando há cabines disponíveis para o atendimento naquele lado da praça; e o tempo de atendimento dos veículos nas cabines varia em função do tipo de veículo, da forma de pagamento e das características da praça com relação ao valor da tarifa, fluxo de tráfego e tipo de usuário predominante. Apresenta-se um exemplo de como esses dados podem ser usados para a determinação do nível de serviço das praças, através de um modelo de simulação, que indicou que o uso da cobrança eletrônica de pedágio reduz consideravelmente o congestionamento nas praças de pedágio: com o fluxo de tráfego próximo da capacidade da praça, o tempo médio gasto na praça é reduzido quase àmetade se $10 \%$ dos usuários optarem pelo pagamento eletrônico da tarifa.

Palavras-chave: praças de pedágio; tempo de atendimento; operação de praças de pedágio; simulação. 


\section{ABSTRACT}

ARAÚJ O, J. J. (2001). Toll plazas operational characteristics. São Carlos, 2001. 104 p. Dissertação (Mestrado) - Escola de Engenharia de São Carlos, Universidade de São Paulo.

The research objective was to analyze the operation of toll plazas in order to give subsidies for its project as well as to establish parameters and procedures to evaluate the service level. The data were collected in five toll plazas in the state of São Paulo, operated in rural highways. The operational aspects studied were: the vehicle arrival process; the speed profile during deceleration at the toll plaza entrance; the process in which drivers select toll booths; the vehicle processing time at toll booths (including payment method); the speed profile during acceleration at the toll plaza exit; and the speed at AVI toll booths, which process just vehicles equipped with electronic toll collection. The conclusions of the colleted data analysis are: the vehicle arrival process can be represented by a negative exponential distribution (for short time intervals); linear models are an acceptable approach to represent the speed profile during deceleration and acceleration of vehicles at toll plazas; the majority of drivers choose the toll booth in the same side that they arrive the toll plaza and, once the side is chosen, they go to the booth with the shortest queue; trucks and buses frequently go to the right side of the toll plaza; some drivers go to a toll booth with queue despite the availability of free booths at that side of the plaza; and the vehicle processing time at toll booths varies with the vehicle type, the payment method and the plaza characteristics related with the toll value, the traffic volume and the predominant user. An example of how this data can be used to determine the service level of toll plazas is showed by using a simulation model. This model indicated that the use of electronic toll collection reduces considerably congestions at toll plazas: when the traffic flow approaches capacity, the average time spent at the toll plaza is reduced near half if $10 \%$ of the users change from manual payment to electronic payment method.

Keywords: toll plazas; processing time; toll plazas operation; simulation. 


\section{Caṕtulo1}

\section{NTRODUÇÃO}

Ao longo dos anos 80 e 90, as rodovias brasileiras passaram por um processo de deterioração causado pelos cortes nos recursos destinados àsua conservação e construção. Para reverter essa situação e permitir a implantação de melhorias no sistema, a União e alguns estados (entre eles o de São Paulo) iniciaram programas de concessão da operação de suas principais rodovias, regulamentados pela Lei $n-8987 / 95$, que trata das concessões de serviços públicos a empresas privadas. Nos termos dessa lei, que vincula remuneração e tarifação, a privatização de rodovias envolve a instalação de praças de arrecadação de pedágio, uma vez que a remuneração das empresas responsáveis pela operação das rodovias privatizadas é feita através da cobrança de tarifas aos usuários.

Um importante aspecto da concessão de rodovias é o controle da qualidade do serviço prestado aos usuários, que envolve aspectos referentes ao estado do pavimento e da sinalização, aos serviços de assistência e àcapacidade e nível de serviço dos diversos segmentos.

\subsection{OBJ ETI VO DA PESQUISA}

O objetivo da pesquisa é analisar as características operacionais de praças de arrecadação de pedágio, de modo a fornecer subsídios para seu projeto e para o estabelecimento de procedimentos e parâmetros para a avaliação do nível de serviço prestado aos usuários. Para tanto, foram definidos os seguintes passos: 


\section{Revisão bibliográfica:}

Visa a realização de um levantamento do estado da técnica relacionada ao projeto e operação de praças de pedágio, incluindo inovações tecnológicas e operacionais, medidas de desempenho operacional, técnicas de modelagem e modelos que representem o seu funcionamento.

\section{Definição da amostra e dos dados a serem coletados:}

Visa a definição dos dados a serem coletados, a avaliação da melhor forma para a coleta desses dados e a escolha de um conjunto de praças de pedágio que represente as diversas tecnologias e os diversos procedimentos operacionais em uso no Estado de São Paulo, de tal modo que seja possível fazer uma caracterização realística do comportamento dos usuários e da operação das praças de pedágio.

\section{Coleta de dados:}

Visa a obtenção dos dados necessários para a caracterização do comportamento dos usuários e a realização de uma análise da operação das praças escolhidas para a coleta de dados.

\section{Análise dos dados:}

Visa, através de uma análise dos dados coletados, a caracterização do comportamento dos usuários e do efeito de políticas operacionais observadas nas praças, comparando o desempenho das praças estudadas através das relações observadas entre os dados coletados em cada uma delas.

\section{Proposta preliminar de um método para avaliação do nível de serviço de praças de pe-} dágio:

Visa a proposta de um método para avaliar o nível de serviço de praças de pedágio, com base nos dados coletados, nos resultados da análise desses dados e com auxílio de um modelo de simulação.

\subsection{J USTI FI CATIVA}

Em abril de 1998, o Estado de São Paulo iniciou o programa de concessão de suas principais 
rodovias. Esse programa transfere para empresas privadas as receitas de pedágio e também os custos de conservação, operação e ampliação das rodovias privatizadas. Antes do início do programa, o estado possuía 45 praças de pedágio. Esse número saltou para 93 em pouco mais de três anos.

Daí, existe uma clara necessidade de se conhecer bem o funcionamento das praças de pedágio visto que a cobrança da tarifa é um dos aspectos mais críticos da qualidade do serviço prestado pelas concessionárias de rodovias, afetando significativamente a percepção do nível de serviço. Demoras excessivas causadas por falhas no projeto, dimensionamento ou operação de uma praça podem influir direta e negativamente na opinião do usuário do sistema.

Apesar de o HCM, o Highway Capacity Manual [TRB, 2000], não apresentar um procedimento específico para praças de pedágio, a aplicação dos seus procedimentos foi a forma escolhida pelo órgão responsável pela fiscalização das concessionárias para avaliar o nível de serviço e garantir a qualidade do serviço prestado aos usuários.

A pesquisa desenvolvida procura caracterizar da forma mais realística possível os parâmetros relacionados àoperação das praças de pedágio do Estado de São Paulo e seus resultados poderão contribuir para aumentar a eficiência das praças de arrecadação de pedágio, ao permitirem a análise de alternativas operacionais e tecnológicas que proporcionem diminuição do tempo de espera nos pedágios e, conseqüentemente, redução do tempo de viagem.

\subsection{ESTRUTURA DO TEXTO}

Este texto está organizado em seis capítulos. O capítulo 1 apresenta os objetivos da pesquisa e uma justificativa para o seu desenvolvimento. O capítulo 2 apresenta as principais características que dizem respeito àoperação de praças de pedágio e o capítulo 3 descreve uma visão geral da utilização de modelos analíticos e de simulação na análise da operação de praças de pedágio.

O capítulo 4 contém a descrição das coletas de dados, apresentando o método apli- 
cado em cada uma delas, os equipamentos utilizados e as praças estudadas, além da análise dos dados coletados. O simulador escolhido, o modelo de simulação desenvolvido, os resultados das simulações e um método para o estabelecimento de critérios para a determinação do nível de serviço de praças de pedágio são apresentados no capítulo 5. O capítulo 6 descreve as conclusões da pesquisa e recomendações para estudos futuros.

Por fim, o anexo A apresenta exemplos de arquivos texto contendo os dados necessários para o funcionamento do simulador, o INTEGRATION, e os resultados das simulações. 


\section{Capítulo2}

\section{OPERAÇÃO DE PRAÇAS DE PEDÁGIO}

Por se constituir num gargalo potencial, a coleta de pedágio pode ter sérias repercussões no gerenciamento e nas operações de tráfego em rodovias. O congestionamento que ela ocasiona pode ser grave o suficiente para que sejam consideradas alternativas no projeto e estratégias operacionais que visem amenizar a situação [Lin e Su, 1994].

O mecanismo básico da coleta de pedágio tem permanecido imutável desde que foram construídos os primeiros sistemas: os motoristas devem desacelerar os veículos e parar em uma cabine de coleta para efetuar o pagamento. Essas paradas impedem o fluxo contínuo do tráfego, aumentam o tempo total de viagem e potencialmente podem reduzir o nível de serviço da rodovia. Existem diversas tecnologias para reduzir o tempo gasto no pagamento da tarifa nas cabines, as mais antigas baseadas em fichas (tokens) e moedas, e as mais modernas baseadas em cartões inteligentes (touchless cards), reconhecimento de placas e transponders. Destas, apenas os sistemas baseados no reconhecimento de placas ou em transponders permitem que a cobrança seja realizada com os veículos em movimento.

Para os usuários, o custo total associado aos pedágios vai além da tarifa paga. Existe também o custo do tempo adicional gasto na passagem pela praça de pedágio, já que os veículos devem desacelerar, esperar nas filas, pagar a tarifa e reacelerar até a velocidade de cruzeiro. Em períodos de grande movimento, como feriados prolongados, este tempo total pode ser significativo nas rodovias que dão acesso a grandes metrópoles. Além do aumento 
do tempo de viagem, os usuários também têm outros custos relacionados aos veículos, entre eles, o aumento do consumo de combustível.

Tendo em vista que a administração de um sistema de transportes deve ser feita de modo a reduzir o seu custo total, no qual se incluem os custos de operação e construção, o custo para o usuário e o custo para o meio-ambiente (associado ao aumento da emissão de gases poluentes e do ruído), o fator preponderante para o estudo da operação de praças de pedágio é a redução do tempo gasto para o pagamento da tarifa.

A redução do atraso adicional causado pelas praças de pedágio pode ser alcançada através de melhoramentos no sistema que têm outros objetivos. Por exemplo, Gazis e Gomory [1994] constataram que melhorias operacionais (instalação de cabines automatizadas), que visavam primordialmente reduzir o custo da mão-de-obra e possíveis desvios de receita, também haviam reduzido o tempo médio de espera dos usuários.

Algumas tecnologias modernas (como a Electronic Toll Collection - ETC ou, em português, coleta eletrônica de tarifa) permitem que os motoristas paguem as tarifas com os veículos em movimento, através do registro automático de sua passagem, e, com isso, podem gerar benefícios econômicos e ambientais significativos. Os veículos podem passar pelas cabines em velocidades entre 40 e $50 \mathrm{~km} / \mathrm{h}$ e os custos de operação do sistema são menores, já que não existe a necessidade de contratar arrecadadores [Doering, 1997].

A coleta eletrônica de tarifa se utiliza da Automatic Vehicle Identification - AVI (definida, em português, como identificação automática de veículos), que tem a capacidade de identificar os veículos ao passarem por pontos específicos na rodovia, sem a necessidade de nenhuma interação com o motorista. A AVI funciona utilizando comunicação entre um transponder, chamado de tag (espécie de etiqueta eletrônica), fixado no pára-brisa do veículo e um sensor instalado na cabine de pedágio ou ao lado da rodovia. Esse sensor pode ler as informações do veículo parado ou se movendo em alta velocidade [Al-Deek et al., 1996]. 


\subsection{CAPACI DADE DE PRAÇAS DE PEDÁGIO}

O principal objetivo da análise da capacidade é estimar o volume máximo de tráfego que pode ser acomodado por um determinado sistema de transporte [Woo e Hoel, 1991]. A capacidade de uma cabine de pedágio pode ser definida como o fluxo máximo horário de veículos que podem atravessá-la em um determinado período de tempo, obedecendo as condições de tráfego e controle [Lin e Su, 1994]. Em uma praça de pedágio, a capacidade é uma das principais medidas de interesse durante a fase de projeto. E, apesar de a relação volume/capacidade (v/c) ser usada na definição do nível de serviço para vários tipos de componentes viários, a capacidade não pode ser facilmente quantificada para praças de pedágio, já que parece não existir concordância em relação ao seu valor real [Woo e Hoel, 1991].

Como o HCM não prevê um método para análise de capacidade e nível de serviço em praças de pedágio, a sua capacidade tem sido estabelecida através de observações empíricas de seu desempenho ou de suposições acerca do fluxo máximo que uma cabine pode atender, o que explica em parte as variações consideráveis nos valores encontrados em diferentes estudos [Woo e Hoel, 1991]. Segundo Zarrillo [2000], observações em campo revelam que a capacidade de uma praça depende das características do tráfego, bem como das características da própria praça, tais como o número de cabines disponíveis e o tipo de cobrança em cada cabine, uma vez que diferentes serviços requerem diferentes tempos de atendimento e a capacidade da praça depende da taxa na qual os veículos podem ser processados.

A Tabela 2.1 sintetiza os valores encontrados em alguns estudos para a capacidade de cabines de pedágio, em função dos tipos de cobrança: manual, automática, mista (eletrônica e manual/automática), eletrônica exclusiva e eletrônica expressa. As cabines com cobrança manual são aquelas que precisam de um arrecadador para realizar o processamento dos veículos. As cabines com cobrança automática são aquelas em que o pagamento é feito através de uma máquina que aceita fichas, moedas ou cartão, não havendo a necessidade de um arrecadador. 
Se a cobrança eletrônica for realizada em paralelo com outro tipo de cobrança (manual ou automática), é denominada como mista. Quando a cabine opera somente veículos com AVI, diz-se que ela é uma cabine eletrônica exclusiva. E, por fim, a cabine eletrônica expressa é uma cabine exclusiva para veículos portadores de AVI que difere da anterior por ser fisicamente separada da praça de pedágio.

Tabela 2.1: Valores encontrados na literatura para capacidade de cabines de pedágio (veíc/h)

\begin{tabular}{lccccc}
\hline \multirow{2}{*}{ ESTUDOS } & \multicolumn{5}{c}{ TI PO DA CABI NE } \\
\cline { 2 - 6 } & Manual & Automática & Mista & $\begin{array}{c}\text { Eletrônica } \\
\text { Exclusiva }\end{array}$ & $\begin{array}{c}\text { Eletrônica } \\
\text { Expressa }\end{array}$ \\
\hline Woo e Hoel [1991] & - & $665-745$ & - & - & - \\
Pietrzyk e Mierzejewski [1993] & 350 & 500 & 700 & 1.200 & 1.800 \\
Lin e Su [1994] & 360 & 775 & - & - & - \\
Pesquera et al. [1997] & 225 & 475 & - & - & - \\
Polus e Reshetnik [1997] & $250-450$ & $550-850$ & - & 1.200 & - \\
\hline
\end{tabular}

Uma cabine de pedágio opera na sua capacidade quando há a formação de fila e quando observa-se que o seu operador está ocupado durante todo o tempo. Alguns autores sugerem que, sob condições de tráfego leve, os operadores consomem mais tempo processando os veículos do que quando pressionados por uma fila, quando eles tendem a executar a transação com maior velocidade [Woo e Hoel, 1991]. O tempo de atendimento pode ser influenciado por vários fatores, entre eles: a experiência dos arrecadadores, o valor da tarifa, o comprimento e a largura das faixas de tráfego laterais ⿳亠े cabines, o método de cobrança e a presença de usuários com o valor exato da tarifa. Os níveis de congestionamento de tráfego também afetam o tempo de atendimento, pois, quando uma fila se forma, os motoristas dispõem de tempo para procurar o valor exato da tarifa antes da transação [Woo e Hoel, 1991].

Observa-se que cabines com significativo tráfego de veículos pesados têm taxas de atendimento mais baixas do que as demais, tornando evidente que o comprimento do veículo e seu poder de aceleração são importantes fatores no que se refere ao tempo de atendi- 
mento. Veículos pesados geralmente possuem uma baixa aceleração devido àsua alta rel ação massa/potência [Woo e Hoel, 1991].

Entre as várias medidas que podem ser tomadas para aumentar a capacidade de uma praça de pedágio, as mais freqüentemente adotadas são [Ardekani e Torres, 1991]:

- uso de cabines exclusivas para portadores de valor exato da tarifa;

- uso de cabines em tandem;

- isenção de cobrança para veículos com alta ocupação;

- alargamento da entrada da praça de pedágio; e

- fixação do valor da tarifa em números não fracionários.

O desempenho de uma praça de pedágio pode ser significativamente afetado por vários fatores, tais como: capacidade de atendimento, distribuição de chegada dos veículos, número de cabines disponíveis, comportamento dos motoristas e projeto geométrico da praça [Lin e Su, 1994].

\subsection{NÍ VEL DE SERV ÇO DE PRAÇAS DE PEDÁGIO}

O nível de serviço é uma medida qualitativa que sintetiza as condições operacionais de um fluxo de tráfego e suas percepções pelos usuários. Fatores tais como velocidade e tempo de viagem, liberdade de manobra, interrupção de tráfego, conforto e segurança geralmente influem no nível de serviço [TRB, 2000]. Apesar de o conceito de nível de serviço englobar todas as condições operacionais de um sistema de transportes, na prática, ele tem sido estabelecido através de uma ou duas medidas de desempenho para cada tipo de sistema [Reilly, 1992].

O nível de serviço de praças de pedágio deve ser quantificado por várias razões: ele possibilita a avaliação de alternativas operacionais e de projeto através de um padrão aceitável, provê uma base sólida para comparação das condições operacionais de várias praças, fornece meios de avaliar as condições antes e depois de alguma alteração na operação das praças e determina a eficiência dessa alteração, e dá aos usuários e operadores uma medida palpável do desempenho global do sistema [Woo e Hoel, 1991]. 
A análise do nível de serviço de praças de pedágio tem sido baseada na utilização de duas medidas relativamente simples - o comprimento médio de fila e o tempo médio no sistema - que efetivamente são capazes de refletir a qualidade do serviço. Essas medidas são facilmente percebidas pelos usuários, além de serem úteis para avaliar a necessidade e o efeito de melhorias específicas ou para estabelecer a qualidade do serviço sob as diversas condições encontradas durante a operação da praça [Woo e Hoel, 1991].

As seguintes condições gerais de operação foram propostas por Woo e Hoel [1991] para cada nível de serviço relativo ò praças de pedágio:

- Nível de serviço A: existe uma baixa densidade de tráfego e pouco atraso. 0 comportamento dos veículos não é afetado pela presença dos demais, apesar de a desaceleração ser necessária. Não há formação de filas e o nível geral de conforto é excelente.

- Nível de serviço B: os veículos começam a desacelerar mais cedo do que quando o nível de serviço é A. A presença de outros veículos no fluxo de tráfego começa a ser notada, entretanto, há boa oportunidade de mudança de faixa. O nível de conforto ainda é alto, porém menor que no nível de serviço $A$.

- Nível de serviço C: o número de veículos parados é significativo. Os atrasos são resultantes de uma antecipação na desaceleração. As filas começam a se formar. Há uma queda considerável de conforto neste nível de serviço.

- $\quad$ Nível de serviço D: os veículos possuem pouca liberdade de manobra para escoIha da cabine. O comprimento da fila se torna significativo e as condições de fluxo interrompido (stop-and-go) se tornam inevitáveis.

- $\quad$ Nível de serviço E: todos os veículos enfrentam filas antes de chegar ⿳亠े cabines. O tráfego de fluxo interrompido (stop-and-go) é um fenômeno típico. Manobras nas aproximações das cabines são quase impossíveis.

- Nível de serviço F: há uma relação v/c maior que 1 , condição que geralmente ocorre quando a taxa de chegada excede a taxa de atendimento. As filas continuam a crescer, avançando até alcançarem a rodovia. 


\subsection{COBRANÇA ELETRÔNI CA DE PEDÁGIO}

A fase de testes para a cobrança eletrônica de pedágio, feita através da identificação automatizada de veículos (AVI), teve início em torno de 1986, nos Estados Unidos [Schaufler, 1997]. Inicialmente, notava-se uma falta de padronização nos métodos de cobrança eletrônica de pedágio, em função da adoção de diferentes tecnologias pelos diversos fornecedores. Dessa forma, logo evidenciou-se a necessidade do desenvolvimento de um procedimento padronizado, devido ao interesse de empresas concessionárias de rodovias, túneis e pontes por sistemas de identificação automática de veículos para a cobrança de pedágio [Spasovic et al., 1995].

As tecnologias AVI podem ser divididas de acordo com a freqüência da radiação eletromagnética, com o método pelo qual o sinal é modulado e com a característica do transponder (gerador ou simples refletor da radiação eletromagnética). E, de forma geral, todas as tecnologias AVI existentes operam através da interceptação da radiação eletromagnética emitida ou refletida por um transponder instalado no veículo, seguida da interpretação da informação contida no sinal e da utilização de um computador para identificar o transponder em um banco de dados [Pietrzyk e Mierzejewski, 1993]. A diferença entre elas recai na forma como essas tarefas são executadas e a freqüência de radiação mais utilizada é 5,8 GHz, embora haja muita discussão em torno do assunto [Pietrzyk e Mierzejewski, 1993].

Os Estados Unidos operam seus sistemas AVI em uma freqüência mais baixa (915 MHz), já que constataram que a freqüência de $5,8 \mathrm{GHz}$, adotada na Europa e no J apão, tem um custo mais alto e que o seu sinal é mais difícil de ser controlado. Porém, pode-se prever uma mudança do sistema americano para uma freqüência mais alta (não necessariamente 5,8 GHz) devido ao número crescente de interferências no sistema [Samuel, 1997].

A transação completa da identificação automatizada de veículos ocorre enquanto os veículos percorrem a área coberta pelo sistema. O comprimento dessa área e a distância de comunicação são determinados pela sensibilidade do receptor, pelo tipo de antena, pelo local e pela potência transmitida. Usualmente essa distância não é maior que 40 m [Spasovic et al., 1995]. 
O potencial dessa tecnologia é muito grande. Além dos benefícios relacionados àcoleta de pedágios, ela possui um valor adicional devido àsua utilização em outras áreas de transportes, tais como gerenciamento de tráfego e informação ao usuário [Spasovic et al., 1995]. A transmissão de informações sobre as condições operacionais das vias contribui para um melhor aproveitamento do espaço viário [Yermack et al., 1995].

O custo inicial de qualquer sistema de cobrança eletrônica é maior que o de sistemas manuais ou automáticos. Porém, como a capacidade de processamento da cobrança eletrônica é consideravelmente maior que a dos métodos convencionais e, não sendo necessários arrecadadores nas cabines, existe uma redução do custo total associado àoperação de praças de pedágio [Dando, 1997].

Atualmente vários países fazem uso da AV, entre eles, Alemanha, Argentina, Austrália, Brasil, Canadá, China, Estados Unidos, França, Inglaterra, Itália, Japão e Suécia [Collard e Alves, 1997; King, 1997; McManus, 1997; Samuel, 1997; Hamet, 1999; Sumner, 1999].

No Brasil, o Estado de São Paulo iniciou o processo de implantação do sistema de cobrança eletrônica de pedágio em junho de 2000, quando teve início sua fase de operação comercial controlada. Durante essa fase, veículos comerciais previamente selecionados foram equipados com tags a fim de testar a tecnologia escolhida e, com isso, realizar os acertos técnicos-operacionais necessários para torná-la disponível em todas as praças das rodovias estaduais.

Como as cabines AVI são instaladas junto a cabines normais - já que as cabines para pagamento manual ainda são operadas -, por motivos de segurança, a velocidade máxima sinalizada para as faixas AVI é $40 \mathrm{~km} / \mathrm{h}$, apesar de a tecnologia permitir passagem de veículos a velocidades bastante superiores a esse valor (em torno de $100 \mathrm{~km} / \mathrm{h}$ ). Quanto maior a velocidade adotada, maior o risco de acidentes decorrentes da diferença de velocidade entre veículos equipados com tags e os que devem parar nas cabines para efetuar o pagamento do pedágio [McDonald e Stammer, 2000]. 


\subsection{TÉCNI CAS OPERACI ONAIS PARA MELHORI A DO NÍ VEL DE SERVI ÇO EM PRAÇAS DE PEDÁGIO}

A melhoria do nível de serviço em uma praça de pedágio pode ser alcançada reduzindo-se a demanda (o fluxo de veículos que chega àpraça), aumentando-se a oferta (a taxa de atendimento de veículos na praça) ou atuando simultaneamente sobre a oferta e a demanda. Esta seção discute algumas técnicas operacionais que podem ser usadas para a melhoria do nível de serviço em praças de pedágio.

\subsubsection{Controle da demanda}

A redução de congestionamento através do controle da demanda realizado pela cobrança de tarifas diferenciadas de acordo com período do dia e a isenção da cobrança para veículos com alta ocupação (HOV, sigla para o termo "high occupancy vehicle") vem ganhando espaço nos últimos anos [Poppe et al., 1994; Turnbull et al., 1994; Chen e Bernstein, 1995; Prendergast, 1995; Spock, 1998; Dahlgren, 2000].

Nos Estados Unidos, a idéia da cobrança diferenciada de tarifas vem sendo seriamente discutida. Seu objetivo principal é limitar a utilização das rodovias nos horários de pico e, com isso, aumentar a eficiência do sistema, já que a taxação sobre congestionamentos é defendida pelos economistas e especialistas em transportes como uma ferramenta útil para aliviar o congestionamento do tráfego [Turnbull et al., 1994; Adler e Cetin, 2000]. Prendergast [1995] ressalta que é preciso acabar com a noção de que as rodovias já foram pagas pelos contribuintes e, por conseguinte, seu uso deve ser livre de taxação, pois a cobrança de pedágio refere-se ao uso dos espaços viários e não ao pagamento dos custos de construção da infra-estrutura.

Ainda que o uso de pedágio como fator de controle da demanda possa encontrar resistência para ser aceito como uma solução para a redução de congestionamentos, com o passar do tempo a receptividade dessa idéia tende a aumentar devido àcomparação com outras alternativas, tais como o aumento do valor do combustível [Prendergast, 1995].

Sob uma avaliação técnica, o desenvolvimento da cobrança eletrônica de tarifa - 
com capacidade de processar de 1.200 a 1.800 veíc/h por cabine, valor consideravelmente superior ⿳亠े capacidades dos métodos tradicionais de coleta - torna possível a implementação eficiente da cobrança de tarifas diferenciadas [Prendergast, 1995].

E, mesmo quando apenas parte dos veículos estão equipados com transponders, o sistema AVI pode ser utilizado para a cobrança de tarifas diferenciadas, desde que sejam adotados critérios que permitam aos usuários não portadores de AVI o conhecimento prévio do valor da tarifa a ser cobrada [Chen e Bernstein, 1995]. Ou seja, as barreiras que impedem o uso de sistemas AVI como mecanismo de cobrança de tarifas de congestionamento não são técnicas e sim, políticas.

Spock [1998] observou que um ponto importante seria o estudo da reação dos usuários a essa cobrança. Não se sabe se eles estariam dispostos a pagar as taxas, se fariam uso da carona programada (transporte solidário), se mudariam seus horários de partida ou suas rotas ou se utilizariam o transporte público. No entanto, qualquer que seja a alternativa escolhida pelos usuários, é certo que haverá uma redução da demanda nos períodos de pico.

O objetivo das faixas para HOVs é prover menores tempos de viagem em rodovias congestionadas para veículos com vários ocupantes, ao que muitas vezes associa-se a isenção do pedágio como um incentivo adicional. O intuito é reduzir o número de veículos com um único ocupante, aumentando as caronas programadas ("carpooling") ou incentivar o uso do transporte público, de tal forma que o número de viagens possa ser reduzido, que a emissão de poluentes possa ser diminuída e que o congestionamento seja amenizado [Schofer e Czepiel, 2000].

Poppe et al. [1994] conduziram estudos no estado do Arizona (Estados Unidos) para analisar o efeito da operação de faixas para HOVs. Os resultados se mostraram bastante favoráveis nos períodos de grande congestionamento nas faixas adjacentes, demonstrando que a implantação de faixas para HOV pode ser considerada uma solução eficiente. 


\subsubsection{Aumento da oferta}

A forma mais simples de se aumentar a capacidade de uma praça de pedágio e de melhorar o nível de serviço é aumentar o número de cabines em operação. Isso implica na construção de praças de grande largura e extensão, o que nem sempre é viável, em função das características físicas do local ou do custo de construção. Para aumentar a capacidade sem aumentar a largura da praça existente, existem três alternativas básicas: a construção de cabines ramificadas, a construção de cabines reversíveis e a construção de cabines em tandem.

Quando é impossível aumentar o número de cabines de pedágio devido àfalta de espaço, ao custo de desapropriações, etc., existe a possibilidade de se aumentar a oferta através de uma solução adotada com sucesso no estado americano de New Jersey, a implantação de cabines de pedágio ramificadas (Figura 2.2), que podem ser construídas antes ou depois da praça de pedágio existente, separadas da via principal [Zlocchi, 1990].

Zilocchi [1990] ressalta que para cada tipo de área (urbana ou rural) e, conseqüentemente, para cada composição e volume de tráfego, devem ser feitas alterações para adequar a localização das cabines ramificadas. Desse modo, cada praça passa a possuir um projeto particular, o que evidencia a necessidade de uma intensa campanha de esclarecimento e educação aos motoristas quando da adoção dessa alternativa.

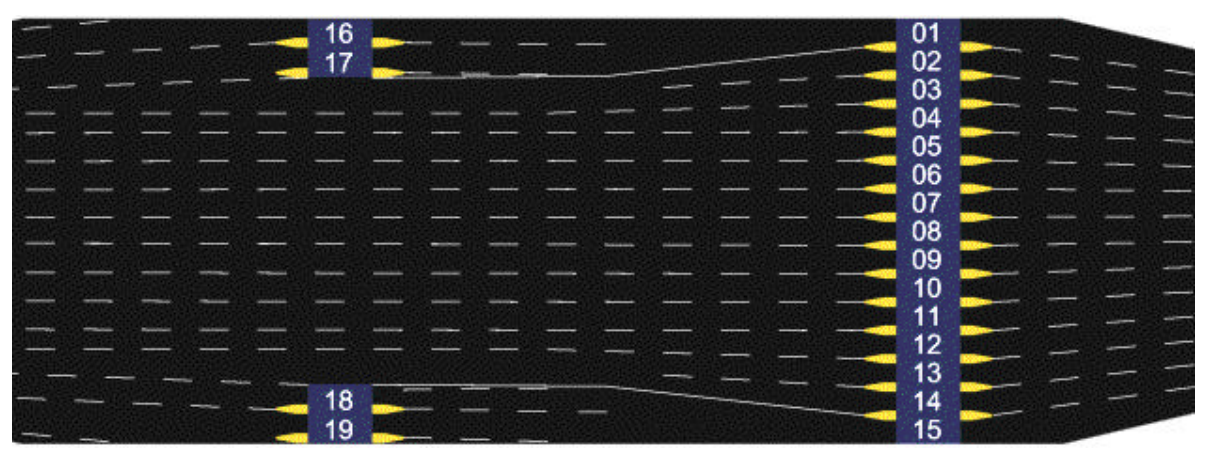

Figura 2.2: Cabines de pedágio ramificadas

Cabines reversíveis também se mostram eficientes quando usadas para aumentar a capacidade de praças de pedágio [Schaufler, 1997]. Para a implantação dessas cabines deve 
existir uma diferença significativa nos volumes de tráfego direcionais nos períodos de pico e entre picos. O sucesso das cabines reversíveis depende também de uma área suficiente na praça para absorver as mudanças nas zonas de transição [Schaufler, 1997]. Algumas concessionárias paulistas fazem uso dessas cabines.

A cobrança de tarifa em um só sentido é outra opção que vem sendo usada por várias concessionárias no Estado de São Paulo para aumento da capacidade das praças de pedágio. Seu conceito é similar ao das cabines reversíveis, já que provê uma capacidade adicional na direção selecionada [Schaufler, 1997].

Do ponto de vista de alguns usuários - principalmente transportadores de carga que fazem a viagem de retorno sem carga -, o pagamento de tarifa numa única direção pode ser inconveniente. Para evitar este problema, uma solução vem sendo adotada em São Paulo: combinação de pedágio unidirecional para automóveis com pedágio bidirecional para ônibus e caminhões. Dessa forma, provê-se um aumento de capacidade e uma redução no tempo de viagem dos veículos particulares, que pagam a tarifa num único sentido, e atendese a injunções políticas das empresas de transporte, cobrando-se metade da tarifa normal em cada direção. As Figuras 2.3 e 2.4 mostram, respectivamente, o layout deste tipo de praça e a praça exclusiva para caminhões e ônibus. Os evasores que continuam pela via principal são fotografados e posteriormente multados.

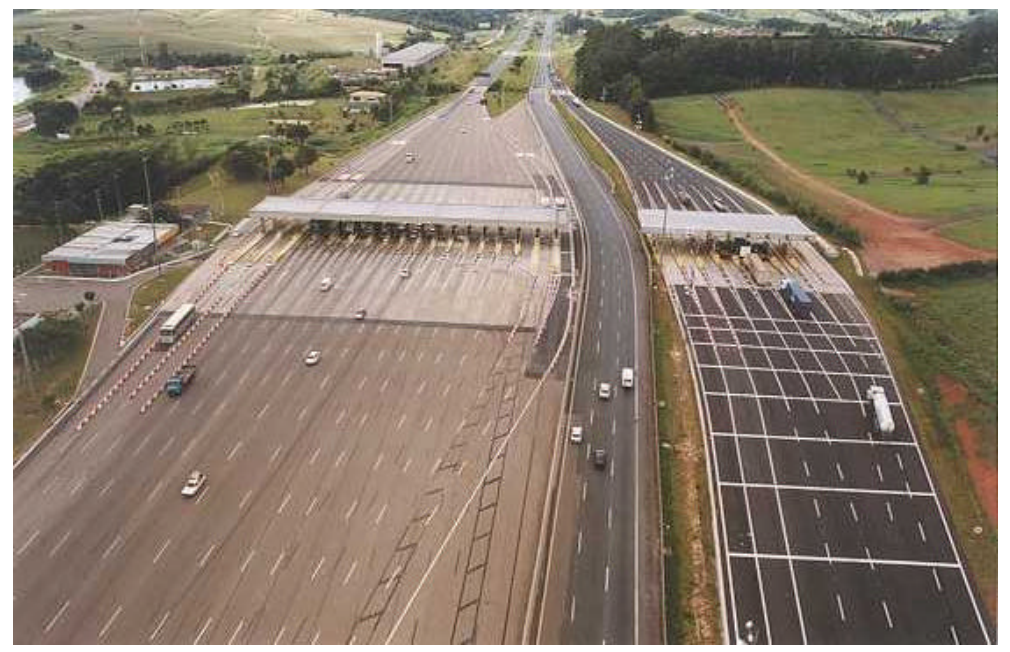

Figura 2.3: Layout da praça com cobrança unidirecional para automóveis e bidirecional para caminhões e ônibus 


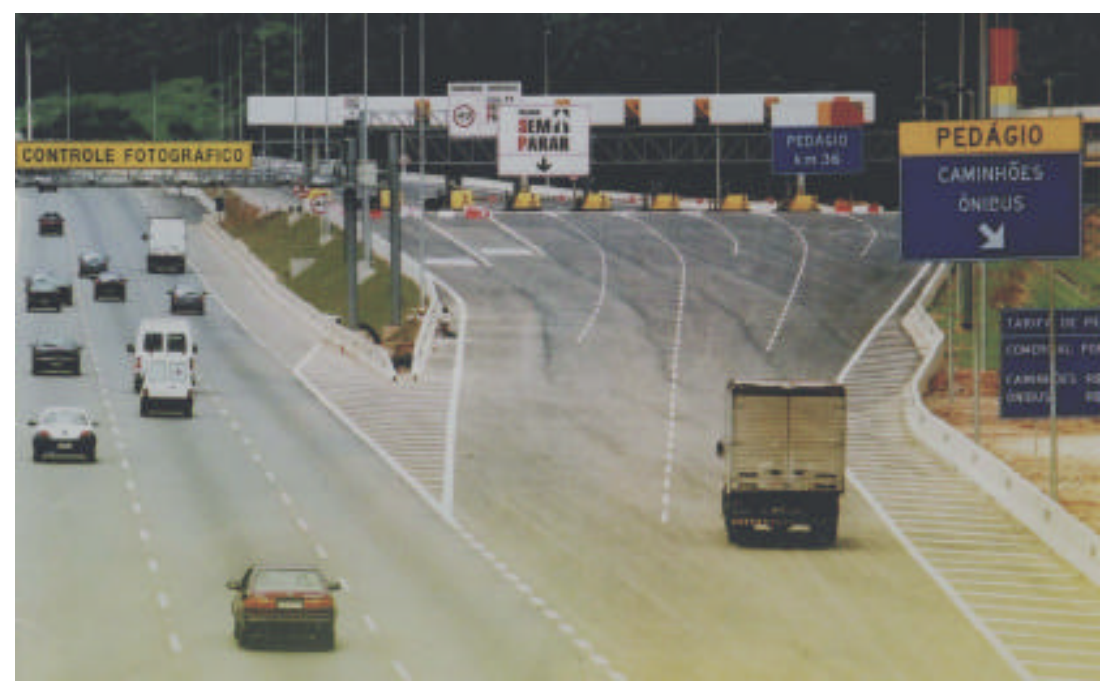

Figura 2.4: Praça de pedágio exclusiva para caminhões e ônibus

Uma terceira alternativa para aumento da capacidade é o uso de cabines de pedágio em tandem, que consiste no alinhamento de duas cabines em uma mesma faixa de tráfego. Dessa forma, permite-se o processamento simultâneo de dois veículos, como se mostra na Figura 2.5 [Schaufler, 1997].

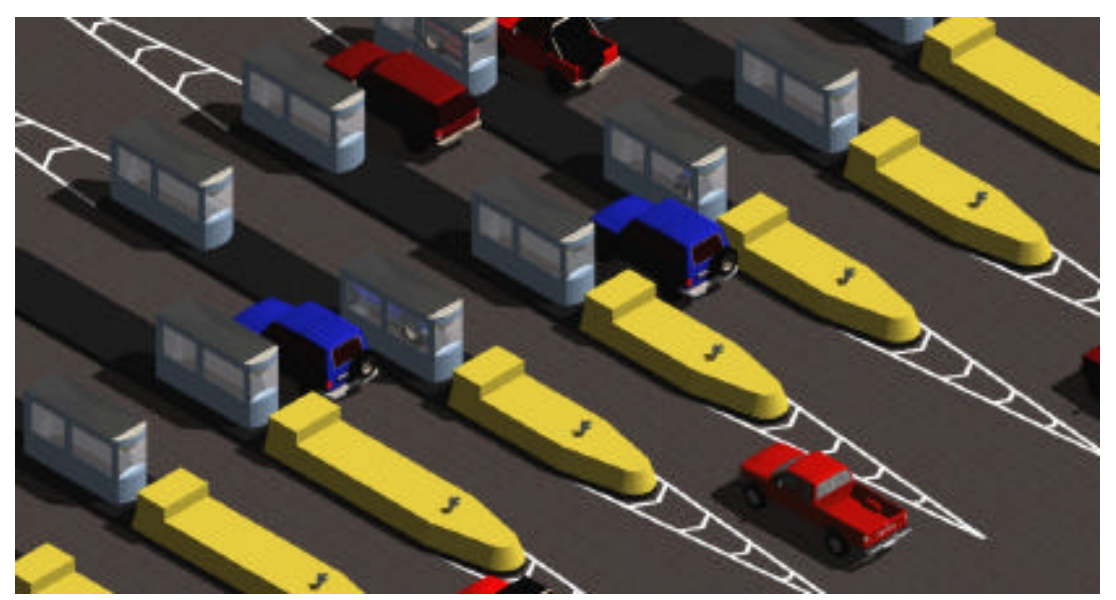

Figura 2.5: Cabines de pedágio em tandem 


\section{Capítulo3}

\section{MODELAGEM DA OPERAÇÃO DE PRAÇAS DE PEDÁGIO}

Um modelo é uma representação simbólica, lógica, matemática ou computacional de um sistema real, que normalmente tem a forma de um conjunto de suposições relativas àop eração e ao funcionamento desse sistema. O modelo também é uma simplificação do sistema real, devendo ser suficientemente detalhado para que as conclusões obtidas sejam representativas e aplicáveis ao sistema [Setti, 1994].

Em alguns casos, os modelos são simples e podem ser resolvidos através de métodos matemáticos, como por exemplo cálculo diferencial, análise de regressão e teoria de filas. Entretanto, muitos sistemas são tão complexos que os modelos que os representam são virtualmente impossíveis de serem resolvidos por técnicas matemáticas. Nestes casos, a simulação deve ser usada para imitar o comportamento do sistema [Banks e Carson, 1984].

Para o estudo de alguns parâmetros relativos àoperação de praças de pedágio, tem-se feito uso da teoria clássica das filas. Porém, estudos recentes [Lin e Su, 1994; Woo e Hoel, 1991] afirmam que a metodologia baseada nessa teoria não se apresenta confiável para a análise global da operação de praças de pedágio, devido àcomplexidade dos fatores envolvidos, o que enfatiza a necessidade de se recorrer àsimulação.

\subsection{CLASSI FI CAÇÃO DOS MODELOS}

Os modelos matemáticos, que englobam os modelos de simulação, podem ser classificados em [Setti, 1994]: 
- estáticos ou dinâmicos: o que os diferencia é se a representação é feita em um dado instante (estático) ou no decorrer do tempo (dinâmico);

- determinísticos ou estocásticos: dependendo da presença ou não de variáveis aleatórias. Para modelos determinísticos, um mesmo conjunto de dados de entrada gera sempre o mesmo conjunto de dados de saída. Isso não ocorre com os modelos estocásticos, que contêm variáveis aleatórias como dados de entrada e, com isso, geram variáveis aleatórias como dados de saída; e

- discretos ou contínuos: em um modelo discreto, as variáveis de estado variam pontualmente no decorrer do tempo. Modelos contínuos possuem variáveis contínuas, ou seja, seus valores variam continuamente ao longo do tempo.

Os modelos também podem ser microscópicos, macroscópicos e mesoscópicos, dependendo do nível no qual o fluxo de tráfego é representado. Modelos microscópicos representam o movimento de todos os veículos. Já os modelos macroscópicos consideram as relações entre as características da corrente de tráfego, tais como fluxo, densidade e velocidade. Os modelos mesoscópicos são um meio termo entre esses dois tipos de modelo, representando pelotões de veículos e incorporando equações para indicar como esses veículos interagem [TRB, 2000].

\subsection{MODELOS ANALÍTICOS DE PRAÇAS DE PEDÁGIO}

Hillier e Lieberman [1988] afirmam que, se for possível construir um modelo matemático que seja tanto uma idealização razoável do problema quanto passível de solução, uma abordagem analítica seria, usualmente, superior àsimulação. Entretanto, o fato de muitos problemas serem tão complexos que não podem ser resolvidos analiticamente faz com que, freqüentemente, a simulação seja a única abordagem prática para a solução do problema.

Diversos modelos analíticos foram desenvolvidos nos últimos anos visando analisar alguns dos parâmetros relativos àoperação de praças de pedágio, entre os quais, os elaborados por Zarrillo et al. [1997] e Widmer et al. [1999]. O primeiro é um modelo matemático que reflete as condições de tráfego em um praça de pedágio com vários tipos de coleta de 
tarifa, incluindo a eletrônica. O modelo estima o atraso e o comprimento de fila baseado em um processo determinístico. Várias configurações da praça foram consideradas, levando em conta as formas de pagamento e suas distribuições percentuais, além do comportamento do motorista para a escolha da cabine a ser utilizada. As equações usadas para calcular as medidas de desempenho foram:

- comprimento de fila na cabine tipo i no minuto $\mathrm{j}\left(\mathrm{Q}_{\mathrm{j} j}\right)$, em veíc:

$$
Q_{j i}=Q_{j-1, i}+\left(q_{j i}-s_{j i}\right)
$$

- atraso na cabine tipo i no minuto $\mathrm{j}\left(\mathrm{D}_{\mathrm{j}}\right)$, em veíc-min:

$$
D_{j i}=\left(\frac{Q_{j-1, i}+Q_{j i}}{2}\right)
$$

- atraso total (D), em veíc-min:

$$
D=\sum N_{i} \sum_{j=1}^{n} D_{j i}
$$

em que $\quad q_{\mathrm{ji}}$ : taxa de chegada em uma cabine tipo i durante o minuto j, em veíc/min; $\mathrm{s}_{\mathrm{ji}}$ : taxa de atendimento da cabine tipo i durante o minuto j, em veíc/min; $\mathrm{N}_{\mathrm{i}}$ : número de cabines do tipo i; e $\mathrm{n}$ : tempo da análise, em min.

No entender dos autores, a solução para se obter um bom desempenho de praças de pedágio é o gerenciamento eficiente da configuração da praça, o que pode ser feito através da comparação dos desempenhos de diferentes configurações com o auxílio de modelos matemáticos.

Widmer et al. [1999] propuseram um algoritmo baseado em modelos estocásticos 
de filas para a determinação dos turnos de trabalho e do número de cabines em cada turno, de forma a fornecer um nível de serviço predeterminado a um custo operacional mínimo. Como medidas de desempenho, foram escolhidos o comprimento médio de fila por cabine, o tempo médio no sistema e a probabilidade do tempo de espera na fila ultrapassar um minuto. O modelo de filas $\mathrm{M} / \mathrm{M} / \mathrm{C}$ foi considerado adequado para representar o processo de operação das praças de pedágio estudadas, tendo-se verificado que a distribuiçaão de chegadas dos veículos seguia a distribuição de Poisson, que o processo de atendimento seguia a distribuição exponencial e que existiam $k$ canais de atendimento (cabines). Foram utilizadas as seguintes equações para o cálculo das medidas de desempenho consideradas:

- $\quad$ probabilidade de o sistema estar vazio (P[0]):

$$
P[0]=\frac{1}{\left[\sum_{n=0}^{k-1} \frac{1}{n !}\left(\frac{\lambda}{\mu}\right)^{n}\right]+\frac{1}{k !}\left(\frac{\lambda}{\mu}\right)^{k} \frac{k \mu}{k \mu-\lambda}}
$$

- comprimento médio de fila (Q), em veíc:

$$
Q=\frac{\lambda \mu(\lambda / \mu)^{k}}{(k-1) !(k \mu-\lambda)^{2}} P[0]
$$

- tempo médio no sistema (d), em min:

$$
d=\frac{\mu(\lambda / \mu)^{k}}{(k-1) !(k \mu-\lambda)^{2}} P[0]+\frac{1}{\mu}
$$

- probabilidade de o tempo de espera na fila ultrapassar um minuto (P[w>1]):

$$
P[w>1]=\frac{P[0](\rho k)^{k}}{(1-\rho) k !} e^{(\lambda-k \mu)}
$$




\author{
em que $\quad \mathrm{k}$ : número de canais de atendimento; \\ $\lambda$ : taxa média de chegadas, em veíc/min; \\ $\mu$ : taxa média de atendimento, em veíc/min; e \\ $\rho$ : grau de congestionamento, $\rho=\lambda /(\mu \mathrm{k})$.
}

A sistemática proposta constitui-se numa ferramenta útil para avaliar o nível de serviço oferecido em praças de pedágio para uma ampla gama de condições operacionais alternativas, tanto em termos de distribuição do fluxo horário de veículos, como de tempos de atendimento oferecidos pelos operadores do sistema de cobrança adotado. Além disso, o modelo tem a vantagem de permitir uma avaliação do custo operacional da praça em função do nível de serviço a ser oferecido, incluindo o dimensionamento de equipes para absorver picos de tráfego e condições especiais previsíveis pelo operadores da rodovia [Widmer et al., 1999].

\title{
3.3 MODELOS DE SI MULAÇÃO
}

Com o avanço da tecnologia, os microcomputadores tornaram-se bastante populares, principalmente na área da engenharia. Essa popularização trouxe grandes benefícios, uma vez que a sua utilização implementou modificações significativas na análise de problemas.

Para a Engenharia de Transportes, uma de suas principais utilidades é a simulação dos sistemas, que torna possível avaliar e prever o impacto de alterações operacionais no sistema real (sem que seja necessário parar a operação do mesmo), além de estudar o desempenho de sistemas durante a fase de projeto (antes da sua construção). Simulando-se o sistema, pode-se coletar dados sobre o seu estado; esses dados podem ser então usados para estimar suas medidas de desempenho [Setti, 1997]. 


\subsubsection{Vantagens e desvantagens da simulação}

Apesar de a simulação ser uma ferramenta apropriada para a análise de vários sistemas, devem ser consideradas as vantagens e desvantagens antes da sua utilização. As principais vantagens da simulação são [Banks e Carson, 1984]:

- uma vez que esteja pronto, o modelo pode ser usado repetidamente para analisar propostas de alterações no funcionamento e na estrutura do sistema;

- a simulação pode ser usada para analisar um sistema proposto mesmo quando os dados de entrada sejam um tanto quanto imprecisos;

- os dados obtidos através da simulação possuem custos bastante inferiores aos dados coletados em campo;

- os modelos de simulação são mais simples de serem compreendidos e aplicados que os modelos analíticos;

- enquanto os modelos analíticos usualmente exigem um grande número de hipóteses simplificadoras para torná-los matematicamente tratáveis, modelos de simulação não possuem essa restrição; e

- em muitos casos, a simulação é o único meio de se resolver um problema.

As principais desvantagens citadas por Banks e Carson [1984] são:

- os modelos podem ser caros, consumindo um longo tempo para a sua elaboração e validação;

- usualmente, é necessário um grande número de replicações para garantir a qualidade dos dados de saída do modelo, o que pode significar custos elevados em alguns casos; e

- o uso da simulação para casos onde técnicas analíticas seriam mais adequadas para a análise do problema.

O advento dos microcomputadores e a ampla disponibilidade de software para simulação abrandam as desvantagens listadas nos dois primeiros itens. 


\subsubsection{Modelos de simulação de praças de pedágio}

A simulação de praças de pedágio permite analisar diversos cenários operacionais, possibilitando assim a comparação de alternativas e o efeito que cada uma delas produz sobre o desempenho global da praça.

Da revisão bibliográfica realizada, pode-se concluir que são quatro os principais modelos de simulação de praças de pedágio desenvolvidos recentemente: Lin e Su [1994], Gulewicz e Danko [1995], Burris e Hildebrand [1996] e Al-Deek et al. [2000]. Esses modelos são discutidos a seguir.

\section{ANÁLI SE DO NÍVEL DE SERVI ÇO EM PRAÇAS DE PEDÁGI O}

A motivação para a elaboração do modelo desenvolvido por Lin e Su [1994] surgiu do fato de não existir uma metodologia definida para a análise do nível de serviço em praças de pedágio, apesar de a coleta de pedágio afetar significantemente a fluidez do tráfego.

Esse estudo usou o comprimento médio de fila e o tempo médio no sistema como medidas de desempenho para classificar a qualidade do serviço prestado em seis níveis, de acordo com os critérios indicados na Tabela 3.1, a seguir. O nível de serviço selecionado é aquele que representa a pior condição operacional através da análise simultânea dos dois parâmetros. Esta tabela apresenta uma comparação com relação ao estudo realizado por Gulewicz e Danko [1995], que será discutido posteriormente.

Como o projeto geométrico da praça de pedágio pode afetar e ser afetado pelo comprimento da fila, os autores consideraram lógico usar o comprimento da fila para classificar os níveis de serviço. Além disso, ele foi usado por ser o parâmetro da operação de tráfego que os motoristas relacionam mais facilmente com as condições de tráfego interrompido (particularmente quando o congestionamento é grande) e por constituir-se numa medida relativamente fácil de quantificar em campo.

Porém, apesar de sua reconhecida importância, o comprimento da fila pode não refletir adequadamente o tempo gasto no sistema, que também é muito importante para os motoristas. Em conseqüência disso, essa medida de desempenho também foi incluída na 
determinação do nível de serviço.

Tabela 3.1: Critérios de nível de serviço

\begin{tabular}{|c|c|c|c|c|}
\hline \multirow{2}{*}{$\begin{array}{l}\text { NÍ VEL DE } \\
\text { SERVIÇo }\end{array}$} & \multicolumn{2}{|c|}{$\begin{array}{c}\text { COMPRI MENTO MÉDIO DA } \\
\text { FI LA POR CABI NE } \\
\text { (veíc) }\end{array}$} & \multirow{2}{*}{$\begin{array}{c}\text { TEMPO MÉDIO } \\
\text { NO SI STEMA } \\
\text { (s/ veíc) }\end{array}$} & \multirow{2}{*}{$\begin{array}{c}\text { TEMPO MÉDI O } \\
\text { DE ESPERA } \\
\text { (s/ veíc) }\end{array}$} \\
\hline & $\begin{array}{l}\text { Lin e Su } \\
\text { [1994] }\end{array}$ & $\begin{array}{c}\text { Gulewicz e Danko } \\
\text { [1995] }\end{array}$ & & \\
\hline A & $\leq 1$ & $\leq 1$ & $\leq 15$ & $\leq 5$ \\
\hline B & $\leq 2$ & $\leq 3$ & $\leq 30$ & $\leq 15$ \\
\hline C & $\leq 3$ & $\leq 5$ & $\leq 45$ & $\leq 25$ \\
\hline D & $\leq 6$ & $\leq 8$ & $\leq 60$ & $\leq 40$ \\
\hline E & $\leq 10$ & $\leq 11$ & $\leq 80$ & $\leq 60$ \\
\hline $\mathrm{F}$ & $>10$ & $>11$ & $>80$ & $>60$ \\
\hline
\end{tabular}

O simulador foi escrito em FORTRAN 77 e o modelo tem oito módulos principais: controle, geração de chegadas, ordem de processamento, escolha da cabine, entrada, saída, sentido do fluxo e produção de relatório de resultados. O módulo de controle permite ao usuário definir as características da praça que está sendo analisada e controlar o processo de simulação. O módulo de geração de chegadas as gera de forma aleatória, usando distribuição exponencial para os headways entre chegadas sucessivas. O módulo ordem de processamento determina a seqüência segundo a qual os veículos serão processados. O módulo escolha da cabine é usado para determinar a cabine que será utilizada pelo veículo que está sendo atendido no pedágio, de tal forma que o simulador possa reproduzir o comportamento dos motoristas.

O processamento dos veículos é tratado nos módulos entrada e saída, que determinam o instante em que o veículo chega àcabine (ou àfila formada na cab ine) e o tempo de atendimento. O tempo de atendimento foi estabelecido de acordo com uma distribuição obtida através da observação de cabines reais. O módulo direção de fluxo permite estabelecer a direção dos fluxos de tráfego pela praça de pedágio.

Os dados de saída do modelo fornecem as seguintes medidas de desempenho do sistema: 
- espera média;

- tempo médio no sistema;

- comprimento médio de fila;

- comprimento máximo de fila;

- capacidade de atendimento em um intervalo de tempo previamente especificado; e

- velocidade com que os veículos cruzam a praça (uma medida derivada do tempo gasto no sistema).

A velocidade média com que um veículo cruza a praça é utilizada para fornecer uma medida relativa de nível de serviço de uma praça em relação a outros componentes da rodovia. O modelo dá um aviso quando o comprimento da fila em alguma cabine ultrapassa os limites da praça, alcançando a rodovia.

Para validação do modelo, foram comparados valores obtidos da simulação com valores observados no sistema real. Os dados usados no estudo foram coletados por meio de câmeras de vídeo. Uma comparação dos comprimentos de fila simulados e observados em intervalos de 10 segundos mostrou que os valores simulados diferiam dos observados em mais de três veículos; o desvio padrão médio dos valores observados foi de 1,26 veículos. 0 tempo médio de permanência no sistema para os dados observados foi de 149,5 s por veículo e para os simulados, 144,5 s por veículo. As discrepâncias entre os comprimentos de fila observados e simulados foram atribuídas àausência de esforço s para combinar os tempos de senviço simulados dos veículos individuais com os valores observados.

Modelos analíticos também foram utilizados para testar o modelo em termos de comprimento médio de fila e tempo médio no sistema. Não foram encontradas diferenças significativas entre os resultados fornecidos pela simulação e pelos modelos analíticos.

\section{AVALI AÇÃO DO NÚMERO ÓTI MO DE CABI NES EM PRAÇAS DE PEDÁGIO}

O estudo realizado por Gulewicz e Danko [1995] consiste numa avaliação da quantidade de cabines necessária para manter um nível de serviço aceitável em uma praça de 
pedágio durante os períodos entre picos de tráfego. Esse estudo faz uma análise para vários níveis de fluxo e composição de tráfego e procura maximizar a eficiência da operação da praça, considerando o comprimento da fila e a espera média.

O modelo de simulação foi elaborado usando a linguagem GPSS e se caracteriza por ser microscópico, devido àgeração e ao processamento individual de cada veículo. O simulador possui mais de 15.000 linhas de código, em virtude do alto grau de detalhamento usado na representação do processamento dos veículos, e, apesar disso, é capaz de simular 8 horas de operação da praça em pouco mais de um minuto.

Para obtenção dos parâmetros de entrada, as chegadas dos veículos foram coletadas independentemente para cada cabine e tipo de veículo (automóveis, ônibus, caminhões leves e caminhões pesados). Os dados foram então analisados com auxílio de um software de estatística para determinar se as chegadas poderiam ser representadas por alguma distribuição teórica. Esse software foi usado para avaliar qual distribuição teórica mais se aproximava dos dados de campo. Depois, foram realizados dois testes estatísticos (KolmogorovSmirnov e Anderson-Darling). Como passaram nos testes, as distribuições teóricas foram utilizadas por serem consideradas uma boa aproximação.

Para coletar os dados da seleção da faixa, que se refere ao comportamento dos motoristas, foram observados os veículos isoladamente, anotando-se o lado da chegada àpra ça (direito ou esquerdo), a fila em cada uma das cabines e a cabine de destino. A partir desses dados, foram observados quatro hábitos globais relativos ao comportamento dos motoristas:

- a maioria dos motoristas escolhia a cabine no mesmo lado em que entravam na praça de pedágio;

- uma vez selecionado o lado da praça, a maioria dos motoristas se dirigia àcabine com a menor fila naquele lado;

- observou-se que alguns motoristas escolhiam a cabine com menor fila, mesmo quando haviam cabines vazias disponíveis para o atendimento. Acreditou-se que isso tenha ocorrido porque eles observaram somente os outros veículos na praça e não os sinais sobre as cabines, o que pode tê-los feito pensar que as cabines 
vazias estivessem fechadas; e

- uma pequena porcentagem de motoristas parecia escolher a cabine de forma aleatória.

Outro comportamento observado, em menor quantidade, foi que os automóveis que chegavam no lado direito da praça tendiam a se mover para o lado esquerdo, a fim de evitar a fila de caminhões.

Esses comportamentos foram replicados no modelo de simulação através de um algoritmo que se baseava em porcentagens observadas para recriar o processo de seleção de cabines. Foram usadas distribuições empíricas para os tempos de atendimento, que levavam em conta as três formas de pagamento possíveis (dinheiro exato, dinheiro com troco e tíquetes). Os autores estudaram também o efeito da variação do número de cabines em operação ao longo do dia de acordo com uma programação de funcionamento.

Para validação do modelo, foram utilizadas duas variáveis: o comprimento das filas e o volume de partidas por intervalo de tempo. Os resultados obtidos indicaram que o modelo tinha um erro médio de 1,20\% na estimativa da fila e um desvio médio de $0,52 \%$ no número de veículos processados, o que significa que o modelo representa adequadamente o sistema estudado.

Na Tabela 3.1 estão apresentados os critérios utilizados nesse modelo para a avaliação do nível de serviço, ressaltando que foram aplicados os mesmos critérios utilizados em interseções semaforizadas, por ter-se considerado que a passagem de veículos por um semáforo é um processo similar ao da passagem de veículos por uma cabine de pedágio, já que em ambos os casos ocorre a formação de uma fila. Numa interseção semaforizada, a medida do desconforto do usuário - e também do nível de serviço - é o tempo parado no sinal; para uma cabine de pedágio, o desconforto do usuário pode ser medido através do tempo parado na fila àespera do atendimento. Esse tempo parado é igual ao total de tempo de atendimento para todos os veículos em fila na frente daquele usuário. 


\section{ANÁLI SE DO I MPACTO DA I MPLANTAÇÃO DE COLETA ELETRÔNI CA DE PEDÁGIO}

O modelo de simulação proposto por Burris e Hildebrand [1996] foi usado para analisar o impacto da implantação da coleta eletrônica de pedágio na ponte Halifax-Dartmouth, localizada na província canadense de Nova Scotia. A concessionária responsável pela operação dessa ponte pretendia substituir as máquinas automáticas de coletas de moedas, que tinham mais de 25 anos de uso e um alto custo de manutenção, por um sistema AVI. Com isso, previa-se uma redução substancial nos tempos de espera, nas emissões de poluentes, no consumo de combustível e nos custos operacionais e administrativos. Essas reduções, no entanto, seriam fortemente dependentes da porcentagem de usuários que utilizassem o sistema AVI, dos níveis de congestionamento e da capacidade na entrada da praça de pedágio, que, em conjunto com algumas variáveis menos críticas (por exemplo, o desempenho dos equipamentos usados até então), tornavam incertos os efeitos globais da coleta eletrônica de pedágio. Por essa razão, os autores decidiram analisar o efeito potencial da coleta eletrônica de pedágio antes da sua implantação.

Para estudar o sistema, foi usada simulação estocástica, por meio de um modelo desenvolvido para permitir a análise de todos os aspectos do processo de coleta de pedágio, incluindo a desaceleração do veículo, a formação de fila, a lógica da escolha da cabine, o tempo de atendimento e a aceleração do veículo. A modelagem escolhida também permitia a inclusão de diferentes tipos de veículos, formas de pagamento e taxas de ocupação das cabines em função do número de cabines em operação. Os resultados gerados pelo modelo de simulação puderam ser usados para analisar o efeito da utilização do sistema AVI de forma mais precisa, se comparados aos métodos analíticos para análise de filas.

Para a construção do modelo, foi necessária grande quantidade de dados empíricos - particularmente, dados do tráfego, incluindo taxas de fluxo horárias, diárias, mensais e anuais. Outros dados também usados no modelo incluíam distribuições dos tempos de atendimento, porcentagens de veículos utilizando cada opção de pagamento, cabine utilizada, tipos de veículos e processo de mudança de faixa.

O modelo usou uma distribuição exponencial para representar o padrão de chegadas 
dos veículos. Ao gerar um novo veículo, o simulador designava-lhe o tipo, que podia ser leve (automóvel) ou pesado (caminhão e ônibus), em função da composição de tráfego observada empiricamente. O tipo de pagamento adotado pelo veículo também foi estabelecido em função das proporções observadas. O processo de seleção da cabine foi baseado no fluxo de tráfego, no tipo de pagamento escolhido, no comprimento da fila em cada cabine e na proximidade da cabine adequada para o tipo de pagamento escolhido.

Para validação do modelo, duas variáveis foram escolhidas: o tempo gasto no sistema e o número de veículos na fila. Os dados foram coletados para diferentes condições de tráfego, tanto para o modelo simulado quanto para a situação real. Uma comparação das distribuições de freqüências acumuladas dos dois conjuntos de dados mostrou que o modelo era altamente preciso, com uma exceção: o número de veículos no sistema durante períodos de fluxos de chegada elevados apresentou uma leve tendência a ser superestimado pelo modelo. Essa superestimação, entretanto, foi pequena: a diferença entre os números observados e estimados pelo modelo superou $5 \%$ em apenas dois casos.

A comparação dos dados do sistema real com os produzidos pelo modelo foi feita por meio do teste t. Os resultados da comparação mostraram que existia uma forte correlação entre os resultados fornecidos pelo modelo e as observações feitas no sistema real: as médias dos valores obtidos pelo modelo estavam dentro de uma faixa de variação de $\pm 4 \%$ das médias observadas no sistema real, àexceção do número total de veículos no sistema, que apresentou uma certa tendência a ser superestimado pelo modelo. O modelo demonstrou-se particularmente preciso na estimativa do parâmetro mais crítico no entender dos autores, o tempo médio do veículo no sistema.

\section{AVALI AÇÃO DA OPERAÇÃO DE PRAÇAS COM COLETA ELETRÔNI CA DE PEDÁGIO}

Com o intuito de fazer uma análise da operação de praças com coleta eletrônica de pedágio, Al-Deek et al. [2000] desenvolveram um modelo de simulação estocástica codificado através da linguagem Visual Basic. Esse modelo é capaz de representar praças com até cinco faixas de tráfego na chegada e até 10 cabines de pedágio em cada direção. Nele, as 
faixas de aproximação estão localizadas a uma distância suficiente antes da praça para que se obtenha condições de fluxo livre.

O modelo de simulação também permite a representação de automóveis e caminhões em cinco tipos de cabines com formas de pagamento diferentes (manual, automática, AVI, manual/AVI e automática/AVI). Os fluxos de tráfego na chegada da praça podem ser inseridos em intervalos de 5, 10, 15, 30 e 60 minutos para cada hora simulada e nove distribuições estatísticas diferentes podem ser usadas pelo usuário para representar parâmetros tais como distribuição de chegadas, distribuição dos tempos de atendimento e distribuição das velocidades de chegada àpr aça.

A estrutura do modelo consiste em três módulos principais: entrada de dados, lógica e algoritmos da simulação e apresentação dos dados de saída. O modelo utiliza arquivos para armazenar os valores atualizados do desempenho do sistema em todos os intervalos de tempo durante a simulação. Uma característica interessante do modelo é que ele provê ao analista um sistema onde os dados são categorizados e apresentados visualmente, fazendo com que sejam facilmente compreendidos.

O modelo divide a área da praça em três zonas: a zona de aproximação, a zona de transição e a zona de cobrança da tarifa. Todas elas tem sua própria configuração e características e os veículos são gerados em cada uma delas de acordo com seus tempos de chegadas. O tempo entre chegadas em cada faixa da zona de aproximação é uma variável aleatória que segue a distribuição especificada pelo usuário nos dados de entrada.

Antes de a simulação começar, são atribuídos, para cada veículo, a classe veicular, o tipo de pagamento e os valores relativos àvelocidade de fluxo livre, ao tempo de reação do motorista e àmáxima taxa de aceleração e de desaceleração.

Durante o movimento do veículo na zona de aproximação são usados algoritmos de car-following e de mudança de faixa para atualizar sua velocidade e posição (lateral e longitudinal em cada zona) durante os intervalos de tempo da simulação. As posições atuais e velocidades dos veículos são determinadas para cada intervalo de tempo, checando-se também se o veículo atingiu o fim da zona em que se encontrava no início do intervalo de tem- 
po.

Ao chegar àzona de cobrança de tarifa, o modelo usa um algoritmo de escolha da faixa para selecionar a cabine que será usada pelo veículo. O veículo mantém-se na faixa da cabine escolhida e entra na fila (se existir), movendo-se até alcançar a cabine. Então, é atribuído um valor para o tempo de atendimento do veículo de acordo com uma distribuição associada ao tipo de cabine. Quando os veículos entram nas filas das cabines, o modelo considera que não é mais possível fazer mudanças de faixa. Após o pagamento da tarifa, o veículo acelera para deixar a praça de pedágio.

A representação dos dados de saída do modelo inclui dados estatísticos que agregam as medidas de desempenho do sistema, gráficos representativos desse dados e animação do movimento do tráfego para visualizar e detectar as condições durante a simulação.

Os dados usados para a validação do modelo foram coletados na praça de HollandEast, uma das mais movimentadas do estado da Flórida (EUA): em junho de 1999, mais de 90.000 veíc/dia passavam por essa praça, sendo 37,41\% deles usuários da AVI.

Uma análise preliminar indicou que não existia diferença significativa entre os tempos de atendimento de cabines do mesmo tipo. A fim de validar o modelo, foram feitas comparações entre os resultados do modelo e as observações de campo através de três diferentes medidas de desempenho: o tempo de atendimento, o tempo médio no sistema e o tempo médio na fila. Através de um teste qui-quadrado, foi verificado que, para um nível de confiança de 95\%, não existiam diferenças significativas entre os tempos de atendimento das cabines simuladas e das cabines observadas em campo, para todos os tipos de cabines.

Como os autores consideraram que o teste qui-quadrado não era apropriado para comparar o tempo médio no sistema e o tempo médio na fila, outro teste estatístico foi usado, o Wilcoxon Signed Rank. Esse teste analisa diferenças entre pares de medidas. Os resultados indicaram que, para um nível de confiança de 95\%, não existiam diferenças significativas entre os tempos médio e total simulados e os observados, para todos os tipos de cabines.

Vários cenários simulados por esse modelo foram conduzidos com o objetivo de in- 
vestigar o impacto do uso da tecnologia AVI. A conclusão obtida foi que os benefícios da AVI dependem da configuração específica da praça. Porém, um dos mais interessantes resultados desse estudo é que, para todas as configurações de praças simuladas com as cabines manuais operando acima da capacidade, a espera total pode ser reduzida à metade se apenas $10 \%$ dos usuários passarem da cobrança manual para a AVI. 


\section{Caṕtulo4}

\section{CARACTERI ZAÇÃO OPERACI ONAL DE PRAÇAS DE ARRECADAÇÃO DE PEDÁGI O}

O processo adotado para a coleta de dados e as análises realizadas estão descritos neste capítulo. Inicialmente, são apresentados os parâmetros escolhidos para a caracterização da operação de praças de pedágio, a escolha das praças de pedágio para serem observadas e os métodos usados para os levantamentos de dados. A seguir, apresenta-se um conjunto de análise dos dados coletados e discute-se os resultados dessas análises. Esta é a etapa mais importante e complexa da pesquisa, visto que a necessidade de obtenção de amostras representativas faz com que os levantamentos de dados sejam tarefas extremamente trabaIhosas.

\subsection{DEFI NI ÇÃO DOS PARÂMETROS E DAS PRAÇAS ESTUDADOS}

Com base na revisão bibliográfica, foram estabelecidos os aspectos a serem estudados para a caracterização operacional de praças de pedágio:

- o processo de chegadas dos veículos às praças;

- o perfil da velocidade durante a desaceleração dos veículos na entrada da praça;

- o processo de escolha da cabine pelos motoristas;

- o processo de atendimento nas cabines;

- a forma de pagamento da tarifa; 
- o perfil da velocidade durante a aceleração dos veículos na saída da praça; e

- as velocidades desenvolvidas nas cabines AVI.

Para que isso fosse possível, foi necessário coletar os seguintes dados:

- headways entre chegadas sucessivas à praça de pedágio;

- tempo gasto para percorrer a distância entre a entrada da praça de pedágio e as filas nas cabines;

- comportamento do motorista na escolha da cabine;

- tempos de atendimento nas cabines, de acordo com a forma de pagamento e o tipo de veículo;

- tempo gasto para percorrer a distância entre a saída das cabines e a saída da praça de pedágio; e

- distribuição de velocidades nas faixas AVI.

As praças de pedágio escolhidas para servir de base para este trabalho possuem características de tráfego e operacionais bastante diversificadas e foram selecionadas com o intuito de caracterizar de uma maneira realística tanto o comportamento dos usuários como a forma com que as concessionárias operam as praças.

Três concessionárias de rodovias do Estado de São Paulo colaboraram com o desenvolvimento deste estudo, permitindo e auxiliando na coleta de dados em algumas de suas praças. As praças escolhidas foram:

- Araraquara, localizada no km 282 da SP310 (Rodovia Washington Luiz) e operada pela Triângulo do Sol;

- Campo Limpo, localizada no km 39 da SP348 (Rodovia dos Bandeirantes) e operada pela AutoBAn;

- Limeira, localizada no km 152 da SP330 (Rodovia Anhangüera) e operada pela AutoBAn;

- Nova Odessa, localizada no km 118 da SP330 (Rodovia Anhangüera) e operada pela AutoBAn; e 
- Sertãozinho, localizada no km 327 da SP322 (Rodovia Atílio Balbo) e operada pela Vianorte.

Um mapa do Estado de São Paulo com a localização das praças estudadas pode ser visto na Figura 4.1.

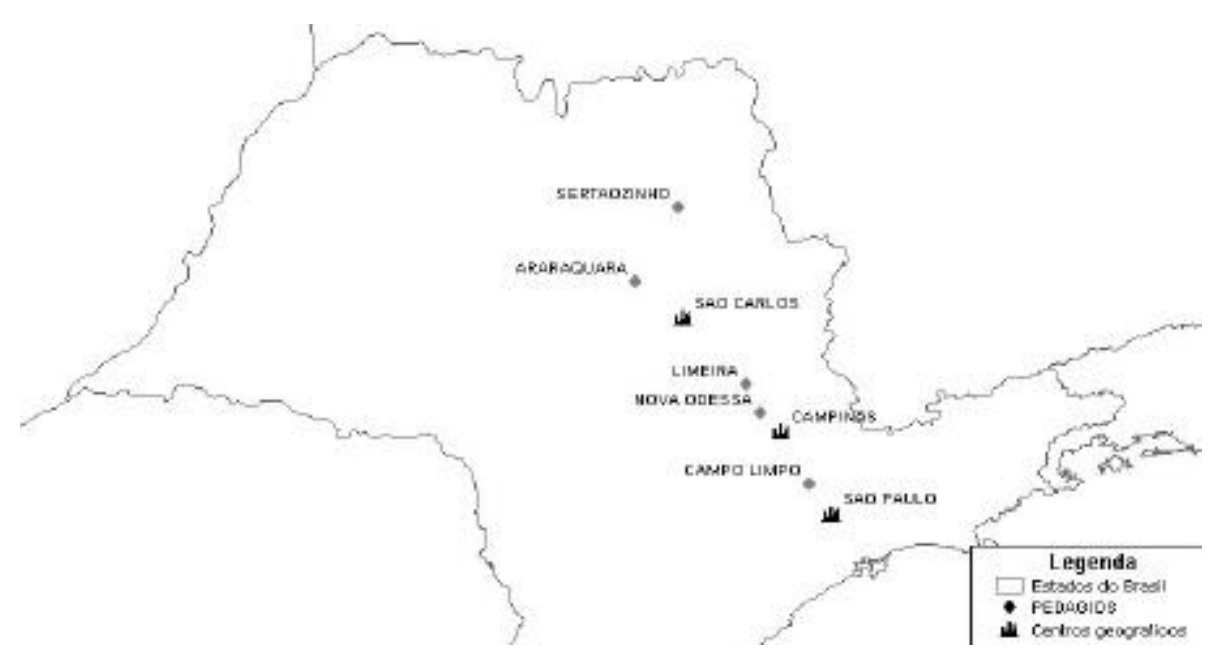

Figura 4.1: Mapa de São Paulo com a localização das praças estudadas

\subsection{TÉCNI CAS E EQUI PAMENTOS UTI LI ZADOS NA COLETA DOS DADOS}

Para a coleta dos dados relativos à operação das praças de pedágio optou-se por usar câmeras de vídeo e sensores para coleta automática de dados. Esta opção foi feita em função da disponibilidade e da eficiência desses equipamentos neste tipo de pesquisa.

\subsubsection{Câmeras de vídeo}

O uso de câmeras de vídeo é bastante comum em estudos para análise do tráfego. Sua maior vantagem é a produção de um cenário permanente, no qual as imagens podem ser revistas para a obtenção de todos os dados necessários [Taylor et al., 1989]. Em contrapartida, a extração dos dados das fitas de vídeo é um processo bastante trabalhoso e que consome muito tempo. Vários estudos sobre praças de pedágio se utilizaram desse método, entre eles: Al-Deek et al. [2000], Lin e Su [1994] e Woo e Hoel [1991].

Durante a fase de planejamento da coleta de dados com o auxílio de câmeras de vídeo, deve-se levar em conta o efeito que a paralaxe possa eventualmente exercer na preci- 
são dos dados obtidos. As câmeras precisam ser posicionadas em locais que possuam boa visibilidade do fenômeno que se deseja estudar para que os dados obtidos representem da forma mais real possível o sistema estudado [Bonneson e Fitts, 1995].

Para este estudo estavam disponíveis duas câmeras filmadoras convencionais, além das instaladas pela AutoBAn em todas as suas praças. As câmeras instaladas por esta concessionária nas imediações de suas praças estão localizadas em postes com altura suficiente para cobrir toda a área da praça e possuem lentes capazes de fazer aproximações da imagem com um alto nível de qualidade, podendo também girar 355 em torno de seu eixo, para a escolha da posição desejada.

\subsubsection{Sensores para coleta automática de dados}

Nesta pesquisa, foram usados sensores automáticos NC-97 para coleta de dados de tráfego (fluxo, composição do tráfego e velocidade). Esses sensores (Figura 4.2) são equipamentos portáteis e programáveis fabricados pela Nu-Metrics Inc. A tecnologia empregada é a VMI Vehicle Magnetic Imaging, que utiliza a distorção do campo magnético da Terra para detectar, contar e classificar os veículos que passam sobre eles [Nu-Metrics, 1997].

A instalação dos sensores requer o uso de uma capa protetora de borracha, fixada no pavimento com o auxílio de pregos e arruelas, conforme apresentado na Figura 4.3. Para introduzir os pregos na camada asfáltica, utiliza-se uma pistola com munição a base de pólvora.

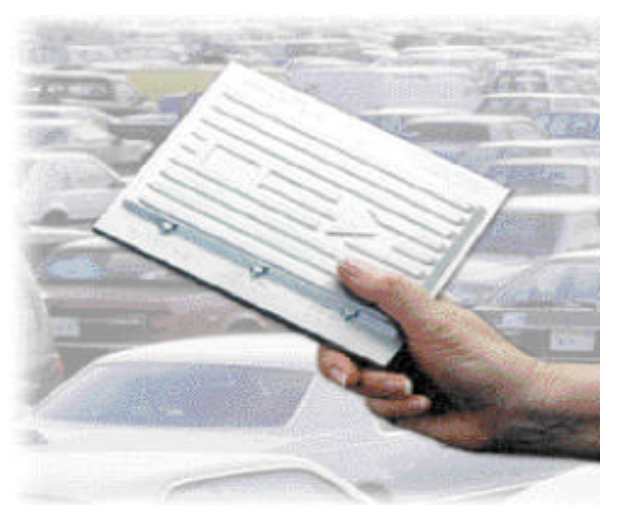

Figura 4.2: Sensor NC-97

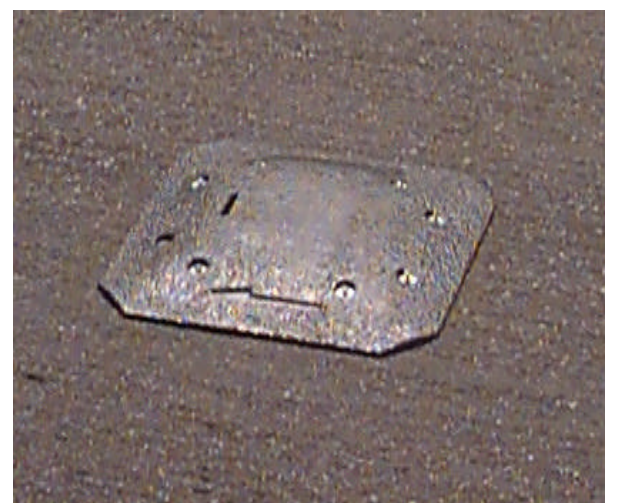

Figura 4.3: Sensor instalado no pavimento 
O sensor NC-97 deve ser programado a cada estudo e, para isso, faz-se uso do programa LP (versão 5.11e). O sensor possui três modos para coleta de dados: frame, sequential e verify. A diferença entre esses modos reside na forma como os dados dos veículos (velocidade, comprimento e instante de passagem) são armazenados no sensor.

O modo utilizado nesta pesquisa foi o sequential, no qual o comprimento, a velocidade e o instante de passagem de cada veículo são armazenados seqüencialmente, para todos os veículos detectados pelo sensor. Ao final de cada estudo, esses dados são recuperados através de um programa específico e, em seguida, transferidos para um computador sob forma de planilha eletrônica. Um exemplo da planilha pode ser visto na Tabela 4.1.

Tabela 4.1: Exemplo de planilha contendo os dados obtidos pelos sensores NC-97

\begin{tabular}{cccccc}
\hline DATA & $\begin{array}{c}\text { INSTANTE } \\
\text { (h:m:s) }\end{array}$ & $\begin{array}{c}\text { VELOCIDADE } \\
(\mathbf{k m} / \mathbf{h})\end{array}$ & $\begin{array}{c}\text { COMPRI MENTO } \\
(\mathbf{m})\end{array}$ & $\begin{array}{c}\text { HEADWAY } \\
\mathbf{( s )}\end{array}$ & $\begin{array}{c}\text { ESTADO DO } \\
\text { SENSOR }\end{array}$ \\
\hline $26 / 04 / 01$ & $11: 00: 02$ & 85 & 3,0 & 2 & *OK* \\
$26 / 04 / 01$ & $11: 00: 31$ & 42 & 3,0 & 29 & *OK* \\
$26 / 04 / 01$ & $11: 01: 06$ & 90 & 3,0 & 35 & *OK* \\
$26 / 04 / 01$ & $11: 01: 54$ & 10 & 3,0 & 48 & *STOP* \\
$26 / 04 / 01$ & $11: 02: 26$ & 0 & 0,0 & 32 & *GONE* \\
$26 / 04 / 01$ & $11: 02: 49$ & 109 & 4,6 & 23 & *OK* \\
\hline
\end{tabular}

Os headways são calculados a partir da diferença entre os instantes de passagem de dois veículos sucessivos e o estado do sensor indica a ocorrência de eventuais falhas na coleta de dados. O estado *OK* indica que não houve problemas no funcionamento dos sensores no instante de detecção, enquanto os estados *STOP* e *GONE* indicam que a velocidade e o comprimento do veículo não puderam ser detectados pelos sensores.

\subsection{COLETAS DE DADOS}

A Tabela 4.2 apresenta os dados que foram coletados em cada uma das praças e os equipamentos utilizados.

Em cada praça foram realizadas várias coletas de dados, em dias da semana e até em meses diferentes. Dessa forma, foram obtidos dados relativos a diferentes características 
de tráfego e operacionais, o que contribuiu para a generalização dos dados.

Nas praças operadas pela AutoBAn, os dados relativos à escolha da cabine e ao tempo de atendimento foram obtidos através de imagens captadas pelas câmeras instaladas pela própria empresa.

Na praça de Araraquara (Triângulo do Sol), os dados relativos aos tempos de atendimento foram adquiridos através de câmeras filmadoras instaladas nas laterais da praça, nos sentidos de cobrança, conforme mostra a Figura 4.4. Para a obtenção de dados sobre a forma de pagamento utilizada pelos usuários, um pesquisador dentro da cabine de pedágio verificava o pagamento e cronometrava o tempo gasto.

Tabela 4.2: Dados coletados e equipamentos utilizados

\begin{tabular}{lll}
\hline \multicolumn{1}{c}{ PRAÇA } & \multicolumn{1}{c}{ DADO COLETADO } & \multicolumn{1}{c}{ EQUI PAMENTO } \\
\hline & processo de chegadas & sensores \\
& perfil da velocidade na desaceleração & câmera e sensores \\
& escolha da cabine & \multicolumn{1}{c}{ câmera } \\
Araraquara & tempo de atendimento & câmera \\
& forma de pagamento & cronômetro \\
& perfil da velocidade na aceleração & câmera e sensores \\
& velocidades na cabine AVI & sensores \\
\hline Campo Limpo & tempo de atendimento & câmera \\
\hline \multirow{2}{*}{ Limeira } & escolha da cabine & câmera \\
& tempo de atendimento & câmera \\
\hline Nova Odessa & tempo de atendimento & câmera \\
\hline \multirow{2}{*}{ Sertãozinho } & tempo de atendimento & cronômetro \\
& forma de pagamento & cronômetro \\
\hline
\end{tabular}

Também em Araraquara, para aquisição de dados sobre as velocidades nas cabines AVI, foram instalados sensores para coleta automática de dados nas entradas dessas cabines. Para aquisição de dados sobre o processo de chegadas e os perfis das velocidades na desaceleração e na aceleração dos veículos, foram instalados câmeras em cima de uma cabine (Figura 4.5) e sensores para coleta automática de dados na entrada e na saída da praça. 


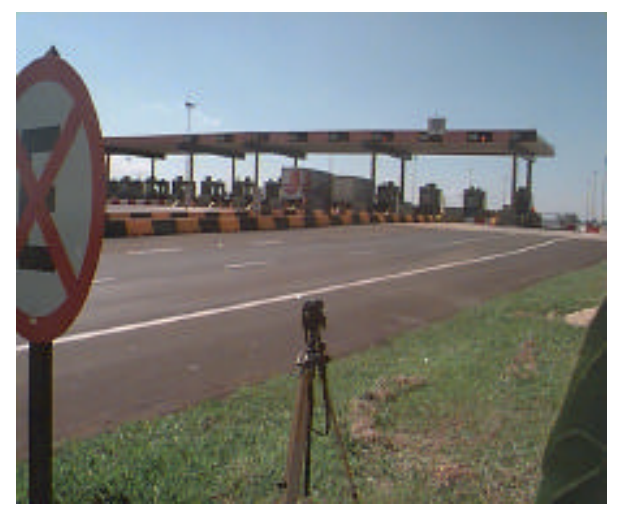

Figura 4.4: Posicionamento da câmera para coleta de tempo de atendimento

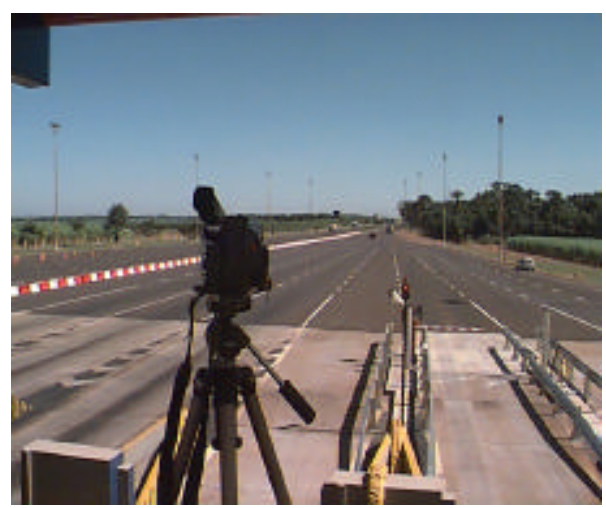

Figura 4.5: Posicionamento da câmera para coleta de perfil de aceleração

Na praça de Sertãozinho (Vianorte), foram obtidos dados sobre a forma de pagamento e o tempo de atendimento através de um pesquisador dentro da cabine de pedágio.

A seguir, estão descritos os procedimentos adotados para a obtenção e apresentadas análises de cada um dos parâmetros estudados.

\subsection{ANÁLI SE DOS DADOS COLETADOS}

Das cinco praças estudadas, duas possuem cobrança bidirecional: Araraquara e Sertãozinho. Para a descrição do sentido de cobrança de pedágio nas praças, designa-se sentido Norte o sentido capital-interior e sentido Sul o sentido interior-capital. As praças de Campo Limpo, Limeira e Nova Odessa cobram pedágio apenas no sentido capital-interior (Norte).

\subsubsection{Processo de chegadas}

A aquisição de dados para análise do processo de chegadas dos veículos foi feita a partir da instalação de dois sensores NC-97 nas faixas da entrada da praça de Araraquara, no sentido Sul (interior-capital). A duração total da coleta foi de 6 horas e obteve-se uma amostra de 2.154 veículos. A coleta de dados em apenas um sentido da praça deu-se em função da restrição no número de sensores disponíveis.

Observando-se a Figura 4.6, pode-se perceber que os fluxos horários de tráfego observados nesse sentido foram crescente ao longo do período estudado, variando entre 262 
e 422 veíc/h. Na mesma figura, apresentam-se também os fatores de hora-pico (FHP) calculados para cada hora observada, no eixo y da direita. O cálculo do FHP é feito através da seguinte equação:

$$
F H P=\frac{V}{4 \times V_{15 \max }}
$$

em que $\quad V$ : fluxo de tráfego horário; e

$$
V_{15 \text { max }} \text { : fluxo de tráfego máximo observado num período de } 15 \text { minutos. }
$$

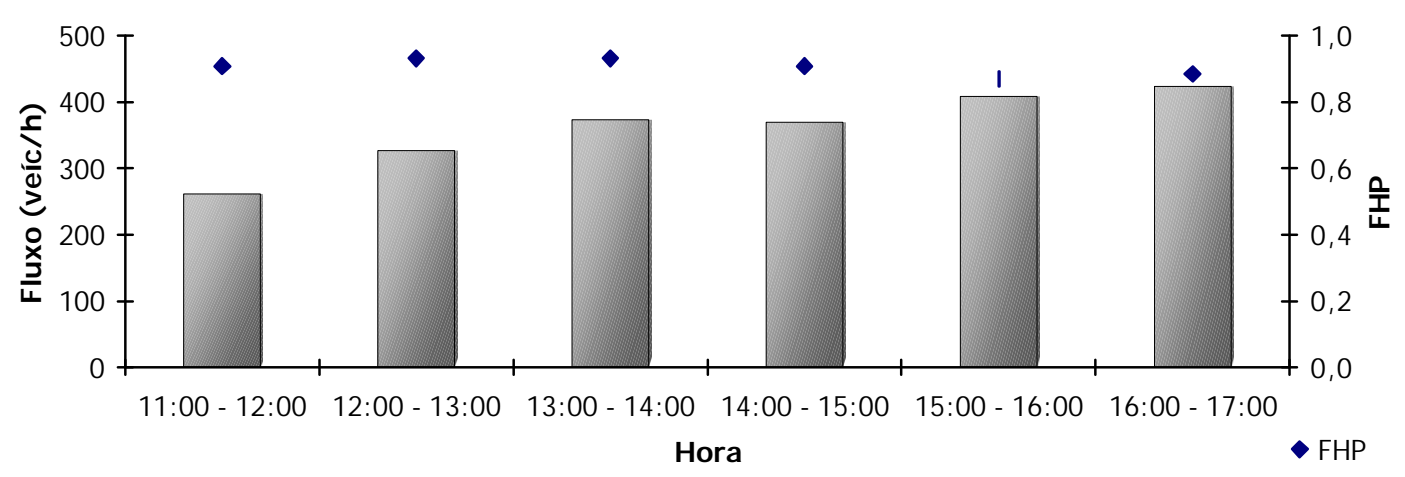

Figura 4.6: Fluxos horários observados e fatores de hora pico, praça de Araraquara

Os fatores de hora-pico para o período estudado variam entre 0,87 e 0,93 , podendo-se notar que eles apresentam uma ligeira tendência decrescente, ou seja, existe uma progressiva redução na variação do fluxo de tráfego dentro de cada hora.

Como foi verificada uma variação no fluxo médio horário, o processo de chegadas não poderia ser analisado para o período de seis horas como um todo. Assim sendo, o processo de chegadas foi estudado em termos das distribuições observadas de headways para cada uma das seis horas separadamente. Através do conhecimento do instante de passagem de cada veículo, foi possível obter uma distribuição dos headways para cada hora observada e, a partir dessa distribuição, fazer um estudo para verificar qual distribuição teórica mais se aproximava da observada. Admitiu-se, como hipótese nula, que os headways 
observados dentro de cada hora analisada obedecem a uma distribuição exponencial negativa.

A probabilidade de ocorrência de um headway $h$, de acordo com uma distribuição exponencial negativa, é expressa pela equação:

$$
P(h \leq t)=1-e^{-\frac{t}{\bar{h}}}
$$

em que

$$
\begin{aligned}
& \mathrm{t}: \text { tempo de duração do headway }(\mathrm{s}) \text {; e } \\
& \overline{\mathrm{h}} \text { : headway médio (s). }
\end{aligned}
$$

Utilizando-se o teste de Kolmogorov-Smirnov, com nível de significância de 5\%, verificou-se que não existiam indícios contrários à hipótese de que os headways pudessem ser modelados por uma distribuição exponencial negativa, conforme mostrado na Tabela 4.3, que apresenta os valores críticos do teste para cada hora. A Figura 4.7 mostra, a título de exemplo, a aderência da distribuição exponencial negativa para o período de 11:00 às $12: 00 \mathrm{~h}$.

Tabela 4.3: Testes de aderência da distribuição exponencial negativa aos headways observados

\begin{tabular}{ccccc}
\hline HORA & $\begin{array}{c}\text { NÚMERO DE } \\
\text { OBSERVAÇõES }\end{array}$ & $\begin{array}{c}\left|\mathbf{P}\left(\mathbf{h}_{\text {obs }}\right)-\mathbf{P}\left(\mathbf{h}_{\text {teórico }}\right)\right| \\
\text { MÁXI MO }^{(a)}\end{array}$ & $\begin{array}{c}\text { VALOR CRÍ TICO } \\
\text { DO TESTE }\end{array}$ & $\begin{array}{c}\text { HI PÓTESE } \\
\mathbf{H}^{(\mathrm{c})}\end{array}$ \\
\hline 11:00-12:00 & 260 & 0,074 & 0,084 & não rejeitada \\
12:00-13:00 & 325 & 0,065 & 0,075 & não rejeitada \\
13:00-14:00 & 375 & 0,060 & 0,070 & não rejeitada \\
14:00-15:00 & 366 & 0,066 & 0,071 & não rejeitada \\
15:00-16:00 & 402 & 0,070 & 0,070 & não rejeitada \\
16:00-17:00 & 424 & 0,048 & 0,066 & não rejeitada \\
\hline
\end{tabular}

(a) diferença absoluta máxima entre os percentuais relativos acumulados das distribuições de headways observados e teóricos

(b) valor crítico do teste calculado pela equação $1,36 / \sqrt{n}$, para uma nível de significância de $5 \%$

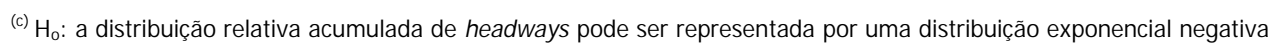




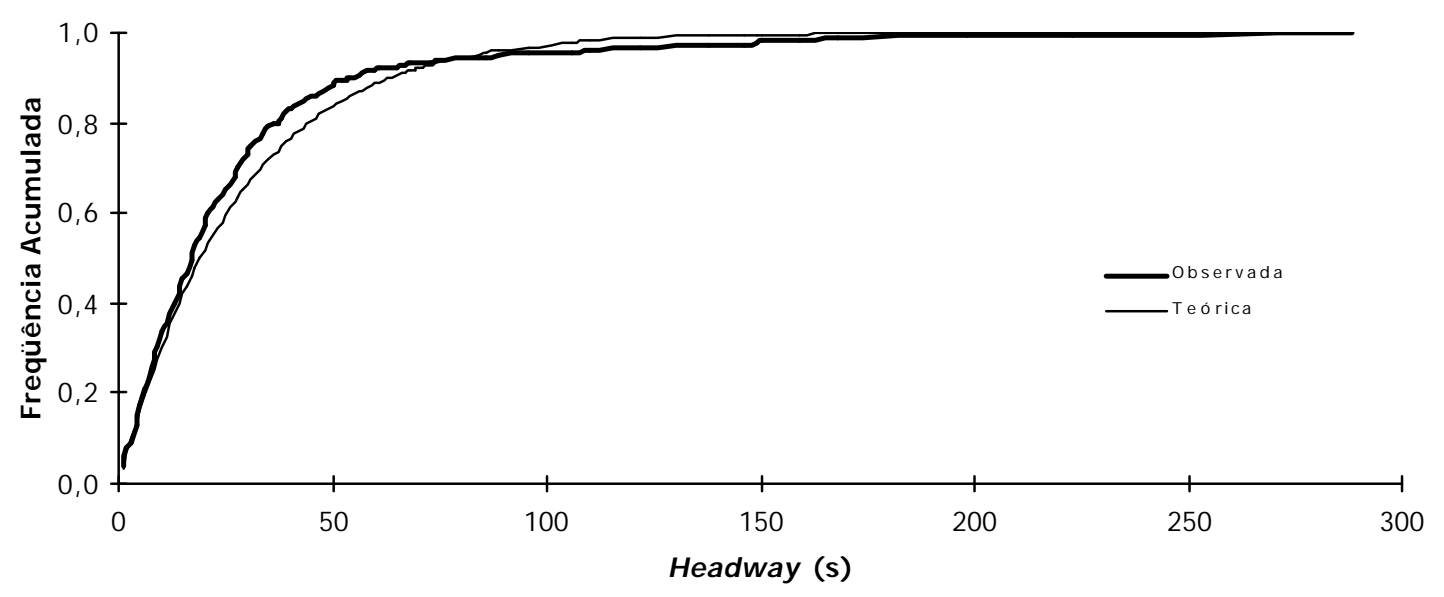

Figura 4.7: Distribuições teórica e observada de headways para o período 11:00-12:00 h

\subsubsection{Perfis da desaceleração e da aceleração}

Ao chegar a uma praça de pedágio, os veículos passam por um ciclo composto por três estágios: desaceleração para que seja possível efetuar o pagamento da tarifa na cabine, espera pelo atendimento (na fila ou na cabine) e aceleração até retornar a sua velocidade de cruzeiro.

Os dados sobre o primeiro e o terceiro estágios desse ciclo foram coletados na praça de Araraquara, através de câmeras de vídeo. A duração da coleta foi de 7 horas, no caso da desaceleração, e de 6 horas, no caso da aceleração. A desaceleração foi coletada no sentido Sul e a aceleração, no sentido Norte. Nessa praça, devido ao baixo fluxo de tráfego, as filas são praticamente inexistentes. Foram consideradas três classes veiculares: automóveis, caminhões e ônibus.

A amostra da desaceleração era composta por 1.731 veículos, sendo 1.282 automóveis $(74,06 \%), 412$ caminhões $(23,80 \%)$ e 37 ônibus $(2,14 \%)$. Na aceleração, foram observados 2.266 veículos: 1.606 automóveis (70,87\%), 633 caminhões (27,93\%) e 27 ônibus $(1,20 \%)$

Segundo Bennett e Dunn [1995], as pesquisas que têm sido feitas sobre a modelagem do comportamento da desaceleração e da aceleração dos motoristas em rodovias podem ser divididas essencialmente em quatro áreas distintas: modelos constantes, modelos 
linearmente decrescentes, modelos polinomiais e modelos baseados na potência dos veículos.

Devido à complexidade dos modelos linearmente decrescentes e à falta dos dados necessários para a construção de um modelo polinomial ou de um modelo baseado na potência dos veículos, admitiu-se neste estudo a hipótese de que os veículos desaceleram e aceleram a uma taxa constante. Para validação de tal hipótese, foi feita uma comparação entre as velocidades calculadas através desta hipótese com velocidades medidas através de sensores NC-97 instalados na entrada e na saída da praça.

As velocidades de cruzeiro na chegada e na saída da praça foram obtidas cronometrando-se o tempo que os veículos gastam para percorrer a praça. Conhecendo-se a distância percorrida e supondo que a velocidade inicial (no caso da aceleração) ou que a velocidade final (no caso da desaceleração) era igual a zero, é possível calcular a velocidade na entrada e na saída da praça.

As velocidades assim calculadas foram comparadas com as velocidades medidas pelos sensores instalados na entrada e na saída da praça. Observou-se que as velocidades calculadas estavam ligeiramente superestimadas, apresentando uma diferença média de 4,33\%, que em parte pode ser atribuída ao erro provocado pela paralaxe ao se obter os tempos de percurso na praça.

Entretanto, considerou-se que a suposição feita (acelerações constantes) poderia ser aceita, visto que as formas alternativas de coleta de dados de velocidade seriam inviáveis face aos recursos disponíveis. A utilização de sensores automáticos para a determinação dos perfis de velocidade implicaria no uso de um grande número desses sensores devido à enorme variação nas trajetórias de veículos ao longo da praça, causada pelo grande número de faixas e pela programação da operação da praça, que varia as cabines em funcionamento ao longo do dia.

A Tabela 4.4 apresenta as velocidades médias calculadas na entrada e na saída da praça para as três classes veiculares, além das médias das taxas de desaceleração e acele- 
ração e dos tempos médios observados. A praça estudada possui uma extensão total de 600 m distribuídos uniformemente, ou seja, 300 m antes do eixo das cabines e 300 m depois do eixo das cabines.

Tabela 4.4: Parâmetros médios observados na desaceleração e aceleração

\begin{tabular}{llccc}
\hline & \multicolumn{2}{c}{ PARÂMETRO } & \multicolumn{3}{c}{ CLASSE VEI CULAR } \\
\cline { 3 - 5 } & & Automóveis & Caminhões & Ônibus \\
\hline \multirow{3}{*}{ Entrada da praça } & Tempo $(\mathrm{s})$ & 19,79 & 23,60 & 23,24 \\
& Velocidade $(\mathrm{km} / \mathrm{h})$ & 95,72 & 78,30 & 79,58 \\
& Taxa de desaceleração $\left(\mathrm{m} / \mathrm{s}^{2}\right)$ & 1,17 & 0,78 & 0,81 \\
\hline \multirow{3}{*}{ Saída da praça } & Tempo $(\mathrm{s})$ & 19,99 & 29,48 & 24,89 \\
& Velocidade $(\mathrm{km} / \mathrm{h})$ & 94,17 & 59,74 & 72,46 \\
& Taxa de aceleração $\left(\mathrm{m} / \mathrm{s}^{2}\right)$ & 1,13 & 0,45 & 0,65 \\
\hline
\end{tabular}

Observando-se a Tabela 4.4, pode-se notar que os automóveis apresentam as mais altas taxas de aceleração e desaceleração, como esperado. Nota-se que um automóvel gasta, em média, aproximadamente 40 segundos para percorrer as regiões que antecedem e sucedem as cabines de pedágio. Considerando-se que a extensão total da praça é $600 \mathrm{~m}$, um carro gastaria 22,75 s para percorrer esta distância, se sua velocidade for $95 \mathrm{~km} / \mathrm{h}$; portanto, o ciclo de desaceleração/aceleração a que são submetidos os automóveis implica num tempo adicional de viagem de aproximadamente 20 segundos, ao qual deve ser adicionado o tempo gasto na fila e no pagamento da tarifa. Para ônibus e caminhões, este atraso seria ainda maior, já que esses veículos iniciam sua desaceleração antes da entrada da praça e terminam de acelerar após saírem da praça.

\subsubsection{Escolha da cabine}

A aquisição de dados sobre o processo de escolha da cabine pelos motoristas foi feita a partir de filmagens feitas na entrada das praças de Araraquara e Limeira. A duração total das coletas foi de 7 horas na praça de Araraquara e de 3 horas na praça de Limeira.

À exemplo do estudo realizado por Gulewicz e Danko [1995], o procedimento adotado para a análise foi a observação isolada de cada veículo e a verificação do lado de che- 
gada à praça (direito ou esquerdo) e da cabine de destino.

A amostra total das duas praças era composta por 4.003 veículos, sendo 2.706 automóveis (67,60\%), 1.180 caminhões (29,48\%) e 117 ônibus (2,92\%).

A partir da observação das fitas, foram observados cinco hábitos globais relativos ao comportamento dos motoristas:

- a grande maioria dos motoristas $(72,78 \%)$ escolhe a cabine no mesmo lado em que chega à praça de pedágio;

- uma vez selecionado o lado da praça, $88,70 \%$ dos motoristas se dirigem à cabine com a menor fila naquele lado;

- caminhões e ônibus tendem a usar as cabines do lado direito da praça. Provavelmente isso ocorra devido à sinalização nas praças, que induz esse comportamento. É rara a existência de veículos pesados no lado esquerdo das praças;

- motoristas de automóveis preferem enfrentar filas de automóveis a enfrentar filas de caminhões, mesmo quando a quantidade de caminhões em fila é muito menor que a de automóveis; e

- alguns motoristas se dirigem a uma cabine com fila mesmo quando há cabines vazias disponíveis para o atendimento naquele lado da praça. Na maioria das vezes, isso ocorre devido a não observação dos sinais luminosos sobre as cabines (que indicam se a cabine está em operação ou não). Esse fenômeno também foi observado no estudo realizado por Gulewicz e Danko [1995].

Outro comportamento observado, porém bastante raro, é a realização de manobras arriscadas, com várias mudanças de faixas até a chegada à cabine. Esse comportamento foi observado inclusive em motoristas de veículos pesados e, segundo informações obtidas nas concessionárias, é considerado a maior causa de acidentes nas praças.

\subsubsection{Tempos de atendimento}

Os dados sobre os tempos de atendimento nas cabines que operam através dos métodos tradicionais de cobrança de pedágio foram obtidos nas cinco praças. A duração da coleta foi 
de 9 horas na praça de Araraquara, 4 horas na praça de Campo Limpo, 5 horas na praça de Limeira, 4 horas na praça de Nova Odessa e 8 horas na praça de Sertãozinho. Esses dados foram obtidos através de filmagens nas praças, com exceção da praça de Sertãozinho (onde os dados foram coletados através de um pesquisador dentro da cabine). Durante a análise foram consideradas três classes veiculares: automóveis, caminhões e ônibus.

O tempo de atendimento foi considerado como sendo o tempo compreendido entre duas descidas sucessivas da cancela que libera os veículos nas cabines, quando havia fila. Quando não existia fila, o tempo de atendimento foi considerado como o tempo compreendido entre o momento em que o veículo parava na cabine para ser atendido e o momento em que a cancela descia após a sua passagem, liberando a cabine para outro veículo.

O posicionamento das câmeras permitia uma boa visualização de três a cinco cabines, dependendo da praça. Desse modo, tornou-se necessário rever várias vezes as fitas com os dados coletados a fim de observar isoladamente cada cabine de pedágio e, com isso, obter o maior número de dados possível.

Durante a análise dos dados, verificou-se que a probabilidade de ocorrência de tempos superiores a 60 segundos era muito baixa, em torno de 1\%, e correspondia a situações excepcionais (por exemplo, problemas mecânicos impedindo a partida do veículo após o pagamento da tarifa). Assim sendo, tempos de atendimento superiores a 60 segundos foram desprezados. Foi considerado na análise um total de 10.257 veículos, sendo 7.911 automóveis (77,13\%), 2.148 caminhões (20,94\%) e 198 ônibus (1,93\%).

O procedimento seguido para a coleta de dados dos tempos de atendimento nas cabines AVI foi diferente do seguido para as formas de cobrança tradicionais. Levando-se em conta que ainda existia um baixo percentual de uso dessa tecnologia, seria inviável coletar dados através de câmeras devido ao tempo que seria gasto para a obtenção de uma amostra de tamanho adequado.

Optou-se, então, por usar sensores automáticos para a coleta de dados de velocidade e tipo de veículo nas cabines AVI. 
Uma coleta preliminar de 5 horas em duas cabines da praça de Araraquara foi realizada com o objetivo de verificar se existia variação na velocidade desenvolvida pelos veículos dentro das cabines AVI. Constatou-se que os veículos mantinham uma velocidade praticamente constante na entrada e na saída da faixa: a variação média foi de 2,08\%.

Desse modo, foram instalados dois sensores nas duas cabines AVI da praça de Araraquara, uma no sentido Sul e outra no sentido Norte. Esses sensores permaneceram instalados por uma semana. Ao contrário dos métodos convencionais de cobrança de pedágio, verificou-se que nas cabines dotadas com AVI não existem diferenças significativas com relação ao atendimento das classes veiculares, tornando desnecessária a estratificação desses dados.

Durante a extração dos dados dos sensores, verificou-se a presença de alguns dados inconsistentes, que apresentavam erros na deteç̧ão do veículo ou velocidades muito fora do seu intervalo de variação. Dos 3.954 veículos da amostra, 9 (0,23\% do total) foram considerados inconsistentes e tiveram que ser desprezados.

A amostra, então, ficou composta por 3.945 veículos que desenvolveram velocidades variando entre 20 e $90 \mathrm{~km} / \mathrm{h}$. Como citado no capítulo 2, a velocidade recomendada é de $40 \mathrm{~km} / \mathrm{h}$.

Com os dados de velocidades e sabendo que existe uma distância de segurança de 30 m que deve ser mantida entre dois veículos sucessivos nas faixas AVI, foi possível calcular os tempos de atendimento.

\section{EFEITO DAS CLASSES VEI CULARES SOBRE O TEMPO DE ATENDI MENTO}

A hipótese de que dasses veiculares diferentes têm tempos de processamento diferentes foi criada a partir da observação empírica do atendimento de veículos e da revisão bibliográfica. A opção por dividir os veículos em três classes surgiu a partir da revisão bibliográfica realizada, que sugeria diferenças relevantes no atendimento de alguns tipos de veículos através dos métodos tradicionais de cobrança de pedágio.

Como esperado, a média dos tempos de atendimento dos automóveis (18,92 s) fi- 
cou abaixo das médias dos tempos dos caminhões $(30,79$ s) e ônibus $(23,96$ s). Esse fato é ocasionado por vários fatores, entre eles: o baixo poder de aceleração dos veículos pesados, a dificuldade na transação gerada pela altura dos caminhões e ônibus em relação às cabines e a largura das faixas laterais às cabines, que quando são muito estreitas fazem com que os veículos pesados se movimentem de forma mais lenta que o normal, a fim de evitar acidentes.

As distribuições observadas e alguns parâmetros estatísticos dos tempos de atendimento para as três classes veiculares estão mostrados na Figura 4.8 e na Tabela 4.5, respectivamente.

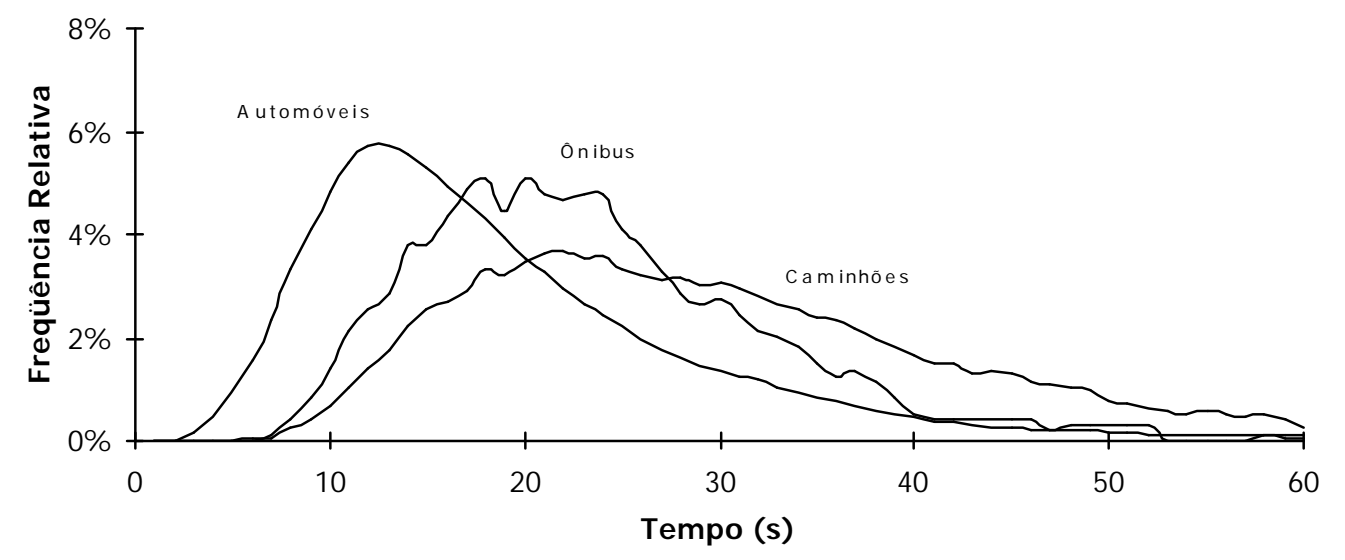

Figura 4.8: Distribuição dos tempos de atendimento dos veículos por classe veicular

Tabela 4.5: Parâmetros relativos aos tempos de atendimento (em segundos), em função da classe veicular

\begin{tabular}{lccc}
\hline \multirow{2}{*}{ PARÂMETROS } & \multicolumn{3}{c}{ CLASSE VEI CULAR } \\
\cline { 2 - 4 } & Automóveis & Caminhões & Ônibus \\
\hline Média & 18,92 & 30,79 & 23,96 \\
Desvio-Padrão & 10,18 & 14,13 & 9,70 \\
Mediana & 16,00 & 28,00 & 22,00 \\
Moda & 13,00 & 20,00 & 16,00 \\
Tamanho da amostra & 7911 & 2148 & 198 \\
\hline
\end{tabular}

Para verificar se a diferença encontrada entre os tempos de atendimento dos caminhões e ônibus era significativa, fez-se uso de análise de variância (ANOVA). A amostra uti- 
lizada para a análise foi criada a partir de uma escolha aleatória e, ao mesmo tempo, sistemática da variável tempo de atendimento. Foram escolhidas aleatoriamente 300 observações da amostra disponível: 30 casos para cada uma das cinco praças e para cada um dos dois tipos de veículo. O resultado da análise feita através do programa SPSS for Windows versão 6.0 é:

\begin{tabular}{lccccc}
\multicolumn{1}{c}{ Font e de Vari ação } & $\begin{array}{c}\text { Soma de } \\
\text { Quadrados }\end{array}$ & $\begin{array}{c}\text { Graus de } \\
\text { Li ber dade }\end{array}$ & $\begin{array}{c}\text { Quadrado } \\
\text { Médi o }\end{array}$ & $\mathrm{F}$ & $\mathrm{F}_{\alpha}$ \\
Ef ei tos pri nci pai s & 2117,948 & 1 & 2117,948 & 44,187 & 0,000 \\
Ti po de veí cul o & 2117,948 & 1 & 2117,948 & 44,187 & 0,000 \\
Expl i cada & 2117,948 & 1 & 2117,948 & 44,187 & 0,000 \\
Resi dual & 14283,595 & 298 & 47,932 & & \\
Tot al & 16401,543 & 299 & 54,855 &
\end{tabular}

Como o valor de $F_{\alpha}$ é menor que 0,05 , o resultado indica que, para um nível de significância de 5\%, existe uma diferença significativa entre os tempos de atendimento de ônibus e de caminhões, sendo que o tempo médio de atendimento dos ônibus é cerca de $22 \%$ menor que o dos caminhões.

\section{EFEITO DA PRAÇA SOBRE O TEMPO DE ATENDI MENTO}

Outro aspecto verificado durante a análise dos dados visava determinar se existiam diferenças nos tempos de atendimento de praça para praça.

Os tempos de atendimento observados para as cinco praças seguem as distribuições mostradas na Figura 4.9, para todos os tipos de veículos. Através dela, pode-se observar que as três praças operadas pela mesma concessionária (Campo Limpo, Nova Odessa e Limeira) possuem distribuições semelhantes. Isso sugere que as características físicas e operacionais das praças, que obedecem a padrões estabelecidos pela concessionária, podem influir diretamente no tempo gasto para os veículos serem processados. 


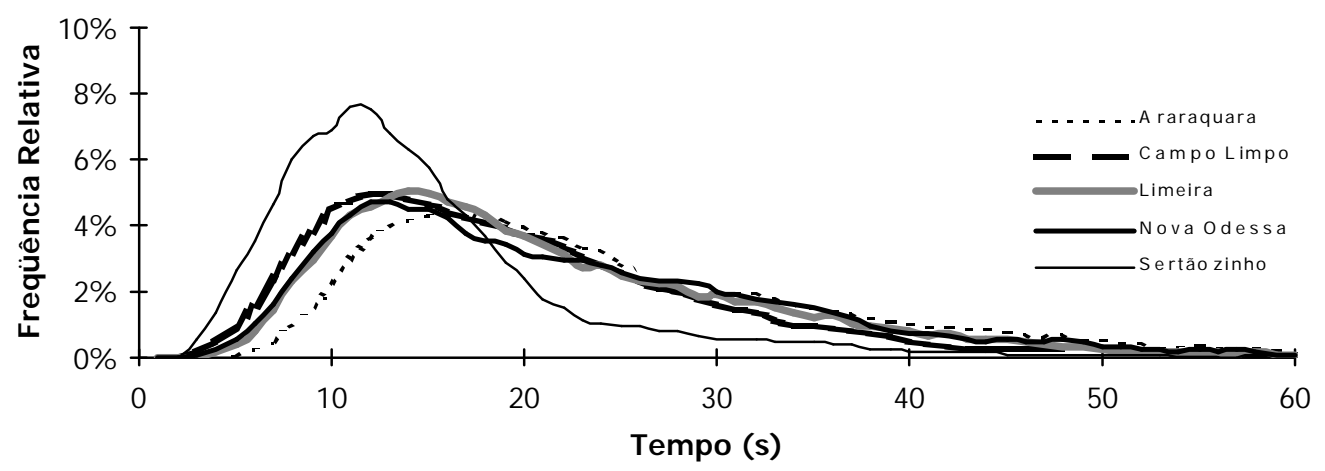

Figura 4.9: Distribuição dos tempos de atendimento dos veículos nas praças, sem estratificação por tipo de veículo

As médias dos tempos de atendimento para as três classes veiculares nas cinco praças de pedágio são apresentadas na Tabela 4.6.

Tabela 4.6: Médias dos tempos de atendimento (em segundos), em função da praça de pedágio

\begin{tabular}{lccc}
\hline \multirow{2}{*}{ PRAÇA } & \multicolumn{3}{c}{ CLASSE VEI CULAR } \\
\cline { 2 - 4 } & Automóveis & Caminhões & Ônibus \\
\hline Araraquara & 22,28 & 34,66 & 25,74 \\
Campo Limpo & 18,81 & 25,82 & 25,65 \\
Limeira & 18,61 & 31,41 & 26,14 \\
Nova Odessa & 18,61 & 32,14 & 24,76 \\
Sertãozinho & 13,29 & 22,64 & 15,69 \\
\hline
\end{tabular}

A análise de variância (ANOVA) foi usada para verificar se as diferenças entre os tempos de atendimento das praças operadas pela mesma concessionária e entre os tempos de atendimento para as três classes veiculares nessas mesmas praças eram significativas, com $\alpha=5 \%$. O número de casos processados foi 270: 30 observações para cada uma das três praças e para cada tipo de veículo. O resultado da ANOVA é apresentado a seguir: 


\begin{tabular}{lrrrrr}
\multicolumn{1}{c}{ Font e de Vari ação } & $\begin{array}{c}\text { Soma de } \\
\text { Quadrados }\end{array}$ & $\begin{array}{c}\text { Graus de } \\
\text { Li ber dade }\end{array}$ & $\begin{array}{r}\text { Quadrado } \\
\text { Médi o }\end{array}$ & \multicolumn{1}{c}{$F$} & $F_{\alpha}$ \\
Ef ei tos pri nci pai s & 3486,684 & 4 & 871,671 & 29,250 & 0,000 \\
Praça & 133,862 & 2 & 66,931 & 2,246 & 0,108 \\
Ti po de veí cul o & 3352,822 & 2 & 1676,411 & 56,253 & 0,000 \\
& & & & & \\
I nt er ações de 2a or dem & 763,807 & 4 & 190,952 & 6,408 & 0,000 \\
Praça-ti po de veí cul o & 763,807 & 4 & 190,952 & 6,408 & 0,000 \\
Expl i cada & 4250,491 & 8 & 531,311 & 17,829 & 0,000 \\
Resi dual & 7778,098 & 261 & 29,801 & & \\
Total & 12028,589 & 269 & 44,716 & &
\end{tabular}

Conclui-se que, para $\alpha=5 \%$, não existe um efeito significativo da praça sobre o tempo de atendimento, reforçando o resultado da análise anterior. Entretanto, verifica-se um efeito significativo do tipo de veículo sobre o tempo de atendimento nas praças da mesma concessionária.

\section{EFEITO DO VALOR DA TARI FA SOBRE O TEMPO DE ATENDI MENTO}

Os dados coletados sugerem que o valor da tarifa pode ter influência direta na distribuição dos tempos de atendimento da praça. Observando-se a Tabela 4.6, pode-se verificar que na praça de Sertãozinho os tempos de atendimento são consideravelmente inferiores aos tempos das demais praças, em todas as classes.

Ao contrário das outras quatro praças, a tarifa em Sertãozinho durante a coleta de dados era inteira $(R \$ 2,00)$, ou seja, não existiam centavos. Desse modo, facilitava-se a transação não só por parte do operador da cabine, que agilizava o atendimento, como também por parte do usuário, que diminuía o tempo gasto na verificação do troco.

A cobrança de tarifa inteira leva a reduções substanciais no tempo de processamento: contrastando o valor da média dos tempos de atendimento dessa praça com a média global, verifica-se uma redução de aproximadamente 30\% nos tempos dos automóveis, $26 \%$ nos tempos dos caminhões e $34 \%$ nos tempos dos ônibus.

Através de uma análise de variância (ANOVA), verificou-se se existem efeitos do valor da tarifa e do tipo de veículo sobre o tempo de atendimento. A variável valor da tarifa 
pode assumir dois valores, tarifa inteira e tarifa fracionada. Foram processados 450 casos: 30 observações para cada uma das cinco praças e para cada um dos tipos de veículo (automóveis, caminhões e ônibus). O resultado da ANOVA é:

\begin{tabular}{|c|c|c|c|c|c|}
\hline Fonte de Vari ação & $\begin{array}{c}\text { Soma de } \\
\text { Quadrados }\end{array}$ & $\begin{array}{c}\text { Graus de } \\
\text { Li ber dade }\end{array}$ & $\begin{array}{l}\text { Quadr ado } \\
\text { Médi o }\end{array}$ & $\mathrm{F}$ & $\mathrm{F}_{\alpha}$ \\
\hline Ef ei tos pri nci pais & 8698,842 & 3 & 2899,614 & 106,891 & 0,000 \\
\hline Ti po de veí culo & 4900,496 & 2 & 2450,248 & 90,326 & 0,000 \\
\hline Val or da tarifa & 3798,346 & 1 & 3798,346 & 140,022 & 0,000 \\
\hline I nt erações de $2^{a}$ or dem & 193,749 & 2 & 96,874 & 3,571 & 0,029 \\
\hline Ti po de veí cul o-tarifa & 193,749 & 2 & 96,874 & 3,571 & 0,029 \\
\hline Expl i cada & 10646, 918 & 5 & 2129,384 & 78,498 & 0,000 \\
\hline Resi dual & 12044, 269 & 444 & 27,127 & & \\
\hline ot al & 22691,187 & 449 & 50,537 & & \\
\hline
\end{tabular}

Ao nível de significância de 5\%, constata-se a existência de um efeito significativo para as duas variáveis analisadas e de um efeito significativo de segunda ordem da combinação dessas duas variáveis sobre o tempo de atendimento.

\section{EFEITO DO FLUXO DE TRÁFEGO DA PRAÇA SOBRE O TEMPO DE ATENDI MENTO}

A revisão bibliográfica realizada sugere que o fluxo de tráfego das praças de pedágio pode influenciar no tempo de atendimento. Isso pode ser explicado através de dois fatores:

- o comportamento dos operadores das cabines, que se sentem pressionados por uma fila crescente e tendem a executar a transação com maior rapidez; e

- o comportamento dos usuários, que, uma vez na fila, dispõem de tempo para providenciar uma quantia que minimize o seu tempo de atendimento.

Para verificar a influência do fluxo de tráfego sobre o tempo de atendimento, fez-se uso da análise de variância. O fluxo foi classificado em três níveis (alto, médio e baixo), atribuídos em função do tráfego médio diário de cada praça. A Tabela 4.7 apresenta a classificação das praças. 
Tabela 4.7: Classificação das praças em função do fluxo de tráfego

\begin{tabular}{lcc}
\hline \multicolumn{1}{c}{ PRAÇA } & $\begin{array}{c}\text { FLUXO DE TRÁFEGO } \\
\text { MÉDI O DI ÁRI O (veíc) }\end{array}$ & $\begin{array}{c}\text { CLASSI FICAÇÃO DO } \\
\text { FLUXO DE TRÁFEGO }\end{array}$ \\
\hline Araraquara & $11.690^{*}$ & baixo \\
Campo Limpo & 50.302 & alto \\
Limeira & 20.974 & médio \\
Nova Odessa & 31.975 & alto \\
Sertãozinho & $14.324^{*}$ & baixo \\
\hline * tráfego médio diário dos dois sentidos da praça &
\end{tabular}

Foram processados 450 casos: 30 observações para cada uma das cinco praças e para cada tipo de veículo. O resultado da ANOVA é:

\begin{tabular}{|c|c|c|c|c|c|}
\hline Fonte de Vari ação & $\begin{array}{c}\text { Sond de } \\
\text { Quadrados }\end{array}$ & $\begin{array}{l}\text { Graus de } \\
\text { Li ber dade }\end{array}$ & $\begin{array}{l}\text { Quadr ado } \\
\text { Médi o }\end{array}$ & $\mathrm{F}$ & $\mathrm{F}_{\alpha}$ \\
\hline Ef ei tos pri nci pais & 6967,566 & 4 & 1741,892 & 51,806 & 0,000 \\
\hline Fl uxo de tráf ego & 814,546 & 2 & 407,273 & 12,113 & 0,000 \\
\hline Ti po de veí cul o & 6153,020 & 2 & 3076,510 & 91,500 & 0,000 \\
\hline I nt erações de $2^{\underline{a}}$ ordem & 394,005 & 4 & 98,501 & 2,930 & 0,021 \\
\hline FI uxo-Ti po de veí cul o & 394,005 & 4 & 98,501 & 2,930 & 0,021 \\
\hline Expl i cada & 7863,374 & 8 & 982,922 & 29,233 & 0,000 \\
\hline Resi dual & 14827,813 & 441 & 33,623 & & \\
\hline Tot al & 22691,187 & 449 & 50,537 & & \\
\hline
\end{tabular}

O resultado indica que, ao nível de significância de 5\%:

- existe um efeito significativo do fluxo de tráfego sobre o tempo de atendimento, considerando todas as praças e tipos de veículos;

- existe um efeito significativo do tipo de veículo sobre o tempo de atendimento; e

- existe um efeito significativo da interação fluxo de tráfego e tipo de veículo sobre o tempo de atendimento.

Outra análise de variância foi realizada para verificar o efeito dessa mesma variável (fluxo de tráfego) sobre os tempos de atendimento das praças operadas pela mesma concessionária. Dessa forma, foram processados 270 casos (30 observações para cada praça e 
para cada tipo de veículo) que apresentaram o seguinte resultado:

\begin{tabular}{|c|c|c|c|c|c|}
\hline Fonte de Vari ação & $\begin{array}{c}\text { Soma de } \\
\text { Quadr ados }\end{array}$ & $\begin{array}{l}\text { Graus de } \\
\text { Li ber dade }\end{array}$ & $\begin{array}{l}\text { Quadr ado } \\
\text { Médi o }\end{array}$ & $\mathrm{F}$ & $\mathrm{F}_{\alpha}$ \\
\hline tos pri nci pais & 3478,103 & 3 & 1159,368 & 36,067 & 0,000 \\
\hline de veí cul o & 3352,822 & 2 & 1676,411 & 52,152 & 0,000 \\
\hline xo de tráf ego & 125,282 & 1 & 125,282 & 3,897 & 0,049 \\
\hline i cada & 3478,103 & 3 & 1159,368 & 36,067 & 0,000 \\
\hline dual & 8550,486 & 266 & 32,145 & & \\
\hline & 12028,589 & 269 & 44,716 & & \\
\hline
\end{tabular}

Para $\alpha=5 \%$, o resultado indica que tanto o fluxo de tráfego quanto o tipo de veículo exercem um efeito significativo sobre os tempos de atendimento observados nas três praças operadas pela mesma concessionária (Limeira, Nova Odessa e Campo Limpo).

\section{EFEITO DO SENTI DO DE FLUXO SOBRE O TEMPO DE ATENDI MENTO}

Duas das cinco praças de pedágio estudadas possuem cobrança bidirecional: Araraquara e Sertãozinho. Como os dados obtidos na praça de Sertãozinho não foram coletados de forma que os dois sentidos de cobrança tivessem amostra de mesma magnitude, foram utilizados apenas os dados obtidos na praça de Araraquara para avaliar se existia alguma relação entre os tempos de atendimento e o sentido de cobrança, em função do tipo de veículo. A ANOVA foi usada, com o processamento de 60 casos: 10 observações para cada um dos sentidos e para cada tipo de veículo. O resultado está apresentado a seguir:

\begin{tabular}{lrrrrc}
\multicolumn{1}{c}{ Font e de Vari ação } & $\begin{array}{c}\text { Soma de } \\
\text { Quadrados }\end{array}$ & $\begin{array}{c}\text { Graus de } \\
\text { Li ber dade }\end{array}$ & $\begin{array}{c}\text { Quadrado } \\
\text { Médi o }\end{array}$ & \multicolumn{1}{c}{ F } & $F_{\alpha}$ \\
Ef ei tos pri nci pai s & 926,362 & 3 & 308,787 & 8,689 & 0,000 \\
Sent i do de fl uxo & 68,908 & 1 & 68,908 & 1,939 & 0,169 \\
Ti po de veí cul o & 857,454 & 2 & 428,727 & 12,063 & 0,000 \\
& & & & & \\
I nt er ações de 2a or dem & 101,356 & 2 & 50,678 & 1,426 & 0,249 \\
Sent i do-ti po de veí cul o & 101,356 & 2 & 50,678 & 1,426 & 0,249 \\
Expl i cada & 1027,719 & 5 & 205,544 & 5,784 & 0,000 \\
Resi dual & 1919,127 & 54 & 35,539 & & \\
Tot al & 2946,846 & 59 & 49,947 & &
\end{tabular}


Ao nível de significância de 5\%, constata-se que não existe efeito significativo do sentido de cobrança sobre o tempo de atendimento $\left(F_{\alpha}=0,169>0,05\right)$ e nem efeito significativo de segunda ordem da combinação do sentido de cobrança e do tipo de veículo $\left(F_{\alpha}=\right.$ $0,249)$.

\section{EFEITO DO TI PO DE USUÁRI O SOBRE O TEMPO DE ATENDI MENTO}

O tipo de usuário de uma praça de pedágio pode ter influência no tempo de atendimento nas cabines. Usuários que passam pela praça com muita freqüência, chamados de "commuters", geralmente se comportam de forma diferente daqueles que a utilizam esporadicamente.

Os commuters, pessoas que viajam diariamente para se deslocar de sua residência até o local de trabalho, procuram reduzir ao máximo o seu tempo de viagem, levando à adoção de medidas que visem diminuir o tempo gasto para o pagamento da tarifa do pedágio.

Para verificar o efeito do tipo de usuário no tempo de atendimento nas cabines, fezse uso de análise de variância. Para isso, as praças foram classificadas de acordo com seu tipo de usuário predominante, apresentado na Tabela 4.8.

Tabela 4.8: Classificação das praças em função do tipo de usuário

\begin{tabular}{lc}
\hline \multicolumn{1}{c}{ PRAÇA } & CLASSI FI CAÇÃO DO \\
& TI PO DE USUÁRI O \\
\hline Araraquara & non-commuter \\
Campo Limpo & commuter \\
Limeira & non-commuter \\
Nova Odessa & misto \\
Sertãozinho & commuter \\
\hline
\end{tabular}

Foram processados 450 casos (30 observações para cada tipo de veículo, para cada uma das 5 praças estudadas). O resultado da ANOVA é: 


\begin{tabular}{|c|c|c|c|c|c|}
\hline Fonte de Vari ação & $\begin{array}{l}\text { Soma de } \\
\text { Quadrados }\end{array}$ & $\begin{array}{l}\text { Graus de } \\
\text { Li ber dade }\end{array}$ & $\begin{array}{l}\text { Quadr ado } \\
\text { Médi o }\end{array}$ & $\mathrm{F}$ & $F_{\alpha}$ \\
\hline Ef ei tos pri nci pais & 9082,920 & 4 & 2270,730 & 74,254 & 0,000 \\
\hline Ti po de veí cul o & 6654,823 & 2 & 3327,412 & 108,809 & 0,000 \\
\hline Ti po de usuário & 2428,096 & 2 & 1214,048 & 39,700 & 0,000 \\
\hline Expl i cada & 9082,920 & 4 & 2270,730 & 74,254 & 0,000 \\
\hline Resi dual & 13608, 267 & 445 & 30,580 & & \\
\hline Tot al & 22691, 187 & 449 & 50,537 & & \\
\hline
\end{tabular}

Conclui-se que, para $\alpha=5 \%$, existe um efeito significativo do tipo de usuário sobre o tempo de atendimento.

\section{EFEITO DA FORMA DE PAGAMENTO SOBRE O TEMPO DE ATENDI MENTO}

Apenas duas praças de pedágio foram utilizadas para coletar dados sobre a forma de pagamento da tarifa pelos usuários. Na praça de Araraquara, os usuários podem fazer o pagamento com dinheiro, cartão de crédito e cupom. Na praça de Sertãozinho, eles podem utilizar dinheiro, cupom e um cartão desenvolvido pela concessionária, que usa um sistema touchless, ou seja, que não requer contato físico para a sua leitura. Esse cartão pode ser usado em todas as praças operadas pela concessionária e é denominado cartão inteligente, por estar equipado com um chip.

Outra forma de pagamento aceita por todas as concessionárias do estado é o cheque, porém, como o procedimento para atender esses usuários é diferente dos demais (eles são liberados nas cabines e devem parar nas laterais da praça para fazer o preenchimento do valor), esses dados ficaram fora da coleta.

Analisando-se os dados coletados, verificou-se que um baixo percentual de usuários recorria ao pagamento através de cupom (uma média de 2,39\% nas duas praças). Desse percentual, $72 \%$ eram motoristas de caminhões. Essa forma de pagamento tende a não existir num futuro muito próximo, visto que os órgãos responsáveis pelos cupons (DERSA e DER-SP) já interromperam sua comercialização por eles terem se tornado instrumentos desatualizados, passíveis de roubos e falsificações e, principalmente, por possuírem custos 
operacionais inviáveis, decorrentes da existência de valores de tarifas diferenciadas na maIha rodoviária do Estado de São Paulo. Por todos esses fatores, desconsiderou-se essa forma de pagamento na análise.

Dos veículos observados na praça de Araraquara, 91,24\% utilizam dinheiro para o pagamento da tarifa. Na praça de Sertãozinho, esse percentual é de 85,99\%. O cartão de crédito é usado por 4,20\% dos usuários em Araraquara e o cartão inteligente, por 12,94\% dos usuários em Sertãozinho.

A Figura 4.10 apresenta as distribuições dos tempos de atendimento de acordo com a forma de pagamento. O pagamento em dinheiro foi dividido em duas classes visto que a tarifa em Araraquara é fracionada e a de Sertãozinho é inteira. Através da figura, pode-se observar que adoção de uma tecnologia como a do cartão inteligente pode gerar grandes benefícios para a operação de uma praça de pedágio. As médias observadas foram $24,28 \mathrm{~s}$ para pagamento em dinheiro em Araraquara e 15,17 s para pagamento em dinheiro na praça de Sertãozinho, 24,17 s para pagamento com cartão de crédito e 9,88 s para pagamento com cartão inteligente.

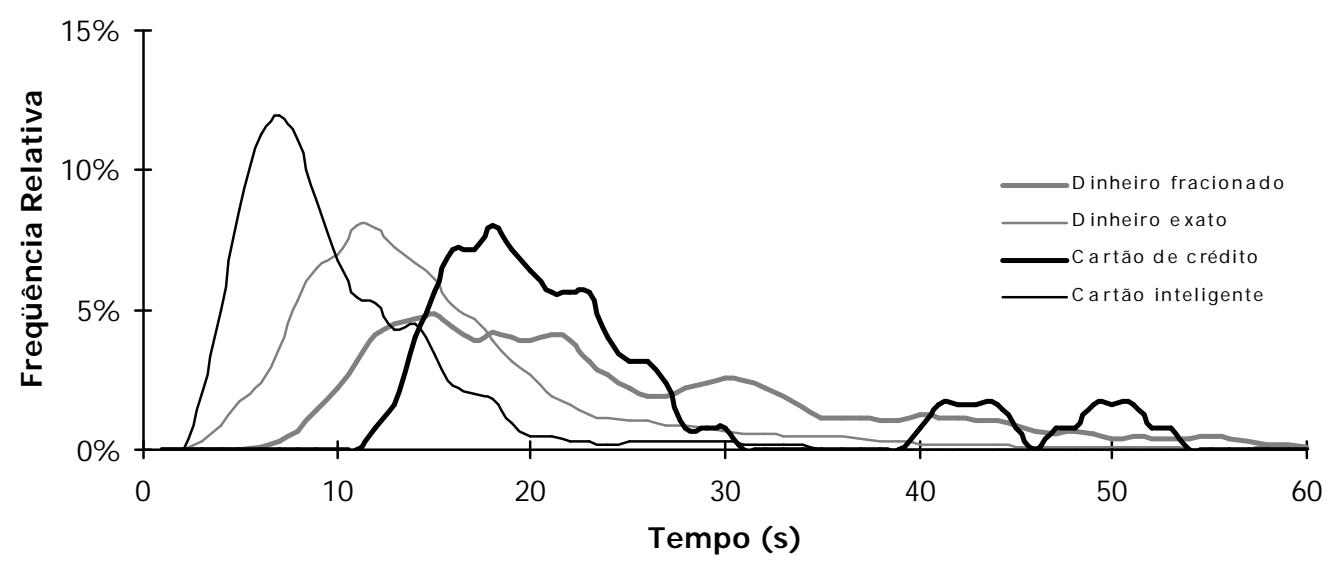

Figura 4.10: Distribuição dos tempos de atendimento em função da forma de pagamento

\subsubsection{Coleta eletrônica de pedágio}

O histograma da Figura 4.11 apresenta a distribuição dos tempos de atendimento obtidos nas cabines AVI. Pode-se perceber que aproximadamente $58 \%$ dos veículos desenvolvem a velocidade recomendada (tempo igual a 3 s), 17\% desenvolvem velocidades inferiores à 
recomendada e $25 \%$, maiores que a recomendada. Os veículos que passam pelo sistema em velocidade superior ao limite estabelecido fazem-no porque têm conhecimento da capacidade de leitura de informações da tecnologia AVI. Alguns adquirem esse conhecimento através da própria experiência de passagem pelo sistema.

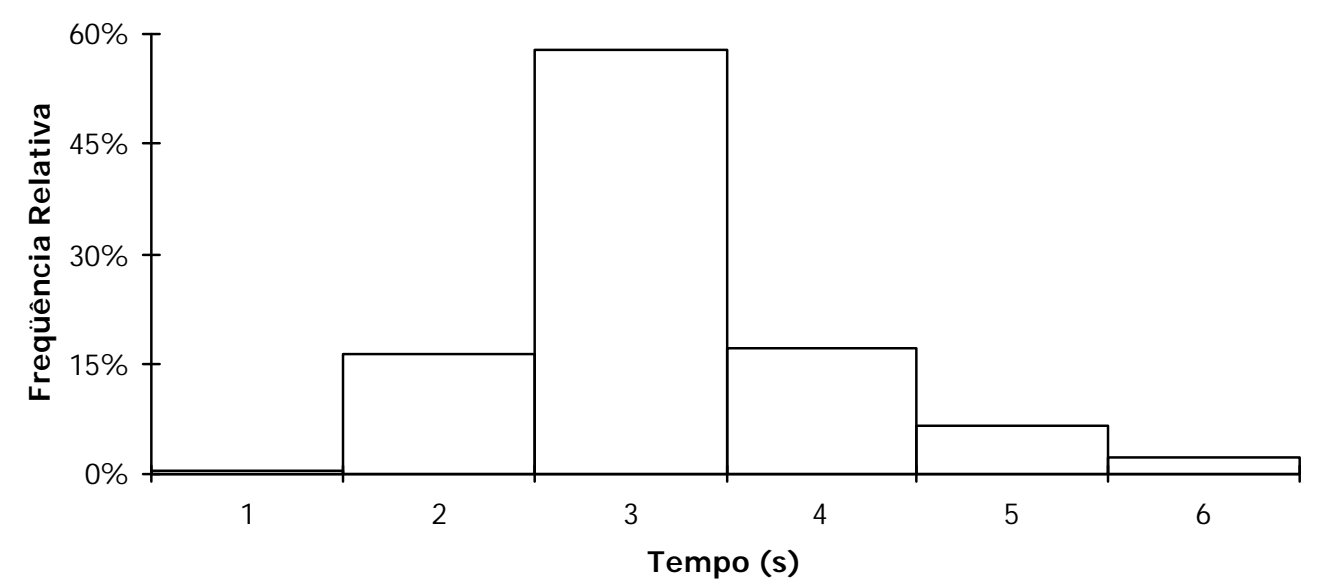

Figura 4.11: Distribuição dos tempos de atendimento nas cabines AVI

Como as cabines do sistema AVı implantado pelas concessionárias paulistas são padronizadas, pode-se considerar que o comportamento dos usuários nas cabines AVI dessa praça reflete o comportamento dos usuários em todo o Estado de São Paulo.

\section{EFEITO DA COLETA ELETRÔNI CA DE PEDÁGI O SOBRE O TEMPO DE ATENDI MENTO}

A coleta eletrônica de pedágio reduz drasticamente o tempo de atendimento dos veículos em uma praça. Isto pode ser observado através da comparação feita entre os tempos das quatros formas de pagamento apresentadas anteriormente e o tempo gasto nas cabines AVI. A Figura 4.12 mostra as distribuições dos tempos de acordo com a forma de pagamento. O tempo médio de atendimento observado nas cabines AVI foi de 3,19 s, significativamente inferior ao observado para outras formas de pagamento. 


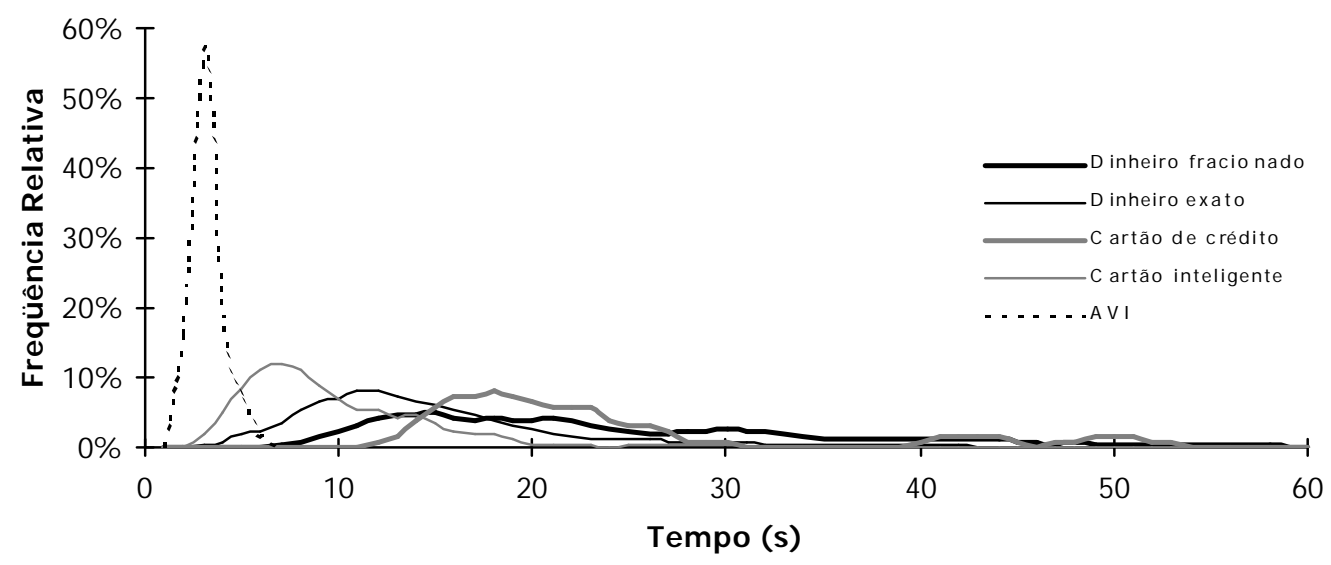

Figura 4.12: Distribuição dos tempos de atendimento

A Tabela 4.9 apresenta alguns parâmetros estatísticos dos tempos de atendimento para as cinco formas de pagamento.

Tabela 4.9: Parâmetros relativos aos tempos de atendimento (em segundos), em função da forma de pagamento

\begin{tabular}{lccccc}
\hline \multirow{2}{*}{ PARÂMETROS } & \multicolumn{5}{c}{ FORMA DE PAGAMENTO } \\
\cline { 2 - 6 } & $\begin{array}{c}\text { Dinheiro } \\
\text { Fracionado }\end{array}$ & $\begin{array}{c}\text { Dinheiro } \\
\text { Exato }\end{array}$ & $\begin{array}{c}\text { Cartão de } \\
\text { Crédito }\end{array}$ & $\begin{array}{c}\text { Cartão } \\
\text { Inteligente }\end{array}$ & AVI \\
\hline Média & 24,28 & 15,17 & 24,17 & 9,88 & 3,19 \\
Desvio-Padrão & 11,38 & 7,75 & 10,79 & 4,94 & 0,87 \\
Mediana & 21,00 & 13,00 & 20,00 & 8,00 & 3,00 \\
Moda & 13,00 & 10,00 & 16,00 & 7,00 & 3,00 \\
Tamanho da amostra & 521 & 804 & 24 & 121 & 3945 \\
\hline
\end{tabular}

A fim de avaliar se as diferenças encontradas entre as cinco formas de pagamento são estatisticamente significativas, utilizou-se a análise de variância usando-se apenas automóveis na análise, já que a porcentagem de caminhões que usam cartão de crédito é muito pequena e não se conseguiu observar nenhum ônibus usando essa forma de pagamento. Foram processados 100 casos (20 observações para cada forma de pagamento) e o resultado da ANOVA é apresentado a seguir: 


$\begin{array}{lccccc} & \begin{array}{c}\text { Soma de } \\ \text { Quadrados }\end{array} & \begin{array}{c}\text { Graus de } \\ \text { Li ber dade }\end{array} & \begin{array}{c}\text { Quadrado } \\ \text { Médi o }\end{array} & F & F_{\alpha} \\ \text { Ent re grupos } & 5301,860 & 4 & 1325,465 & 148,980 & 0,000 \\ \text { Resi dual } & 845,209 & 95 & 8,897 & & \\ \text { Tot al } & 6147,070 & 99 & & & \end{array}$

Pode-se concluir que, ao nível de significância de 5\%, existe um efeito do tipo de pagamento sobre o tempo de atendimento.

Outra análise estatística foi realizada para verificar se existem diferenças significativas entre as formas de pagamento, o teste de Scheffé, considerado mais apropriado para comparações que não seja pareadas [Howell, 1987]. As formas de pagamento foram classificadas de 1 a 5 na ordem apresentada na Tabela 4.9 e o resultado do teste de Scheffé é:

\begin{tabular}{|c|c|c|c|c|c|c|}
\hline \multirow[b]{2}{*}{$\begin{array}{l}\text { Pagament o } \\
\text { (I ) }\end{array}$} & \multirow[b]{2}{*}{$\begin{array}{l}\text { Pagament o } \\
(\mathrm{J})\end{array}$} & \multirow[b]{2}{*}{$\begin{array}{l}\text { Dif er ença das } \\
\text { Médi as }(1-J)\end{array}$} & \multirow[b]{2}{*}{$\begin{array}{l}\text { Erro } \\
\text { Padrão }\end{array}$} & \multirow[b]{2}{*}{$\mathrm{F}_{\alpha}$} & \multicolumn{2}{|c|}{ conf $\mathrm{i}$ ança $=90 \%$} \\
\hline & & & & & $\begin{array}{l}\text { Li mite } \\
\text { I nf eri or }\end{array}$ & $\begin{array}{l}\text { Li mite } \\
\text { Superi or }\end{array}$ \\
\hline & 1,00 & & & & & \\
\hline & 2,00 & $8,8250(*)$ &, 9432 &, 000 & 6,1538 & 11,4962 \\
\hline \multirow[t]{5}{*}{1,00} & 3,00 & 1,8750 & , 9432 & , 418 & $-0,7962$ & 4,5462 \\
\hline & 4,00 & $14,5550(*)$ &, 9432 &, 000 & 11,8838 & 17,2262 \\
\hline & 5,00 & $19,1250(*)$ & , 9432 &, 000 & 16,4538 & 21, 7962 \\
\hline & 1,00 & $-8,8250(*)$ & , 9432 &, 000 & - 11, 4962 & $-6,1538$ \\
\hline & 2,00 & & & & & \\
\hline \multirow[t]{5}{*}{2,00} & 3,00 & $-6,9500(*)$ &, 9432 &, 000 & $-9,6212$ & $-4,2788$ \\
\hline & 4,00 & $5,7300(*)$ &, 9432 &, 000 & 3,0588 & 8,4012 \\
\hline & 5,00 & $10,3000(*)$ & , 9432 &, 000 & 7,6288 & 12,9712 \\
\hline & 1,00 & $-1,8750$ &, 9432 &, 418 & $-4,5462$ & 0,7962 \\
\hline & 2,00 & $6,9500(*)$ &, 9432 &, 000 & 4,2788 & 9,6212 \\
\hline \multirow[t]{3}{*}{3,00} & 3,00 & & & & & \\
\hline & 4,00 & $12,6800(*)$ &, 9432 &, 000 & 10,0088 & 15,3512 \\
\hline & 5,00 & $17,2500(*)$ & , 9432 &, 000 & 14,5788 & 19,9212 \\
\hline
\end{tabular}




$\begin{array}{rrrrrrr}1,00 & -14,5550(*) & , 9432 & , 000 & -17,2262 & -11,8838 \\ 4,00 & 2,00 & -5,7300(*) & , 9432 & , 000 & -8,4012 & -3,0588 \\ & 3,00 & -12,6800(*) & , 9432 & , 000 & -15,3512 & -10,0088 \\ 4,00 & & & & & \\ & 5,00 & 4,5700(*) & , 9432 & , 000 & 1,8988 & 7,2412 \\ & 1,00 & -19,1250(*) & , 9432 & , 000 & -21,7962 & -16,4538 \\ 5,00 & -10,3000(*) & , 9432 & , 000 & -12,9712 & -7,6288 \\ & 2,00 & -17,2500(*) & , 9432 & , 000 & -19,9212 & -14,5788 \\ & 3,00 & -4,5700(*) & , 9432 & , 000 & -7,2412 & -1,8988 \\ & 4,00 & & & & & \end{array}$

* A diferença das médi as é si gnifi cativa ao ní vel de $0,10$.

Pode-se notar que as diferenças entre médias dos tempos de atendimento para cada forma de pagamento são estatisticamente significativas ao nível de confiança $\alpha=0,10$, a menos do pagamento em dinheiro fracionado e pagamento com cartão de crédito, cujos tempos médios de atendimento não são estatisticamente diferentes. Portanto, pode-se concluir que:

- a tecnologia de cobrança que produz os menores tempos de atendimento é a AVI, já que os veículos apenas reduzem sua velocidade ao passar próximo do sensor;

- existem vantagens significativas, do ponto de vista do tempo de atendimento, em se ter tarifas inteiras, já que há uma significativa redução no tempo de pagamento quando a tarifa é inteira, se comparado com o tempo médio de atendimento quando a tarifa é fracionada;

- o uso de cartão inteligente é a segunda melhor alternativa, em termos do tempo de atendimento, por dispensar a interação com o arrecadador; e

- o uso de cartão de crédito não traz ganhos do ponto de vista do tempo de processamento, já que o seu tempo de processamento é igual ao pagamento de tarifa fracionada em dinheiro. Suas vantagens residem na eliminação do dinheiro 
na transação e em oferecer mais uma opção de pagamento aos usuários.

O tempo de atendimento dos veículos é considerado muito importante na análise da operação de praças de pedágio porque ele está diretamente relacionado à capacidade delas. Além disso, a determinação do nível de serviço tem sido baseada no tempo médio gasto no sistema e no comprimento médio da fila, ambos derivados do tempo gasto no atendimento. 


\section{Capítulo5}

ESTUDO DE CASO:

AVALI AÇÃO DO NÍ VEL DE SERVI ÇO

ATRAVÉS DE UM MODELO DE SI MULAÇÃO

Este capítulo descreve como os parâmetros operacionais estudados no capítulo 4 podem ser usados na avaliação do nível de serviço de uma praça de pedágio, através de um modelo de simulação. Também são apresentadas as principais características do simulador usado neste trabalho, o INTEGRATION, a lógica utilizada no desenvolvimento do modelo de simulação usado para avaliação do nível de senviço da praça e uma discussão sobre os resultados obtidos através da simulação. O modelo desenvolvido é bastante simplificado e tem como motivação principal ilustrar como a simulação pode ser usada na análise da operação de praças de pedágio.

Durante o desenvolvimento da pesquisa cogitou-se o uso de outros simuladores, mas a escolha do INTEGRATION deu-se em função da sua reconhecida capacidade para simular sistemas como o estudado e da sua disponibilidade. Além disso, este simulador foi recalibrado por Demarchi [2000] para representar adequadamente as condições de tráfego de rodovias paulistas. Os conceitos básicos nos quais o INTEGRATION é baseado têm mostrado flexibilidade e capacidade suficiente para modelar uma grande quantidade de sistemas complexos.

No final do capítulo, baseados nos dados resultantes das simulações, são apresentados critérios e sugestões para a análise do nível de serviço de praças de pedágio. 


\subsection{NTEGRATI ON}

O INTEGRATION é um modelo de simulação de tráfego que traça os movimentos individuais dos veículos da sua origem até o seu destino, atualizando suas posições na rede viária simulada a cada décimo de segundo. O modelo pode ser utilizado na representação dos diversos elementos que compõem o sistema de transporte rodoviário, tais como vias expressas, vias arteriais, interseções semaforizadas ou não, praças de pedágio, entre outros. Este simulador teve seu desenvolvimento iniciado no Canadá na década de 80 por Michel Van Aerde.

Embora sua abordagem seja essencialmente microscópica, o modelo é calibrado de forma que o comportamento emergente do fluxo de veículos como um todo, em condições de equilíbrio, satisfaça também relações macroscópicas de tráfego, tal como a relação fluxovelocidade [Van Aerde, 2000]. Uma característica do INTEGRATION que torna o seu uso bastante atrativo é a possibilidade de visualizar o fluxo de tráfego no decorrer da simulação e, com isso, identificar mais facilmente os fenômenos que nele ocorrem, como por exemplo a formação de filas. Essa característica permite que o usuário detecte mais rapidamente eventuais erros de modelagem do sistema.

A análise detalhada do INTEGRATION foge dos propósitos deste capítulo. Serão descritos a seguir apenas os aspectos julgados necessários para o entendimento dos princípios da simulação de praças de pedágio. Assim, será analisada a forma como o INTEGRATION trata o sistema simulado e serão apresentados os dados necessários para o desenvolvimento do modelo e as lógicas fundamentais utilizadas na simulação de praças de pedágio.

\subsubsection{Estrutura básica do I NTEGRATI ON}

Um sistema de tráfego é composto por vários elementos relacionados àvia e aos veículos. No INTEGRATION, a rede de tráfego é modelada através de nós e tramos. Os nós podem representar interseções entre duas vias ou quaisquer outros pontos onde ocorra mudança nas características das vias, tais como redução ou aumento no número de faixas.

Os tramos promovem a ligação entre os nós e representam as vias por onde os veículos trafegam. A cada tramo é associada uma relação fluxo-velocidade, que determina o 
padrão de velocidades dos veículos quando presentes nesse tramo.

O tráfego nos tramos da rede é gerado a partir de demandas, originadas em um ou mais nós da rede, e que têm como destino um ou mais nós, diferentes dos nós de origem. No INTEGRATION, a demanda é caracterizada por uma distribuição temporal de viagens, que define os instantes de entrada dos veículos na rede e o tipo de veículo gerado.

A modelagem da rede baseia-se em informações provenientes de arquivos de entrada do tipo texto (ASCII). Para simular uma praça de pedágio são utilizados obrigatoriamente cinco arquivos com dados de entrada, relacionados abaixo:

- arquivo de nós: contém as coordenadas cartesianas, as características e os atributos dos nós da rede;

- arquivo de tramos: contém a estrutura dos tramos, suas coordenadas cartesianas e suas características, tais como comprimento, número de faixas e parâmetros que definem a relação entre fluxo, velocidade e densidade (velocidade de fluxo livre, velocidade na capacidade, capacidade e densidade de congestionamento);

- arquivo de semáforos: contém informações sobre a programação semafórica. Apesar de não conter nenhum tipo de dado para a simulação de praças de pedágio, sua presença é necessária para a execução das simulações - assim, este arquivo contém apenas uma linha de comentário;

- arquivo de demandas: contém a matriz origem/destino, indicando a magnitude de cada demanda, o instante de início e fim de sua geração, o padrão de geração das viagens e a composição veicular; e

- arquivo de incidentes: contém informações que permitem simular a ocorrência de incidentes, tais como o fechamento temporário de uma faixa de tráfego. Sua presença é necessária para a execução da simulação, mesmo que nenhum incidente seja simulado. Nesta simulação, o arquivo de incidentes contém apenas uma linha de comentário, como o arquivo de semáforos.

A simulação de uma praça de pedágio também requer a utilização de um arquivo 
opcional do INTEGRATION, que é o arquivo de parada. Esse arquivo faz com que classes de veículos predefinidas parem em um ponto especificado de um tramo por um período de tempo definido pelo usuário.

Além dos arquivos mencionados, é necessário um arquivo de controle, denominado arquivo mestre, que especifica os parâmetros globais da simulação e contém as informações sobre os nomes dos arquivos de entrada e saída de dados, suas localizações e o tempo de simulação.

Exemplos de arquivos de dados podem ser vistos no anexo $\mathrm{A}$.

\subsubsection{Lógicas fundamentais do I NTEGRATI ON}

No INTEGRATION, o movimento dos veículos em uma praça de pedágio é governado por cinco lógicas distintas, são elas:

- geração dos veículos;

- relação interveicular ("car-following”);

- escolha da rota;

- mudança de faixas; e

- filas.

A velocidade, a aceleração e o posicionamento longitudinal e transversal de cada veículo presente na rede são atualizados a cada décimo de segundo, de acordo com as cinco lógicas, analisadas a seguir.

\section{GERAÇÃO DOS VEÍ CULOS}

A geração individual dos veículos ocorre de uma maneira que satisfaz ao processo de chegadas especificado pelo usuário nos arquivos de entrada de dados. O INTEGRATION possibilita a geração de veículos com headways distribuídos de três formas distintas: determinística (headways constantes), seguindo uma distribuição exponencial negativa e seguindo uma distribuição exponencial negativa deslocada. 


\section{RELAÇÃO I NTERVEI CULAR}

Em cada tramo da rede, veículos em uma mesma faixa de tráfego movem-se segundo um padrão definido através de um modelo combinado de fluxo e "car-following" [Van Aerde, 1995]. O modelo é microscópico na medida em que o comportamento de cada veículo é modelado individualmente; os parâmetros do modelo, entretanto, são calibrados macroscopicamente, de forma que o comportamento agregado do fluxo de tráfego, em condições de equilíbrio, possa ser representado através da relação entre fluxo, velocidade e densidade definida para o tramo.

Nesse modelo, a velocidade de cada veículo é função do espaçamento entre ele e o veículo que trafega àsua frente. A equação que relaciona essas duas variáveis é dada a seguir:

$$
\mathrm{S}=\mathrm{c}_{1}+\frac{\mathrm{c}_{2}}{\mathrm{v}_{\mathrm{f}}-\mathrm{V}}+\mathrm{c}_{3} \mathrm{~V}
$$

em que s : espaçamento entre veículos consecutivos na mesma faixa de tráfego, em km;

v : velocidade, em $\mathrm{km} / \mathrm{h}$;

$\mathrm{V}_{\mathrm{f}}$ : velocidade do fluxo livre, em $\mathrm{km} / \mathrm{h}$;

$\mathrm{C}_{1}$ : constante de calibração 1, em km;

$\mathrm{c}_{2}$ : constante de calibração 2 , em $\mathrm{km}^{2} / \mathrm{h}$; e

$C_{3}$ : constante de calibração 1 , em $\mathrm{h}$.

A Figura 5.1a representa a relação microscópica entre velocidade e espaçamento que governa o movimento dos veículos individualmente. As Figuras 5.1b, 5.1c e 5.1d mostram, respectivamente, as relações macroscópicas entre densidade e velocidade, fluxo e velocidade e fluxo e densidade. A densidade $k$ pode ser calculada pela equação (5.2) e o fluxo q calculado pela relação fundamental de tráfego, expressa na equação (5.3):

$$
k=\frac{1}{c_{1}+\frac{c_{2}}{v_{f}-v}+c_{3} v}
$$




$$
q=v k
$$

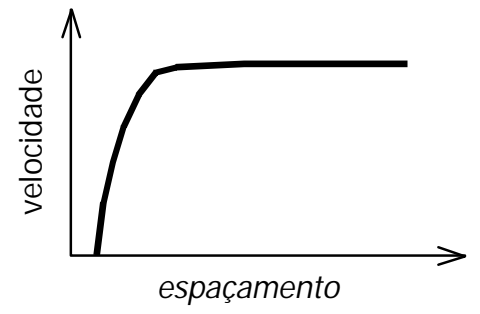

(a)

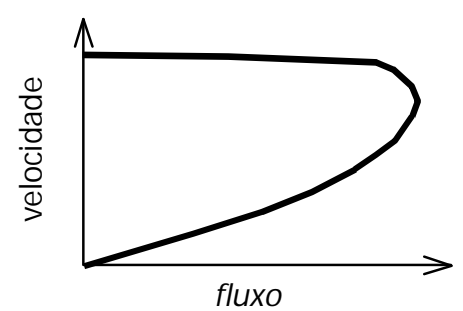

(c)

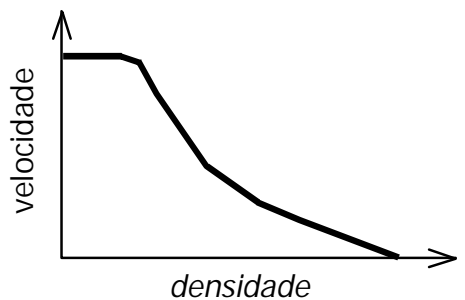

(b)

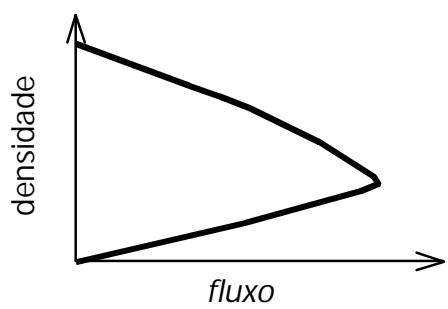

(d)

Figura 5.1: Relações entre as variáveis de tráfego [Van Aerde, 2000]

As constantes $c_{1}, c_{2}$ e $c_{3}$ representam relações entre os parâmetros característicos obtidos através de calibração macroscópica da curva fluxo x velocidade e o coeficiente $c_{v c}$ é utilizado para ajustar a velocidade na capacidade:

$$
\begin{gathered}
c_{v c}=\frac{2 v_{c}-v_{f}}{\left(v_{f}-v_{c}\right)^{2}} \\
c_{2}=\frac{1}{k_{j}\left(c_{v c}+\frac{1}{v_{f}}\right)} \\
c_{3}=\frac{1}{v_{c}}\left(\frac{v_{c}}{q_{c}}-c_{1}-\frac{c_{2}}{v_{f}-v_{c}}\right)
\end{gathered}
$$


sendo $\quad V_{f}$ : velocidade do fluxo livre, em $\mathrm{km} / \mathrm{h}$;

$\mathrm{v}_{\mathrm{c}}$ : velocidade na capacidade, em $\mathrm{km} / \mathrm{h}$;

$\mathrm{q}_{\mathrm{c}}$ : fluxo máximo ou capacidade da via, em veíc/h; e

$\mathrm{k}_{\mathrm{j}}$ : densidade de congestionamento, em veíc/ $\mathrm{km}$.

O modelo de fluxo proposto por Van Aerde [1995] consiste numa generalização do modelo proposto por Greenshields [1935], que corresponde ao caso em que as constantes $c_{1}$ e $c_{3}$ são iguais a zero. A introdução de mais parâmetros no modelo torna a modelagem mais flexível, permitindo que o modelo se adapte de melhor maneira aos dados coletados nas praças de pedágio.

Durante a simulação, a velocidade de cada veículo é atualizada a cada décimo de segundo, a partir do espaçamento existente entre ele e o veículo que trafega imediatamente àsua frente. Rearranjando os termos da equação ( 5.1), obtém-se uma equação quadrática:

$$
c_{3} v^{2}+\left(c_{1}-c_{3} v_{f}-s\right) v+\left(s-c_{1}\right) v_{f}-c_{2}=0
$$

A velocidade pode então ser determinada calculando-se as raízes da equação (5.8). Entretanto, somente a raiz onde $0 \leq \mathrm{v} \leq \mathrm{v}_{\mathrm{f}}$ interessa, sendo calculada conforme a seguinte equação:

$$
v=\frac{-b-\sqrt{b^{2}-4 a c}}{2 a}
$$

e os valores de a, b e c são:

$$
\begin{gathered}
a=c_{3} \\
b=c_{1}-c_{3} v_{f}-s
\end{gathered}
$$




$$
c=\left(s-c_{1}\right) v_{f}-c_{2}
$$

\section{ESCOLHA DA ROTA}

A escolha da rota pelo veículo é determinada por uma lógica interna do INTEGRATION. Em geral, existem várias maneiras para atribuir rotas aos veículos. Algumas das técnicas são estáticas e determinísticas, enquanto outras são estocásticas e dinâmicas.

Independentemente da técnica utilizada para determinar as rotas, a escolha do próximo tramo que um veículo deve percorrer é feita através de uma lista que contém, para cada veículo, a seqüência de tramos a ser percorrida da sua origem até o seu destino. Antes de percorrer um tramo, o veículo consulta a lista para saber qual o próximo tramo que deve utilizar para alcançar o seu destino de forma mais eficiente. Quando seu percurso nesse tramo está completo, o processo é repetido até alcançar o tramo cujo nó é o último destino.

\section{MUDANÇA DE FAI XAS}

Uma praça de pedágio, por sua natureza, possui mais de uma faixa de tráfego para que seja possível a escolha da cabine em que será feito o atendimento. No simulador, as mudanças de faixas são classificadas em desejáveis ou obrigatórias. As mudanças desejáveis são condicionadas pelo tráfego e as mudanças obrigatórias são condicionadas pela geometria de via. Ao longo um determinado tramo, um veículo pode realizar manobras dos dois tipos.

A lógica usada pelo INTEGRATION para determinar se uma mudança de faixa desejável deve ser realizada consiste na verificação de três alternativas de velocidade para cada veículo, a cada décimo de segundo. A primeira alternativa representa a velocidade potencial na qual o veículo pode continuar a trafegar na faixa em que se encontra, enquanto a segunda e a terceira alternativas representam as velocidades potenciais nas quais o veículo poderia trafegar nas faixas imediatamente àesquerda e àdireita da faixa atual. Essas comparações de velocidades são feitas com base no headway em cada faixa e em condições predefinidas para o veículo permanecer na faixa atual ou mover para a faixa adjacente. O veículo, 
então, muda para a faixa que permitirá a viagem com a maior das três velocidades potenciais.

Enquanto que as mudanças de faixa desejáveis são feitas com o objetivo de aumentar a velocidade, as mudanças obrigatórias representam uma necessidade para que o veículo possa continuar a trafegar através de uma ligação com outro tramo ao final de cada tramo percorrido. Em geral, a lógica implementada no simulador requer que o veículo permaneça em uma das faixas que está diretamente ligada com o próximo tramo que o veículo deve percorrer. Assim, supondo-se que exista uma saída conectada àfaixa da direita de um dado tramo, um veículo que esteja trafegando na faixa da esquerda deve mudar de faixa antes de alcançar a saída, se sua trajetória incluir esse tramo.

\section{FILAS}

Um subproduto natural da lógica do "car-following" é a representação de filas (os congestionamentos), que mostra os veículos parados ao longo de um dado tramo ou de vários tramos. Essa representação é baseada na diferença entre as taxas de chegada e partida em um tramo. As filas podem propagar-se para os tramos a montante ("back-propagation") se o número de veículos na fila exceder a capacidade do tramo, que é calculada para cada faixa de tráfego como o produto entre a densidade de congestionamento e o comprimento do tramo.

\subsection{DESCRI ÇÃO DO MODELO PROPOSTO}

O modelo desenvolvido para a simulação de praças de pedágio utilizou os dados coletados para a caracterização da operação das praças, apresentados no capítulo 4.

A praça de pedágio simulada é fictícia e possui cinco cabines em operação, sendo uma delas uma cabine AVI.

Na simulação, foram consideradas três classes veiculares: automóveis, caminhões e veículos portadores de AVI. Com base nos resultados das análises realizadas, a diferença entre automóveis e caminhões refere-se ao seu tempo de processamento na cabine de pe- 
dágio. Os ônibus foram deixados de lado por representarem uma fração minúscula do tráfego observado. Os veículos portadores de tags AVI são considerados uma única classe, já que os tempos de processamento observados independem da classe veicular.

A tela do simulador contendo a representação da praça e os nós e tramos da rede simulada podem ser observados na Figura 5.2. A rede completa é composta por 22 nós e 25 tramos e cada veículo percorre uma distância de 1.700 m, sendo $600 \mathrm{~m}$ dentro da praça de pedágio. Essa diferença deve-se ao fato da rede abranger não só a praça de pedágio, mas também uma parte da rodovia antes e depois da praça. A construção de rede foi baseada em um projeto de uma praça de pedágio cedido por uma concessionária de rodovias do Estado de São Paulo, a Triângulo do Sol.
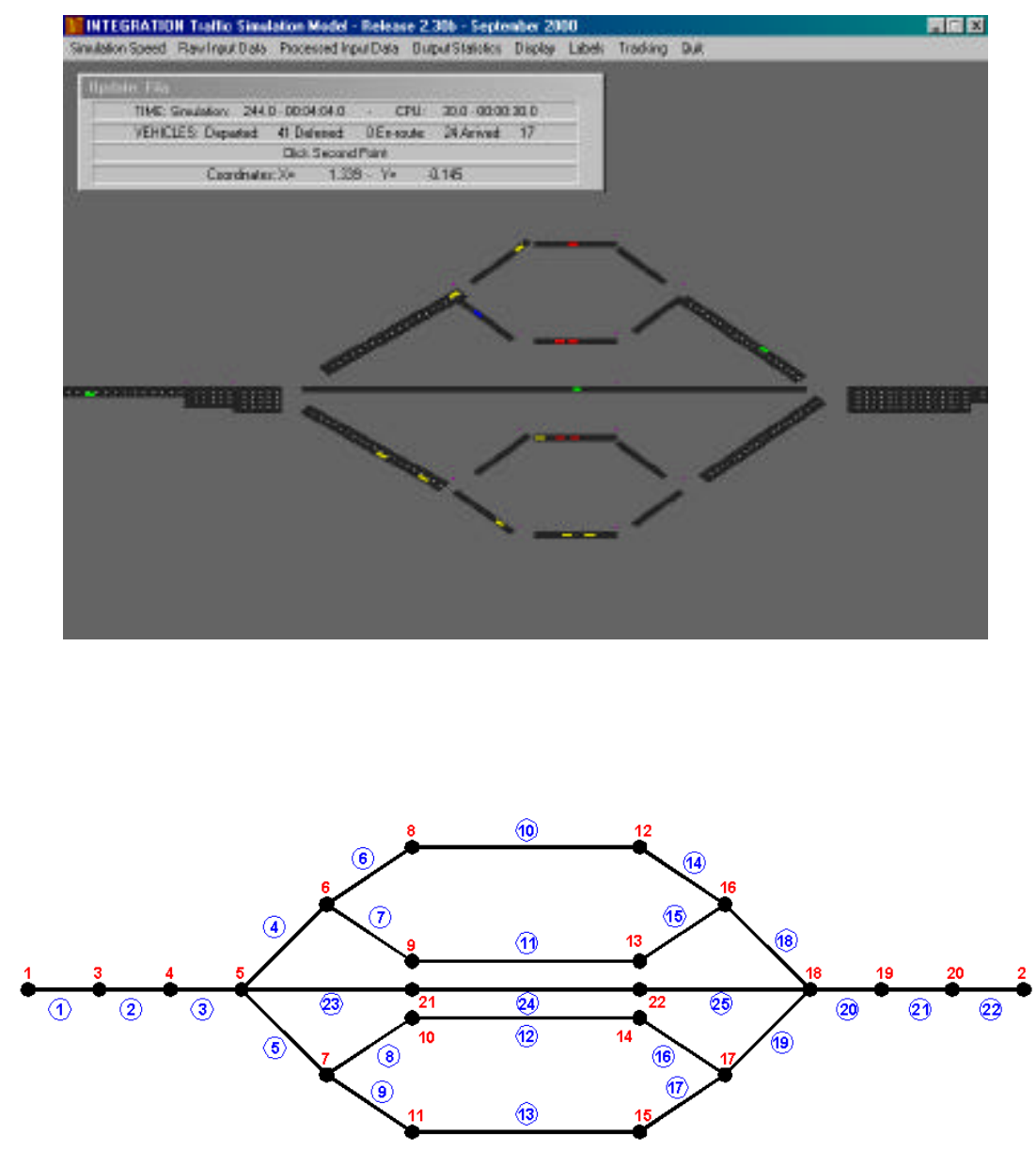

Figura 5.2: Tela do INTEGRATION e rede simulada (sem escala) 


\subsubsection{Dados de entrada do modelo de simulação}

Os dados necessários para a elaboração do modelo se referem ao processo de geração dos veículos, ao coeficiente de variação das velocidades desenvolvidas por cada uma das classes veiculares simuladas e aos tempos de atendimento para cada classe veicular e seus respectivos coeficientes de variação. Para introdução no modelo, foram considerados apenas os dados obtidos nas coletas de dados realizadas na praça de Araraquara.

Como apresentado no capítulo 4, os dados coletados indicam que a distribuição de chegadas do veículos àpraça de pedágio pode ser representada por uma distribuição exponencial negativa. Dessa forma, essa foi a distribuição utilizada para a geração dos veículos no modelo de simulação.

A partir dos valores obtidos nas coletas de dados, fez-se o cálculo dos coeficientes de variação da velocidade e do tempo de atendimento para cada uma das três classes veiculares geradas, de acordo com a equação:

$$
c v(x)=\frac{s(x)}{\bar{x}}
$$

em que $\quad \operatorname{cv}(x)$ : coeficiente de variação;

$\mathrm{s}(\mathrm{x})$ : desvio-padrão; e

$\bar{x}$ : média.

A Tabela 5.1 apresenta os valores calculados para os coeficientes de variação em função da classe veicular. Esta tabela apresenta também os valores que foram utilizados no modelo proposto. Os veículos equipados com tags AVI não possuem tempo de atendimento, já que não param nas cabines para pagar a tarifa. 
Tabela 5.1: Coeficientes de variação

\begin{tabular}{lcccc}
\hline & \multicolumn{4}{c}{ COEFI CI ENTE DE VARI AÇÃo } \\
\cline { 2 - 5 } CLASSE VEI CULAR & \multicolumn{2}{c}{ Calculado para a amostra } & \multicolumn{1}{c}{ Utilizado no modelo } \\
\cline { 2 - 5 } & Velocidade & $\begin{array}{c}\text { Tempo de } \\
\text { Atendimento }\end{array}$ & Velocidade & $\begin{array}{c}\text { Tempo de } \\
\text { Atendimento }\end{array}$ \\
\hline Automóveis & 0,15 & 0,51 & 0,10 & 0,51 \\
Caminhões & 0,15 & 0,43 & 0,10 & 0,43 \\
Portadores de AVI & 0,27 & - & 0,10 & - \\
\hline
\end{tabular}

A não utilização dos coeficientes de variação da velocidade calculados para a amostra deu-se em função do seu elevado valor. Para os automóveis e caminhões, as distribuições de velocidades ao longo da praça obtidas apresentam uma dispersão muito grande que, em parte pode ser atribuída àforma com que as velocidades foram estimadas. A di spersão das velocidades nas faixas AVI também é muito grande, e poderia ser explicada pela forma com que os usuários se comportam diante de uma tecnologia até então recente (na época da coleta de dados, o sistema AVI tinha terminado a etapa de testes, durante a qual era usado apenas veículos das concessionárias e de algumas empresas selecionadas). Dessa forma, decidiu-se por uma redução no valor do coeficiente de variação das velocidades, com base na observação do comportamento do tráfego na simulação.

Das três classes veiculares simuladas, os veículos equipados com tags AVI não param nas cabines, já que só precisam reduzir a velocidade para passar pelas faixas com os sensores. Apenas veículos de duas das classes simuladas precisam parar nas cabines para efetuar o pagamento: automóveis e caminhões. Seus tempos médios de atendimento, obtidos através das coletas de dados, foram, respectivamente, 22 s e 35 s. Observando a Tabela 5.1, pode-se perceber que, mesmo apresentando uma grande dispersão, os coeficientes de variação dos tempos de atendimento calculados foram utilizados no modelo. A justificativa para isso é que constatou-se, a partir de toda a amostra obtida nas coletas de dados, que os tempos de atendimento possuem um intervalo de variação muito grande dentro de uma mesma classe veicular. Assim, considerou-se que os coeficientes de variação calculados refletiam de forma adequada os tempos de atendimento dos veículos nas cabines.

Dadas as restrições de recursos e de tempo, e considerando-se que o propósito da 
simulação é apenas ilustrar a aplicação dos parâmetros que caracterizam a operação de praças de pedágio, optou-se por uma validação simplificada do modelo de simulação, baseada na observação do comportamento dos veículos. O simulador foi considerado validado quando o comportamento dos veículos era compatível com o esperado.

\subsection{EXPERI MENTOS DE SI MULAÇÃO}

Vários experimentos de simulação foram realizados para verificar o efeito da variação da taxa de fluxo horário e da composição do tráfego sobre o sistema, conforme se verá a seguir. Foram consideradas duas medidas de desempenho para a análise dos dados gerados pela simulação: o tempo médio gasto no sistema (considerada a medida de desempenho primária) e o comprimento médio de fila por cabine.

O tempo total gasto pelos veículos na rede é fornecido em um arquivo de resultados da simulação através do tempo total gasto em cada um dos tramos da rede. Somando-se o tempo gasto em cada tramo por cada um dos veículos, tem-se o tempo total e o tempo médio. Entretanto, esse tempo gerado compreende o tempo que é gasto para percorrer a praça de pedágio, trechos da rodovia e ainda esperar por atendimento na cabine do pedágio.

O comprimento médio de fila por cabine, por não ser um resultado direto do modelo fornecido nos arquivos de saída da simulação, foi estimado através da observação da fila no sistema a cada minuto decorrido, em cada um dos cenários simulados.

Uma das características do INTEGRATI ON é a existência de veículos cujo comportamento é monitorado ao longo da rede, chamados de "probe vehicles". O programador pode estabelecer uma porcentagem (entre 0 e 100\%) dos veículos gerados como sendo "probes". Para os veículos "probes", o INTEGRATION fornece dados toda vez que o veículo chega ao fim do tramo percorrido. A partir desses registros, pode-se determinar a seqüência de tramos percorridos e o tempo gasto para percorrer cada tramo.

Como a medida de desempenho primária adotada é o tempo médio gasto no sistema (praça de pedágio), foi necessário simular cada um dos cenários sem que a praça exis- 
tisse, para verificar qual o tempo médio gasto para percorrer um trecho com a extensão da praça simulada, sob as condições de tráfego admitidas para cada cenário simulado. Assim, pôde-se calcular o tempo adicional ocasionado pela operação de pagamento de pedágio a partir da diferença entre o tempo médio gasto na rede com o pedágio e o tempo médio gasto sem o pedágio.

\subsubsection{Cenários simulados}

O objetivo das simulações realizadas foi determinar como as medidas de desempenho adotadas variam com o aumento do fluxo de veículos e com a porcentagem de veículos equipados para a cobrança de pedágio por meio do sistema AV. Para tanto, foi preciso determinar a capacidade teórica da praça de pedágio. As seguintes equações foram utilizadas para o cálculo:

- tempo médio de atendimento $(\mathrm{T})$, em s:

$$
\mathrm{T}=\frac{\%_{\text {auto }} \times \mathrm{T}_{\text {auto }}+\%_{\text {cam }} \times \mathrm{T}_{\text {cam }}}{100}
$$

- capacidade da praça de pedágio (C), em veíc/h:

$$
\mathrm{C}=\frac{3600}{\mathrm{~T}} \times \mathrm{n}
$$

em que $\quad \%_{\text {auto }}$ : percentagem de automóveis;

$\%_{\text {cam }}$ : percentagem de caminhões;

$\mathrm{T}_{\text {auto }}$ : tempo médio de atendimento para os automóveis, em s;

$\mathrm{T}_{\text {cam }}$ : tempo médio de atendimento para os caminhões, em s; e

$\mathrm{n}$ : número de cabines.

Para o cálculo da capacidade da praça, considerou-se uma composição básica do fluxo de tráfego ( $70 \%$ de automóveis e 30\% de caminhões) e um tempo médio de atendi- 
mento de 22 s para os automóveis e 35 s para os caminhões. A capacidade calculada foi de 556 veíc/h.

Dessa forma, foram criados cenários nos quais o fluxo de tráfego variava de 100 a 600 veíc/h (com incrementos de 100 veíc/h) e a porcentagem de veículos usando o sistema AVI variava de $0 \%$ a $20 \%$ (com incrementos de $5 \%$ ), conforme apresentado na Tabela 5.2 .

Tabela 5.2: Descrição dos cenários simulados

\begin{tabular}{|c|c|c|c|c|c|}
\hline CENÁRIO & $\begin{array}{c}\text { FLUXO } \\
\text { (veíc/ h) }\end{array}$ & $\begin{array}{c}\text { FLUXO/ } \\
\text { CAPACIDADE }\end{array}$ & $\begin{array}{c}\text { AUTOMÓVEIS } \\
(\%)\end{array}$ & $\begin{array}{c}\text { CAMI NHÕES } \\
(\%)\end{array}$ & $\begin{array}{l}\text { AVI } \\
(\%)\end{array}$ \\
\hline 1 & 100 & 0,180 & 70 & 30 & 0 \\
\hline 2 & 100 & 0,180 & 70 & 25 & 5 \\
\hline 3 & 100 & 0,180 & 65 & 25 & 10 \\
\hline 4 & 100 & 0,180 & 60 & 25 & 15 \\
\hline 5 & 100 & 0,180 & 60 & 20 & 20 \\
\hline 6 & 200 & 0,360 & 70 & 30 & 0 \\
\hline 7 & 200 & 0,360 & 70 & 25 & 5 \\
\hline 8 & 200 & 0,360 & 65 & 25 & 10 \\
\hline 9 & 200 & 0,360 & 60 & 25 & 15 \\
\hline 10 & 200 & 0,360 & 60 & 20 & 20 \\
\hline 11 & 300 & 0,540 & 70 & 30 & 0 \\
\hline 12 & 300 & 0,540 & 70 & 25 & 5 \\
\hline 13 & 300 & 0,540 & 65 & 25 & 10 \\
\hline 14 & 300 & 0,540 & 60 & 25 & 15 \\
\hline 15 & 300 & 0,540 & 60 & 20 & 20 \\
\hline 16 & 400 & 0,719 & 70 & 30 & 0 \\
\hline 17 & 400 & 0,719 & 70 & 25 & 5 \\
\hline 18 & 400 & 0,719 & 65 & 25 & 10 \\
\hline 19 & 400 & 0,719 & 60 & 25 & 15 \\
\hline 20 & 400 & 0,719 & 60 & 20 & 20 \\
\hline 21 & 500 & 0,899 & 70 & 30 & 0 \\
\hline 22 & 500 & 0,899 & 70 & 25 & 5 \\
\hline 23 & 500 & 0,899 & 65 & 25 & 10 \\
\hline 24 & 500 & 0,899 & 60 & 25 & 15 \\
\hline 25 & 500 & 0,899 & 60 & 20 & 20 \\
\hline 26 & 600 & 1,079 & 70 & 30 & 0 \\
\hline 27 & 600 & 1,079 & 70 & 25 & 5 \\
\hline 28 & 600 & 1,079 & 65 & 25 & 10 \\
\hline 29 & 600 & 1,079 & 60 & 25 & 15 \\
\hline 30 & 600 & 1,079 & 60 & 20 & 20 \\
\hline
\end{tabular}


Para a obtenção do tempo médio gasto no sistema foi necessário simular duas vezes cada cenário durante 10 horas, tendo sido desprezados os primeiros 30 minutos para que o sistema entrasse em equilíbrio. Além disso, para que as amostras de resultados possuíssem tamanhos semelhantes, apesar da diferença nos fluxos gerados, variou-se a porcentagem de veículos "probes" que iriam ser observados pelo simulador para a geração dos arquivos de resultados. Cada uma das amostras ficou composta por, aproximadamente, 950 veículos.

A observação da fila média por cabine necessitou que cada cenário fosse simulado por um período de 2 horas e 30 minutos, tomando-se o cuidado de desprezar os 30 minutos iniciais para equilibrar o sistema.

\subsubsection{Discussão dos resultados obtidos na simulação}

Através da observação das curvas das medidas de desempenho obtidas com os resultados dos cenários descritos na Tabela 5.2, evidenciou-se a necessidade da criação de cenários adicionais. Esses cenários permitiram um melhor ajuste das curvas e estão apresentados na Tabela 5.3.

Tabela 5.3: Descrição dos cenários adicionais simulados

\begin{tabular}{cccccc}
\hline CENÁRIO & $\begin{array}{c}\text { FLUXO } \\
\text { (veíc/ h) }\end{array}$ & $\begin{array}{c}\text { FLUXO/ } \\
\text { CAPACI DADE }\end{array}$ & $\begin{array}{c}\text { AUTOMÓVEIS } \\
\text { (\% ) }\end{array}$ & $\begin{array}{c}\text { CAMI NHÕES } \\
\text { (\%) }\end{array}$ & $\begin{array}{c}\text { AVI } \\
\text { (\%) }\end{array}$ \\
\hline 31 & 350 & 0,629 & 70 & 30 & 0 \\
32 & 350 & 0,629 & 70 & 25 & 5 \\
33 & 350 & 0,629 & 65 & 25 & 10 \\
34 & 350 & 0,629 & 60 & 25 & 15 \\
35 & 350 & 0,629 & 60 & 20 & 20 \\
36 & 450 & 0,809 & 70 & 30 & 0 \\
37 & 450 & 0,809 & 70 & 25 & 5 \\
38 & 450 & 0,809 & 65 & 25 & 10 \\
39 & 450 & 0,809 & 60 & 25 & 15 \\
40 & 450 & 0,809 & 60 & 20 & 20 \\
41 & 550 & 0,989 & 70 & 30 & 0 \\
42 & 550 & 0,989 & 70 & 25 & 5 \\
43 & 550 & 0,989 & 65 & 25 & 10 \\
44 & 550 & 0,989 & 60 & 25 & 15 \\
45 & 550 & 0,989 & 60 & 20 & 20 \\
46 & 700 & 1,259 & 60 & 20 & 20 \\
\hline
\end{tabular}


As Figuras 5.3 e 5.4 mostram a variação das medidas de desempenho adotadas de acordo com o fluxo e a composição do tráfego.

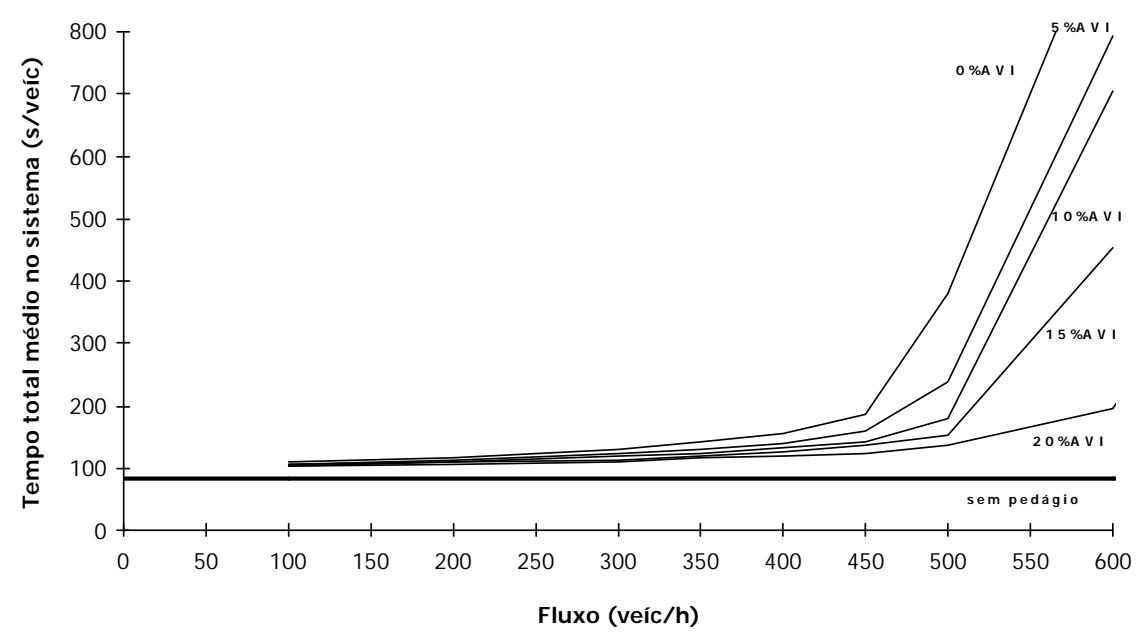

Figura 5.3: Resultados obtidos na simulação para o tempo médio gasto no sistema

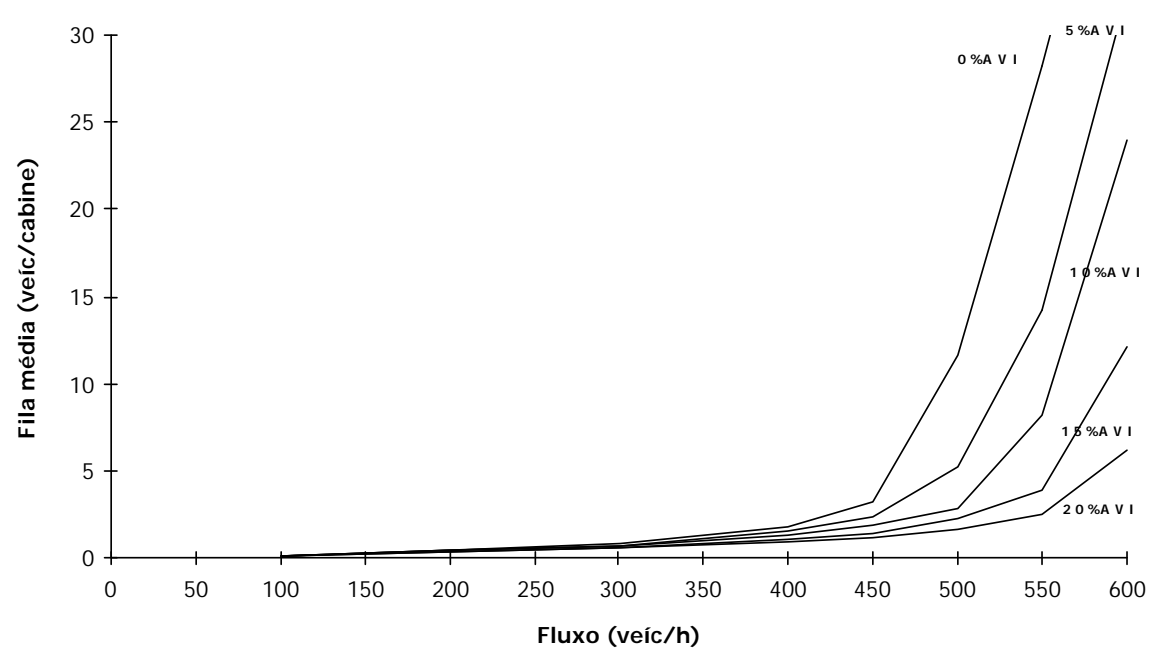

Figura 5.4: Resultados obtidos na simulação para o comprimento médio de fila por cabine

Observando-se as Figuras 5.3 e 5.4, fica evidente que o uso de cobrança eletrônica de pedágio reduz consideravelmente o congestionamento na praça de pedágio. Quando o fluxo de tráfego se aproxima da capacidade, se apenas 10\% dos usuários estiverem equipados com tags $\mathrm{AVI}$, o tempo médio gasto no sistema pode ser reduzido quase à metade, comprovando os benefícios gerados por essa tecnologia de cobrança. Portanto, seria extre- 
mamente conveniente que as concessionárias passassem a incentivar o uso das cabines AVI, eliminando ou reduzindo a cobrança da taxa mensal dos usuários e/ou o valor cobrado na aquisição do tag. Outro tipo de incentivo àadoção do sistema AVI de pagamento de tarifa seria a construção de faixas especiais para veículos portadores de tags, que permitiriam que esses usuários evitassem os congestionamentos que se formam na entrada das praças em períodos de movimento intenso, como em feriados prolongados.

\subsection{ANÁLI SE DE CRI TÉRI OS PARA AVALI AÇÃo dO NÍ VEL DE SERVI ÇO DE PRAÇAS DE PEDÁGIO}

A revisão bibliográfica realizada para este trabalho indicou a existência de dois estudos que propuseram critérios para a avaliação do nível de serviço de praças de pedágio: Lin e Su [1994] e Gulewicz e Danko [1995]. Os critérios adotados em cada um dos estudos estão apresentado na Tabela 3.1 do capítulo 3, repetida na Tabela 5.4 para conveniência do leitor.

Tabela 5.4: Critérios de nível de serviço adotados por Lin e Su [1994] e Gulewicz e Danko [1995]

\begin{tabular}{ccccc}
\hline & $\begin{array}{c}\text { COMPRI MENTO MÉDIO DA } \\
\text { FI LA POR CABI NE } \\
\text { Ní VEL DE }\end{array}$ & $\begin{array}{c}\text { TEMPO MÉd) } \\
\text { NO SI STEMA } \\
\text { (s/ veíc) }\end{array}$ & $\begin{array}{c}\text { TEMPO MÉDIO } \\
\text { DE ESPERA } \\
\text { (s/ veíc) }\end{array}$ \\
\cline { 2 - 5 } SERVI çO & $\begin{array}{c}\text { Lin e Su } \\
\text { [1994] }\end{array}$ & $\begin{array}{c}\text { Gulewicz e Danko } \\
{[1995]}\end{array}$ & $\begin{array}{c}\text { Lin e Su } \\
{[1994]}\end{array}$ & $\begin{array}{c}\text { Gulewicz e Danko } \\
\text { [1995] }\end{array}$ \\
\hline A & $\leq 1$ & $\leq 1$ & $\leq 15$ & $\leq 5$ \\
B & $\leq 2$ & $\leq 3$ & $\leq 30$ & $\leq 15$ \\
C & $\leq 3$ & $\leq 5$ & $\leq 45$ & $\leq 25$ \\
D & $\leq 6$ & $\leq 8$ & $\leq 60$ & $\leq 40$ \\
E & $\leq 10$ & $\leq 11$ & $\leq 80$ & $\leq 60$ \\
F & $>10$ & $>11$ & $>80$ & $>60$ \\
\hline
\end{tabular}

A partir dos resultados obtidos na simulação, procedeu-se uma análise para verificar a consistência dos critérios utilizados por esses autores em relação àpraça simulada.

\subsubsection{Tempo médio no sistema}

Uma das medidas de desempenho utilizadas por Lin e Su [1994] foi o tempo médio gasto no 
sistema, definido como a soma do tempo gasto na fila e do tempo gasto no atendimento. Gulewicz e Danko [1995] utilizaram o tempo médio de espera na fila como medida de desempenho. Como este estudo considerou o tempo médio no sistema como medida de desempenho, foi necessário adicionar o tempo médio de atendimento aos critérios propostos por Gulewicz e Danko [1995] para tornar possível a análise.

A Tabela 5.5 apresenta os fluxos de tráfego da praça simulada que correspondem aos limites dos seis níveis de senviço ( $\mathrm{A}$ a F), de acordo com os critérios sugeridos por cada um dos estudos.

Tabela 5.5: Fluxos de tráfego limites para critérios baseados no tempo médio no sistema (veíc/h)

\begin{tabular}{clcccccc}
\hline \multirow{2}{*}{ TRÁFEGO } & \multirow{2}{*}{ ESTUDO } & \multicolumn{7}{c}{ Ní VEL DE SERV ÇO } \\
\cline { 3 - 7 } & & A & B & C & D & E & F \\
\hline \multirow{2}{*}{ 0\% AVI } & Lin e Su [1994] & $<100$ & 148 & 296 & 364 & 414 & $>414$ \\
& Gulewicz e Danko [1995] & 148 & 258 & 322 & 380 & 426 & $>426$ \\
\hline \multirow{2}{*}{$5 \% \mathrm{AVI}$} & Lin e Su [1994] & $<100$ & 175 & 325 & 406 & 452 & $>452$ \\
& Gulewicz e Danko [1995] & 175 & 300 & 358 & 417 & 458 & $>458$ \\
\hline \multirow{2}{*}{$10 \% \mathrm{AVI}$} & Lin e Su [1994] & $<100$ & 208 & 363 & 451 & 476 & $>476$ \\
& Gulewicz e Danko [1995] & 208 & 341 & 400 & 457 & 486 & $>486$ \\
\hline \multirow{2}{*}{$15 \% \mathrm{AVI}$} & Lin e Su [1994] & $<100$ & 243 & 400 & 461 & 500 & $>500$ \\
& Gulewicz e Danko [1995] & 243 & 347 & 420 & 480 & 502 & $>502$ \\
\hline \multirow{2}{*}{$20 \% \mathrm{AVI}$} & Lin e Su [1994] & $<100$ & 316 & 457 & 504 & 541 & $>541$ \\
& Gulewicz e Danko [1995] & 316 & 427 & 482 & 514 & 562 & $>562$ \\
\hline
\end{tabular}

Considerando-se que a capacidade da praça de pedágio deve corresponder ao nível de serviço $E$, pode-se observar que os critérios sugeridos nos dois estudos podem não ser adequados para a praça simulada: para a composição básica do tráfego ( $0 \% \mathrm{AVI})$, a capacidade teórica calculada da praça é de 556 veíc/h enquanto que o limite do nível de serviço $\mathrm{E}$ é 414 veíc/h (ou seja, relação v/c $=0,744$ ), se aplicados os critérios proposto por Lin e Su [1994]. Se aplicados os critérios propostos por Gulewicz e Danko [1995], o limite do nível de serviço E é 426 veíc/h (relação v/c = 0,766).

\subsubsection{Fila média por cabine}

A segunda medida de desempenho considerada nos dois estudos foi a fila média por cabine, 
medida em número de veículos. A Tabela 5.6 apresenta os fluxos de tráfego da praça simulada que correspondem aos limites do nível de serviço considerado, de acordo com os critérios sugeridos por cada um dos estudos.

Tabela 5.6: Fluxos de tráfego limites para critérios baseados na fila média ( veíc/h)

\begin{tabular}{clcccccc}
\hline \multirow{2}{*}{ TRÁFEGO } & \multirow{2}{*}{ ESTUDO } & \multicolumn{7}{c}{ NÍ VEL DE SERV ÇO } \\
\cline { 3 - 7 } & & A & B & C & D & E & F \\
\hline \multirow{2}{*}{ 0\% AVI } & Lin e Su [1994] & 304 & 400 & 436 & 468 & 490 & $>490$ \\
& Gulewicz e Danko [1995] & 304 & 436 & 458 & 480 & 498 & $>498$ \\
\hline \multirow{2}{*}{$5 \%$ AVI } & Lin e Su [1994] & 320 & 420 & 460 & 505 & 529 & $>529$ \\
& Gulewicz e Danko [1995] & 320 & 460 & 495 & 514 & 533 & $>533$ \\
\hline \multirow{2}{*}{ 10\% AVI } & Lin e Su [1994] & 332 & 450 & 500 & 528 & 555 & $>555$ \\
& Gulewicz e Danko [1995] & 332 & 500 & 519 & 550 & 559 & $>559$ \\
\hline \multirow{2}{*}{ 15\% AVI } & Lin e Su [1994] & 348 & 478 & 521 & 564 & 588 & $>588$ \\
& Gulewicz e Danko [1995] & 348 & 521 & 554 & 578 & 595 & $>595$ \\
\hline \multirow{2}{*}{ 20\% AVI } & Lin e Su [1994] & 400 & 521 & 559 & 600 & $>600$ & - \\
& Gulewicz e Danko [1995] & 400 & 559 & 578 & $>600$ & - & \\
\hline
\end{tabular}

Observando-se a Tabela 5.6, verifica-se que os critérios sugeridos nos dois estudos para o nível de serviço E podem não ser adequados, devido aos valores abaixo da capacidade teórica calculada encontrados para a composição básica do tráfego: 490 veíc/h (v/c = 0,881), para Lin e Su [1994], ou 498 veíc/h $(v / c=0,896)$, para Gulewicz e Danko [1995]. Entretanto, os critérios para os níveis de serviço A e B parecem ser uma boa sugestão para avaliação da fila média por cabine. No nível de serviço A, a relação v/c é 0,547 e no nível de serviço B, a relação v/c é 0,719 (critério de Lin e Su [1994]) ou 0,784, se for usado o critério de Gulewicz e Danko [1995].

\subsubsection{Um método para estabelecimento de critérios para avaliação do nível de serviço de praças de pedágio}

Desta forma, pode-se notar que um dos aspectos que ainda deve ser melhor estudado é a definição do limite superior do nível de serviço E, que depende da definição da capacidade da praça. Uma forma de definir a capacidade da praça seria, por exemplo, determinar o fluxo de chegada que corresponde a uma situação tal que a fila fique contida no limite da 
praça, sem estender-se pelo trecho de rodovia à montante da entrada da praça. Esse fluxo de saturação da praça poderia ser determinado através de um modelo de simulação, ainda na fase de projeto da praça, já que seria uma característica única da praça e o projetista poderia controlá-lo, variando a extensão reservada para as filas, o número de cabines ou ambos.

Como as restrições de recursos e de tempo para o desenvolvimento deste estudo e as limitações do modelo de simulação usado impedem uma investigação mais detalhada deste aspecto, a discussão a seguir irá tratar apenas do esboço geral de um método para estabelecimento de critérios para determinação de nível de serviço em praças de pedágio.

O método proposto é baseado no uso de um modelo de simulação. O passo inicial seria estabelecer a capacidade da praça, com base, por exemplo, numa definição como a proposta feita anteriormente: o maior fluxo no qual a fila limita-se àpraça de pedágio, sem propagar-se pela rodovia. Os limites dos demais níveis de serviço seriam estabelecidos em função do tempo médio no sistema, a exemplo do que foi feito por Lin e Su [1994] e Gulewicz e Danko [1995]. Por exemplo, o limite do nível de serviço A poderia ser estabelecido considerando-se que o tempo médio no sistema não deve ultrapassar a soma do tempo de atendimento do veículo com a metade do tempo de atendimento de outro veículo, o que corresponderia a menos de um veículo na fila.

Uma vez estabelecidos os limites dos níveis de serviço, a verificação operacional do nível de senviço na praça seria realizada através do comprimento médio das filas, já que é muito mais simples observar a extensão da fila do que medir o tempo médio no sistema. A correlação entre essas duas medidas de desempenho pode ser feita através do modelo de simulação. A Tabela 5.7 apresenta os valores obtidos ao se correlacionar a fila média nas cabines com o tempo médio no sistema, usando-se um conjunto arbitrário de critérios de avaliação do nível de serviço para a praça simulada. As Figuras 5.5 e 5.6 mostram como esta correlação é feita, a partir das curvas fluxo-tempo médio no sistema e fluxo-fila média nas cabines. 
Tabela 5.7: Correlação entre as medidas de desempenho usadas para avaliar o nível de serviço de praças de pedágio

\begin{tabular}{ccc}
\hline $\begin{array}{c}\text { Ní VEL DE } \\
\text { SERV ÇO }\end{array}$ & $\begin{array}{c}\text { TEMPO MÉDIO NO SI STEMA } \\
\text { (s/ veíc) }\end{array}$ & $\begin{array}{c}\text { FI LA MÉDI A } \\
\text { (veíc) }\end{array}$ \\
\hline A & $\leq 40$ & $\leq 1$ \\
B & $\leq 60$ & $\leq 2$ \\
C & $\leq 90$ & $\leq 3$ \\
D & $\leq 120$ & $\leq 4$ \\
E & $\leq 650$ & $\leq 30$ \\
F & $>650$ & $>30$ \\
\hline
\end{tabular}

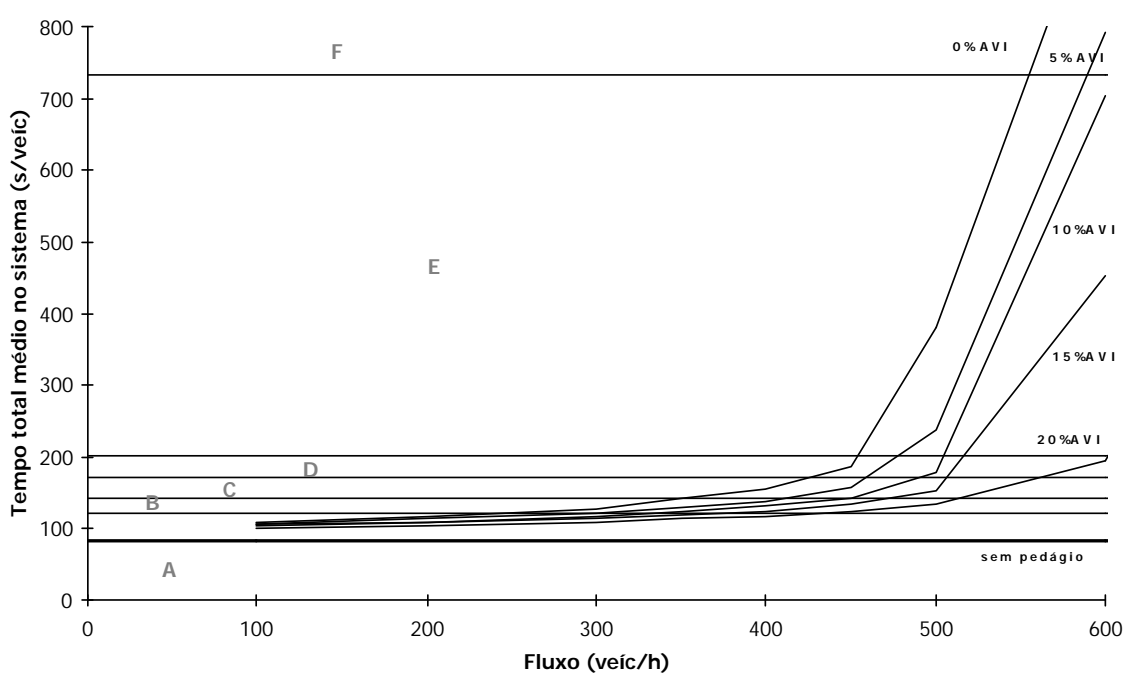

Figura 5.5: Níveis de serviço para critérios do tempo médio no sistema

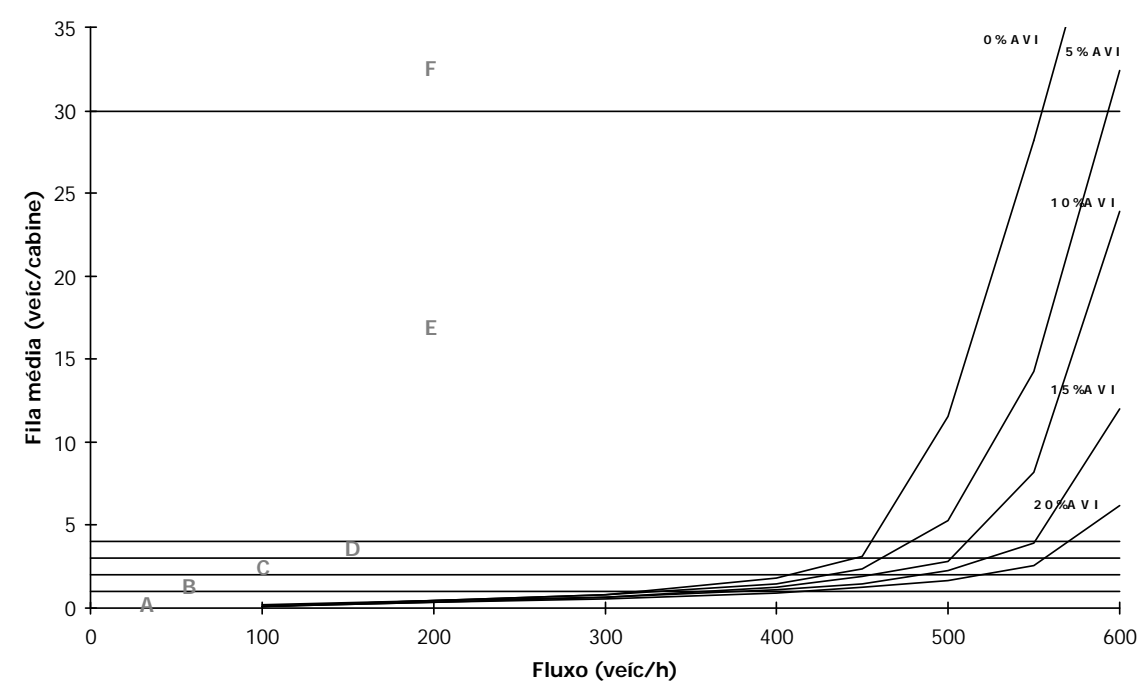

Figura 5.6: Níveis de serviço para critérios da fila média 


\section{Capítulo6}

\section{CONCLUSÕES E RECOMENDAÇÕES}

A meta da pesquisa relatada nesta dissertação foi analisar as características operacionais de praças de arrecadação de pedágio, a fim de fornecer subsídios para o seu projeto e para o estabelecimento de parâmetros e procedimentos para avaliação do nível de serviço.

O primeiro passo seguido foi a realização de um levantamento para o conhecimento da literatura relacionada àoperação de praças de pedágio, que incluía inovações tecnológ icas e operacionais, medidas de desempenho para análise do nível de serviço e técnicas de modelagem que representassem o funcionamento das praças, bem como alguns modelos desenvolvidos.

Com base na revisão bibliográfica realizada, foram estabelecidos os processos que deveriam ser estudados para estabelecer valores típicos e distribuições dos parâmetros que descrevem a operação das praças de pedágio. Esses processos são: as chegadas de veículos фे praças, a desaceleração dos veículos na entrada da praça, a escolha da cabine pelos motoristas, o atendimento dos veículos nas cabines (incluindo a forma de pagamento da tarifa), a aceleração dos veículos na saída da praça e o atendimento nas cabines de cobrança eletrônica de pedágio (AVI).

Cinco praças de pedágio foram escolhidas para servir de base para este trabalho: Campo Limpo, Nova Odessa e Limeira (operadas pela AutoBAn); Araraquara (operada pela Triângulo do Sol) e Sertãozinho (operada pela Vianorte). Elas foram selecionadas visando 
uma caracterização realística do comportamento dos usuários e da forma de operação das praças pelas concessionárias do Estado de São Paulo.

Os dados coletados nas cinco praças foram então analisados para verificar o efeito de algumas políticas operacionais observadas nas praças e para comparar o desempenho das praças em função das relações entre os dados coletados em cada uma delas. Essa análise fez uso da ANOVA e do teste de Scheffé, tendo-se chegado के seguintes conclusões:

- a tecnologia de cobrança da tarifa de pedágio que produz os menores tempos de atendimento é a eletrônica (AVI), já que os veículos não precisam parar para efetuar o pagamento;

- existem vantagens significativas, do ponto de vista do tempo de atendimento, em se ter tarifas inteiras, já que há uma significativa redução no tempo de pagamento quando se compara os tempos médios de atendimento dessa tarifa com os da tarifa fracionada;

- das tecnologias de cobrança de tarifa analisadas, o uso de cartão inteligente é a segunda melhor alternativa em termos do tempo de atendimento, por dispensar a interação com o arrecadador; e

- o uso de cartão de crédito não traz ganhos do ponto de vista do tempo de processamento. Suas vantagens residem na eliminação do dinheiro na transação e em oferecer mais uma opção de pagamento aos usuários.

Após a análise dos dados coletados, apresenta-se um exemplo de como esses dados podem ser usados para a determinação do nível de serviço das praças. Para tanto, fez-se uso de um modelo de simulação.

\subsection{CONCLUSÕES}

Da análise dos dados coletados, pode-se concluir que:

1. O processo de chegadas dos veículos \$̀ praças de pedágio pode ser representado por uma distribuição exponencial negativa, se o intervalo de tempo em estudo for relativamente curto (uma hora). 
2. Modelos lineares podem ser usados para a determinação do perfil da velocidade durante a desaceleração e a aceleração do veículos nas praças.

3. A maioria dos motoristas escolhe a cabine no mesmo lado em que chega àpraça de pedágio e, uma vez selecionado o lado, se dirigem àcabine com menor fila.

4. Caminhões e ônibus tendem a usar as cabines do lado direito da praça e alguns motoristas se dirigem a uma cabine com fila mesmo quando há cabines disponíveis para o atendimento naquele lado da praça.

5. O tempo de atendimento dos veículos nas cabines varia em função do tipo de veículo, da forma de pagamento e das características da praça com relação ao valor da tarifa, fluxo de tráfego e tipo de usuário predominante.

Da análise dos resultados obtidos através do modelo de simulação desenvolvido, pode-se concluir que o uso da cobrança eletrônica de pedágio reduz consideravelmente o congestionamento nas praças de pedágio, especialmente quando o fluxo de tráfego se aproxima da capacidade; se $10 \%$ dos usuários optarem pelo pagamento eletrônico da tarifa, o tempo médio gasto na praça reduz-se quase àmetade.

A diminuição do tempo de atendimento dos veículos é uma meta que deve ser perseguida por todas as concessionárias de rodovias. Tentativas feitas nesse sentido, como a implantação de um sistema próprio de coleta de pedágio e o incentivo àadesão da coleta eletrônica, são sempre válidas quando se pensa em melhorar a operação das praças e aumentar o conforto oferecido aos usuários.

\subsection{RECOMENDAÇÕES}

Tendo em vista a experiência de coletar dados e analisá-los, podem ser feitas algumas recomendações para o desenvolvimento de estudos futuros. O primeiro aspecto do estudo realizado que deveria ser aprimorado diz respeito à obtenção de dados sobre o perfil da desaceleração e da aceleração dos veículos nas praças de pedágio. Esses dados devem ser coletados de forma que possibilite determinar a variação da desaceleração e aceleração ao longo da praça. O método escolhido para a coleta desses dados, em função das limitações 
dos recursos disponíveis, impediu uma determinação precisa dos perfis de velocidade ao longo da entrada e da saída da praça. Dados mais acurados poderiam ser obtidos, por exemplo, com um melhor posicionamento das câmeras (em pontos mais altos para redução da paralaxe) ou com auxílio de radar, se sua presença não afetar o comportamento dos motoristas. Uma outra opção, ainda que envolva uma grande disponibilidade de recursos, seria a instalação de sensores similares ao NC-97 no pavimento ao longo da extensão da praça. Uma última opção seria a utilização de medições de GPS cinemático diferencial em que veículos seriam instrumentados com equipamento GPS que coletariam dados sobre sua posição ao longo da praça. Nesse caso, a precisão da medida seria excelente, mas há a dificuldade em se obter uma amostra de tamanho significativo, já que o ciclo de viagem pode ser longo.

Uma segunda recomendação diz respeito àamostra de praças de pedágio. Seria conveniente que fossem estudadas praças de outros estados, a fim de verificar diferenças no comportamento dos usuários e na forma de operação das praças pelas concessionárias.

Um modelo de simulação mais elaborado deve ser desenvolvido para substituir o modelo usado que, em função das restrições de tempo e recursos, é muito pouco detalhado. A validação do modelo usado deixa a desejar; para o desenvolvimento de critérios de nível de serviços é essencial que o modelo seja submetido a um processo de validação mais rigoroso. Se os recursos estiverem disponíveis, seria conveniente que se desenvolvesse um modelo mais complexo, similar ao criado por Al-Deek et al. [2000]. Esse modelo, se submetido a um processo de calibração e validação apropriado, permitiria uma melhor representação da operação de praças de pedágio.

A recomendação final trata do estabelecimento dos limites entre os níveis de serviço e de uma melhor definição do que seja a capacidade da praça. O exemplo usado tem limitações claras no que diz respeito aos limites entre os níveis de serviço. Considerando-se a fila média como medida de desempenho, um aumento de um veículo na fila média faz com que o nível passe de A para B, de B para C e de C para D; o limite para o nível de serviço E, no entanto, é cerca de 30 veículos. A disparidade nos limites está relacionada aos tempos mé- 
dios de espera máximos em cada nível de serviço, que foram definidos a partir das sugestões de Lin e Su [1994] e Gulewicz e Danko [1995]. Seria conveniente que os limites entre os níveis fossem definidos com maior cuidado, a partir de análises mais detalhadas. 
ANEXOA:

Arquivos do I NTEGRATI ON 
Este anexo apresenta exemplos de arquivos de entrada de dados e arquivos de resultados gerados pelo INTEGRATION. Os arquivos possuem formato tipo texto (ASCII) e contém dados tabulados em colunas separadas por espaços.

Os itens a seguir mostram exemplos de arquivos utilizados para simular durante uma hora uma praça de pedágio com cinco cabines, sendo uma AVI, com fluxo de tráfego de 500 veíc/h composto por $65 \%$ de automóveis, $25 \%$ de caminhões e $10 \%$ de veículos portadores de AVI.

Após a listagem de cada arquivo é apresentada uma tabela com a descrição de todos os dados listados. Essa descrição restringe-se aos dados necessários para as simulações feitas por esta pesquisa. Sendo assim, os interessados na descrição de outros dados devem consultar o manual do INTEGRATION [Van Aerde, 2000].

\section{A.1 ARQUI VO MESTRE}

O arquivo mestre contém o tempo de simulação, os nomes dos arquivos essenciais para a simulação e os nomes dos arquivos de resultados. Esses arquivos devem ser adequadamente localizados através dos seus diretórios.

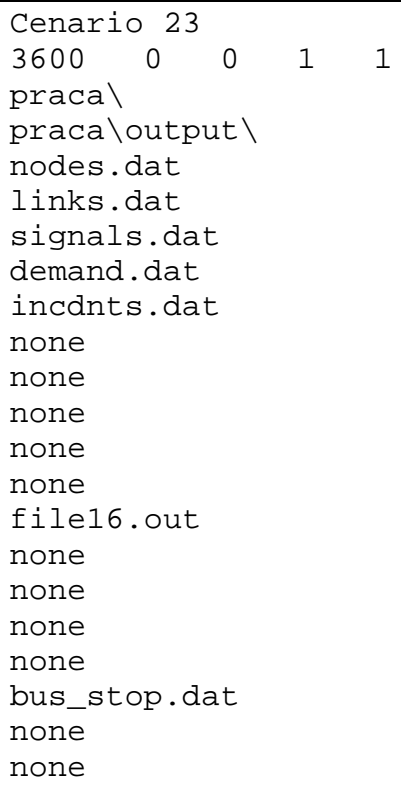


Tabela A.1: Descrição dos dados do arquivo mestre

\begin{tabular}{ccl}
\hline LI NHA & COLUNA & \multicolumn{1}{c}{ DESCRI ÇÃo } \\
\hline 1 & 1 & Identificação do cenário estudado (até 40 caracteres) \\
\hline & 1 & Tempo total da simulação (s) \\
& 2 & Freqüência da geração do arquivo file10 (s) \\
2 & 3 & Freqüência da geração dos arquivos file12-14 (s) \\
& 4 & Opção de rota \\
& 5 & Opção de pausa no tempo de simulação \\
\hline 3 & 1 & Nome do diretório em que se encontram os arquivos de entrada de dados \\
\hline 4 & 1 & Nome do diretório em que devem ser gerados os arquivos de resultados \\
\hline $5-9$ & 1 & Nome dos arquivos essenciais para a simulação \\
\hline $10-13$ & 1 & A palavra none deve aparecer nessas linhas \\
\hline 14 & 1 & Nome do arquivo padrão de resultado \\
\hline $15-27$ & 1 & Nome dos arquivos opcionais de entrada e de saída \\
\hline
\end{tabular}

\section{A.2 ARQUI VO DE NÓS}

O arquivo de nós contém as coordenadas dos nós da rede simulada, definindo quais nós constituem origem ou destino das demandas geradas.

\begin{tabular}{|rrrrr|}
\hline \multicolumn{2}{|c}{ Lista de nós } \\
22 & 1 & 1 & & \\
1 & 0.001 & 0.210 & 3 & 0 \\
2 & 1.600 & 0.210 & 2 & -2 \\
3 & 0.500 & 0.210 & 4 & 0 \\
4 & 0.550 & 0.210 & 4 & 0 \\
5 & 0.600 & 0.210 & 4 & 0 \\
6 & 0.780 & 0.350 & 4 & 0 \\
7 & 0.780 & 0.070 & 4 & 0 \\
8 & 0.850 & 0.420 & 4 & 0 \\
9 & 0.850 & 0.280 & 4 & 0 \\
10 & 0.850 & 0.140 & 4 & 0 \\
11 & 0.850 & 0.001 & 4 & 0 \\
12 & 0.950 & 0.420 & 4 & 0 \\
13 & 0.950 & 0.280 & 4 & 0 \\
14 & 0.950 & 0.140 & 4 & 0 \\
15 & 0.950 & 0.001 & 4 & 0 \\
16 & 1.020 & 0.350 & 4 & 0 \\
17 & 1.020 & 0.070 & 4 & 0 \\
18 & 1.170 & 0.210 & 4 & 0 \\
19 & 1.320 & 0.210 & 4 & 0 \\
20 & 1.480 & 0.210 & 4 & 0 \\
21 & 0.850 & 0.210 & 4 & 0 \\
22 & 0.950 & 0.210 & 4 & 0 \\
\hline
\end{tabular}


Tabela A.2: Descrição dos dados contidos no arquivo de nós

\begin{tabular}{ccl}
\hline LI NHA & COLUNA & \multicolumn{1}{c}{ DESCRI ÇÃO } \\
\hline 1 & 1 & Nome do arquivo (até 40 caracteres) \\
\hline \multirow{2}{*}{2} & 1 & Número de nós do arquivo \\
& 2 & Fator de escala para as coordenadas x \\
& 3 & Fator de escala para as coordenadas y \\
\hline \multirow{3}{*}{$3+$} & 1 & Número identificador do nó \\
& 2 & Coordenada x do nó \\
& 3 & Coordenada y do nó \\
& 4 & Tipo de nó (origem, destino, intermediário ou origem e destino) \\
& 5 & Identificador de macro-zonas \\
\hline
\end{tabular}

\section{A.3 ARQUI VO DE TRAMOS}

O arquivo de tramos contém as informações sobre os tramos da rede simulada. Essas informações se referem ao comprimento, aos nós de origem e destino e aos parâmetros que definem a relação fluxo-velocidade de cada tramo.

\begin{tabular}{|c|c|c|c|c|c|c|c|c|c|}
\hline Lis & ta & de & tramos & & & & & & \\
\hline 25 & 1 & 1 & $1 \quad 1$ & 1 & & & & & \\
\hline 1 & 1 & 3 & 0.500 & 110 & 2000 & 2 & 0.10 & 90 & 110 \\
\hline 2 & 3 & 4 & 0.050 & 110 & 2000 & 4 & 0.10 & 90 & 110 \\
\hline 3 & 4 & 5 & 0.050 & 110 & 2000 & 5 & 0.10 & 90 & 110 \\
\hline 4 & 5 & 6 & 0.200 & 90 & 2000 & 2 & 0.10 & 75 & 110 \\
\hline 5 & 5 & 7 & 0.200 & 90 & 2000 & 2 & 0.10 & 75 & 110 \\
\hline 6 & 6 & 8 & 0.100 & 65 & 2000 & 1 & 0.10 & 50 & 110 \\
\hline 7 & 6 & 9 & 0.100 & 65 & 2000 & 1 & 0.10 & 50 & 110 \\
\hline 8 & 7 & 10 & 0.100 & 65 & 2000 & 1 & 0.10 & 50 & 110 \\
\hline 9 & 7 & 11 & 0.100 & 65 & 2000 & 1 & 0.10 & 50 & 110 \\
\hline 10 & 8 & 12 & 0.100 & 50 & 2000 & 1 & 0.10 & 40 & 110 \\
\hline 11 & 9 & 13 & 0.100 & 50 & 2000 & 1 & 0.10 & 40 & 110 \\
\hline 12 & 10 & 14 & 0.100 & 50 & 2000 & 1 & 0.10 & 40 & 110 \\
\hline 13 & 11 & 15 & 0.100 & 50 & 2000 & 1 & 0.10 & 40 & 110 \\
\hline 14 & 12 & 16 & 0.100 & 50 & 2000 & 1 & 0.10 & 40 & 110 \\
\hline 15 & 13 & 16 & 0.100 & 50 & 2000 & 1 & 0.10 & 40 & 110 \\
\hline 16 & 14 & 17 & 0.100 & 50 & 2000 & 1 & 0.10 & 40 & 110 \\
\hline 17 & 15 & 17 & 0.100 & 50 & 2000 & 1 & 0.10 & 40 & 110 \\
\hline 18 & 16 & 18 & 0.200 & 90 & 2000 & 2 & 0.10 & 75 & 110 \\
\hline 19 & 17 & 18 & 0.200 & 90 & 2000 & 2 & 0.10 & 75 & 110 \\
\hline 20 & 18 & 19 & 0.150 & 100 & 2000 & 5 & 0.10 & 90 & 110 \\
\hline 21 & 19 & 20 & 0.150 & 100 & 2000 & 3 & 0.10 & 90 & 110 \\
\hline 22 & 20 & 2 & 0.100 & 105 & 2000 & 2 & 0.10 & 90 & 110 \\
\hline 23 & 5 & 21 & 0.275 & 90 & 2000 & 1 & 0.10 & 75 & 110 \\
\hline 24 & 21 & 22 & 0.150 & 50 & 2000 & 1 & 0.10 & 40 & 110 \\
\hline 25 & 22 & 18 & 0.275 & 90 & 2000 & 1 & 0.10 & 75 & 110 \\
\hline
\end{tabular}


Tabela A.3: Descrição dos dados contidos no arquivo de tramos

\begin{tabular}{ccl}
\hline LINHA & COLUNA & \multicolumn{1}{c}{ DESCRIÇÃO } \\
\hline 1 & 1 & Nome do arquivo (até 40 caracteres) \\
\hline 2 & 1 & $\begin{array}{l}\text { Número de tramos do arquivo } \\
\text { Fatores de escala para o comprimento do tramo, a velocidade de fluxo livre, a } \\
\text { capacidade, a velocidade na capacidade e a densidade de congestionamento }\end{array}$ \\
\hline & $2-6$ & Número identificador do tramo \\
& 2 & Número do nó inicial ou de origem do tramo \\
& 3 & Número do nó final do tramo \\
& 4 & Comprimento do tramo $(\mathrm{Km})$ \\
$3+$ & 5 & Velocidade de fluxo livre no tramo $(\mathrm{km} / \mathrm{h})$ \\
& 6 & Fluxo de saturação (veíc/ $\mathrm{h} /$ faixa) \\
& 7 & Número de faixas \\
& 8 & Coeficiente de variação da velocidade \\
& 9 & Velocidade na capacidade $(\mathrm{km} / \mathrm{h})$ \\
& 10 & Densidade de congestionamento (veíc/ $/ \mathrm{km} /$ faixa) \\
\hline
\end{tabular}

A Figura A.1 apresenta a rede completa simulada com seus respectivos nós e tramos.

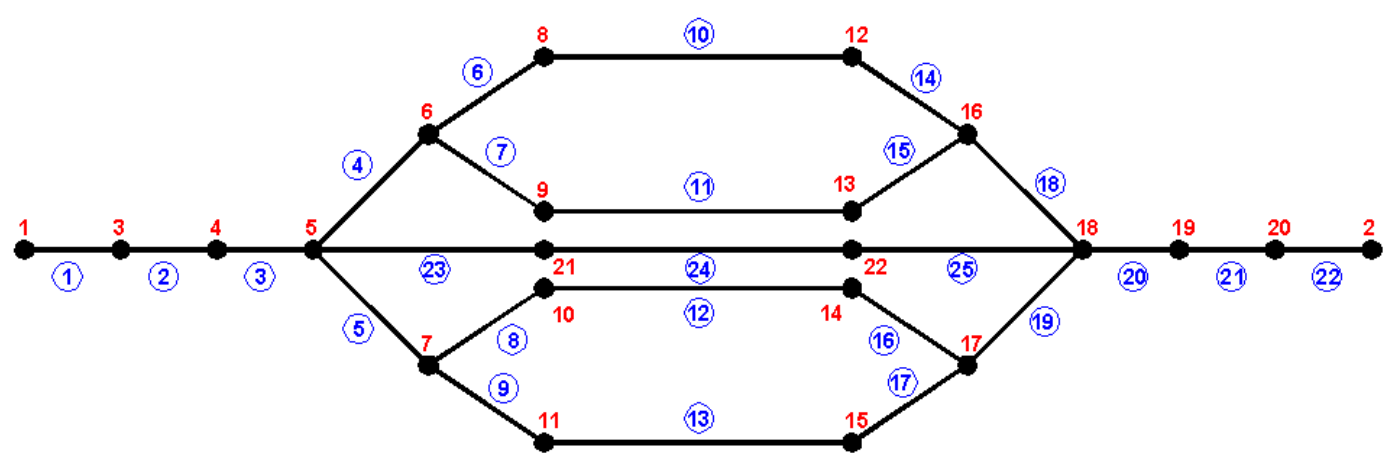

Figura A.1: Rede simulada (sem escala) 


\section{A.4 ARQUI VO DE SEMÁFOROS}

O arquivo de semáforos é necessário para a simulação apesar de não conter nenhum dado. Nesse caso, a primeira linha pode conter uma identificação para o arquivo e a segunda linha deve conter o número 0 .

semaforos

0

\section{A.5 ARQUI VO DE DEMANDA}

Este arquivo contém o fluxo horário a ser gerado durante o período de simulação e a composição do tráfego, além da distribuição dos headways e do fator de equivalência entre eles.

\begin{tabular}{|cccccccccccccc|}
\hline \multicolumn{2}{|c}{ demanda } \\
1 & 0 & 0 & 1 & & & & & & & & & & \\
1 & 1 & 2 & 500 & 1 & 0 & 3600 & 0.65 & 0.25 & 0.10 & 0 & 0 & 0.20 & 2 \\
\hline
\end{tabular}

Tabela A.4: Descrição dos dados contidos no arquivo de demanda

\begin{tabular}{ccl}
\hline LI NHA & COLUNA & \multicolumn{1}{c}{ DESCRIÇÃo } \\
\hline 1 & 1 & Nome do arquivo (até 40 caracteres) \\
\hline & 1 & Número de demandas geradas \\
2 & 2 & Número do primeiro par O-D a ser utilizado pelo modelo \\
& 3 & Número do último par O-D a ser utilizado pelo modelo \\
& 4 & Fator de escala para a demanda \\
\hline & 1 & Número identificador da demanda \\
& 2 & Número do nó de origem da demanda \\
& 3 & Número do nó de destino da demanda \\
& 4 & Demanda (veíc/h) \\
& 5 & Porcentagem de headways com distribuição exponencial \\
& 6 & Tempo de início da demanda (s) \\
& 7 & Tempo de término da demanda (s) \\
& $8-12$ & Porcentagem da demanda composta por cada tipo de veículo \\
& 13 & Porcentagem da demanda que será utilizada para gerar o arquivo file16 \\
& 14 & Fator de equivalência entre espaçamentos \\
\hline
\end{tabular}

\section{A.6 AQUI VO DE I NCI DENTES}

À exemplo do arquivo de semáforos, o arquivo de incidentes é necessário para a simulação apesar de não conter nenhum dado. A primeira linha pode conter uma identificação para o arquivo e a segunda linha deve conter o número 0. 
incidentes

0

\section{A.7 ARQUI VO DE PARADA (BUS_STOP.DAT)}

Este arquivo contém os dados que tornam possível simular o atendimento dos veículos na praça de pedágio. Ele é um arquivo opcional, ou seja, não é necessária a sua existência para rodar O INTEGRATION.

\begin{tabular}{|cccccccc|}
\hline \multicolumn{7}{l}{ parada } \\
8 & & & & & \\
1 & 10 & 0.050 & 1 & 22 & 0.51 & 10000 & 0.015 \\
2 & 11 & 0.050 & 1 & 22 & 0.51 & 10000 & 0.015 \\
3 & 12 & 0.050 & 1 & 22 & 0.51 & 10000 & 0.015 \\
4 & 13 & 0.050 & 1 & 22 & 0.51 & 10000 & 0.015 \\
5 & 10 & 0.050 & 1 & 35 & 0.43 & 01000 & 0.015 \\
6 & 11 & 0.050 & 1 & 35 & 0.43 & 01000 & 0.015 \\
7 & 12 & 0.050 & 1 & 35 & 0.43 & 01000 & 0.015 \\
8 & 13 & 0.050 & 1 & 35 & 0.43 & 01000 & 0.015 \\
\hline
\end{tabular}

Tabela A.5: Descrição dos dados contidos no arquivo de parada (bus_stop.dat)

\begin{tabular}{ccl}
\hline LI NHA & COLUNA & \multicolumn{1}{c}{ DESCRI ÇÃO } \\
\hline 1 & 1 & Nome do arquivo (até 40 caracteres) \\
\hline 2 & 1 & Número de pontos de parada \\
\hline & 1 & Número identificador do ponto de parada \\
& 2 & Número do tramo onde o ponto de parada está localizado \\
& 3 & Localização do ponto de parada em relação ao final do tramo $(\mathrm{km})$ \\
$3+$ & 4 & Faixa na qual o ponto de parada está localizado \\
& 5 & Tempo médio de parada (s) \\
& 6 & Coeficiente de variação do tempo de parada $(\mathrm{s})$ \\
& 7 & Classe veicular que pára no ponto \\
& 8 & Comprimento da área do ponto de parada $(\mathrm{km})$ \\
\hline
\end{tabular}

\section{A.8 ARQUI VO DE RESULTADOS}

O arquivo file10.out é o arquivo padrão de resultado. Entretanto, para obter os resultados requeridos por esta pesquisa fez-se uso de um arquivo de resultado opcional, o file16.out.

Este arquivo apresenta, além de outras informações, o tempo gasto por cada veículo gerado na simulação em cada um dos tramos da rede. A partir desses dados, pode-se obter o tempo total gasto pelos veículos no sistema. 


\begin{tabular}{|rrrrrl|}
\hline 194.6 & 21 & 2 & 1 & 16.4 & $\cdots$ \\
196.2 & 21 & 2 & 2 & 1.6 & $\cdots$ \\
198.1 & 21 & 2 & 3 & 1.9 & $\cdots$ \\
209.2 & 21 & 2 & 4 & 11.1 & $\cdots$ \\
215.8 & 21 & 2 & 6 & 6.6 & $\cdots$ \\
251.1 & 28 & 1 & 1 & 18.8 & $\cdots$ \\
254.8 & 28 & 1 & 2 & 3.7 & $\cdots$ \\
266.0 & 28 & 1 & 3 & 11.2 & $\cdots$ \\
269.7 & 21 & 2 & 10 & 53.9 & $\cdots$ \\
276.6 & 28 & 1 & 5 & 10.6 & $\cdots$ \\
276.9 & 21 & 2 & 14 & 7.2 & $\cdots$ \\
285.8 & 28 & 1 & 8 & 9.2 & $\cdots$ \\
285.9 & 21 & 2 & 18 & 9.0 & $\cdots$ \\
291.3 & 21 & 2 & 20 & 5.4 & $\cdots$ \\
296.6 & 21 & 2 & 21 & 5.3 & $\cdots$ \\
$\cdots$ & & & & \\
(demais & linhas do arquivo não mostradas) \\
\hline
\end{tabular}

Tabela A.6: Descrição dos resultados gerados no arquivo file16.out

\begin{tabular}{ccl}
\hline LI NHA & COLUNA & \multicolumn{1}{c}{ DESCRI ÇÃO } \\
\hline \multirow{3}{*}{$1+$} & 1 & Tempo de simulação (s) \\
& 2 & Número de identificação do veículo \\
& 3 & Classe veicular \\
& 4 & Número do tramo \\
& 5 & Tempo decorrido (s) \\
\hline
\end{tabular}

\section{A.9 ARQUI VO DE ESTATÍ STI CAS DA SI MULAÇÃO (RUNERR.OUT)}

Este arquivo apresenta diversas informações, tais como o número máximo de tramos ou veículos possíveis de ser simulado na versão do INTEGRATION que está sendo utilizada, eventuais erros de codificação, estatísticas do tempo de simulação, número de veículos a ser gerado, número de veículos em trânsito e número de viagens finalizadas.

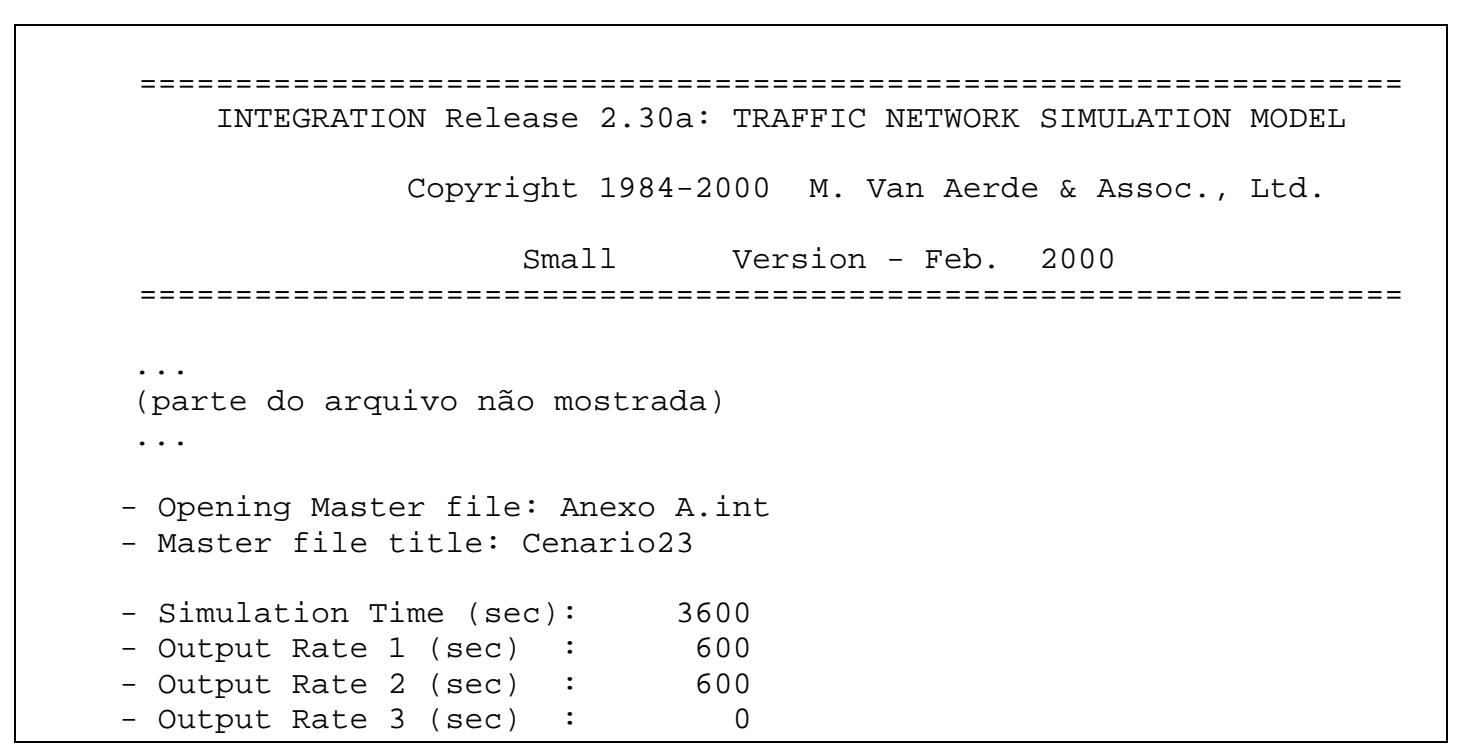




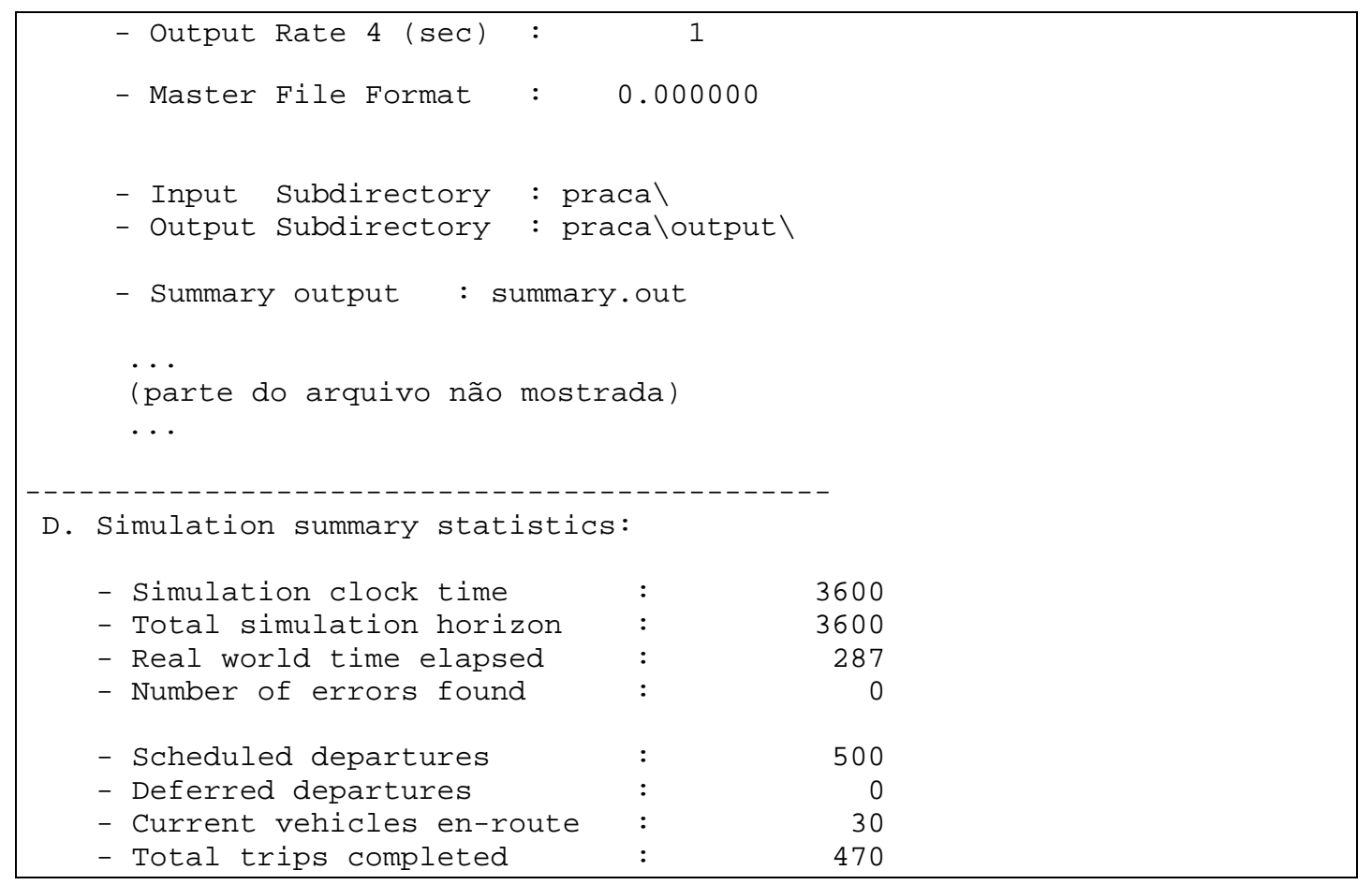

Tabela A.7: Descrição das estatísticas apresentadas no arquivo runerr.out

\begin{tabular}{cl}
\hline TíTULO & \multicolumn{1}{c}{ DESCRI ÇÃO } \\
\hline Simulation clock time & Tempo total de simulação previsto (s) \\
Total simulation horizon & Tempo total simulado (s) \\
Real world time elapsed & Tempo real de simulação (s) \\
Scheduled departures & Número total de veículos previsto para ser gerado durante a simulação \\
Deferred departures & Veículos que não chegam a entrar na rede durante a simulação \\
Current vehicles en-route & Veículos em trânsito no final da simulação \\
Total trips completed & Total de viagens finalizadas \\
\hline
\end{tabular}




\section{REFERÊNCI AS BI BLIOGRÁFI CAS}

Adler, J. L.; Cetin, M. [2000]. A Direct Redistribution Model of Congestion Pricing. Transportation Research Board, 79 ${ }^{\text {th }}$ Annual Meeting, National Research Council, Washington, D.C.

Al-Deek, H. M.; Radwan, A. E.; Mohammed, A. A; Klodzinski, J. G. [1996]. Evaluating the Improvements in Traffic Operations at a Real-Life Toll Plaza with Electronic Toll Collection. ITS J ournal, v. 3, n. 3, p. 205 - 223.

Al-Deek, H. M.; Mohamed, A. A.; Radwan, E. A. [2000]. A New Model for the Evaluation of Traffic Operations at Electronic Toll Collection Plazas. Artigo submetido ao $79^{\text {th }}$ Transportation Research Board Annual Meeting, National Research Council, Washington, D.C., Janeiro 2000.

Ardekani, S. A.; Torres, F. J. [1991]. Economic Evaluation of Toll Plaza Operations. Transportation Research Record 1305, Transportation Research Board, National Research Council, Washington, D.C., p. 160 - 168.

Banks, J.; Carson II, J. S. [1984]. Discrete-Event System Simulation. Prentice-Hall, Englewood Cliffs, New Jersey, EUA, p. 4.

Bennett, C. R.; Dunn, R. C. M. [1995]. Driver Deceleration Behaviour on a Freeway in New Zealand. Transportation Research Record 1510, Transportation Research Board, National Research Council, Washington, D.C., p. 70 - 75. 
Bonneson, J. A.; Fitts, J. W. [1995]. Traffic Data Collection Using Video-Based Systems. Transportation Research Record 1477, Transportation Research Board, National Research Council, Washington, D.C., p. 31 - 40.

Burris, M. W.; Hildebrand, E. D. [1996]. Using Microsimulation to Quantify the Impact of Electronic Toll Collection. ITE Journal, v. 66, n. 7, p. 21 - 24.

Chen, O. J.; Bernstein, D. [1995]. AM/PM Congestion Pricing with a Single Toll Plaza. Transportation Research Record 1498, Transportation Research Board, Washington, D.C., p. $23-31$.

Collard, A.; Alves, J. [1997]. Video Systems Breaks Through the Barriers of TransponderBased Tolling. ITS: Intelligent Transport Systems, n. 8, p. 52 - 54.

Dahlgren, J. [2000]. High Occupancy Vehicle/Toll Lanes: How Do They Operate and Where

Do They Make Sense? Artigo submetido ao $79^{\text {th }}$ Transportation Research Board Annual Meeting, National Research Council, Washington, D.C., Janeiro 2000.

Dando, M. [1997]. Electronic Toll Market. ITS: Intelligent Transport Systems, n. 8, p. 56 58.

Demarchi, S. H. [2000]. Influência dos Veículos Pesados na Capacidade e Nível de Serviço de Rodovias de Pista Dupla. São Carlos. 166p. Tese (Doutorado) - Escola de Engenharia de São Carlos, Universidade de São Paulo.

Doering, R. W. [1997]. Automatic Vehicle Identification Technology. SAIC Science and Technology Trends, p. 170 - 178.

Gazis, D. C.; Gomory, R. E. [1994]. Delays at Toll Booths - Why Wait in Line? Transportation Quarterly, v. 48, n. 2, p. 107 - 114.

Greenshields, B. D. [1935]. A Study of Traffic Capacity. Proceedings of HRB, v. 14, p. 448 477. Highway Research Board, Washington, D.C.

Gulewicz, V.; Danko, J. [1995]. Simulation-Based Approach to Evaluating Optimal Lane Staffing Requirements for Toll Plazas. Transportation Research Record 1484, Transportation Research Board, Washington, D.C., p. 33 - 39. 
Hamet, P. [1999]. Europe - the General Direction. Tolltrans, Traffic Technology International Supplement, out/nov 1999, p. 10 - 11.

Hillier, F. S.; Lieberman G. J. [1988]. Introdução à Pesquisa Operacional. Trad. por Helena L. Lemos. 3. ed. São Paulo, Campus/Edusp.

Howell, D. C. [1987]. Statistical Methods for Psychology. Duxbury Press Boston, Boston, EUA, p. 353.

King, J. [1997]. Bridging the Gap with Better Data. ITS: Intelligent Transport Systems, n. 8, p. 46.

Lin, F. B.; Su, C. W. [1994]. Level of Service Analysis of Toll Plazas on Freeway Main Lines. J ournal of Transportation Engineering, v. 120, n. 2, p. 246 - 263.

McDonald, D. R.; Stammer, R. E. [2000]. Creation of a Toll Plaza Design Model. Transportation Research Board, 79 ${ }^{\text {th }}$ Annual Meeting, National Research Council, Washington, D.C.

McManus, S. [1997]. Trucks Take Pioneering Role in German Toll Plans. ITS: Intelligent Transport Systems, n. 8, p. 44.

Nu-Metrics [1997]. NC-97 Manual. Uniontown, PA - U.S.A. - Nu-Metrics Customer Service Dept.

Pesquera, C. I.; González, S. L.; Contreras, C. M. [1997]. Short-Term Improvements to Increase Capacity of Highly Congested Mainline Toll Plazas in Puerto Rico. Transportation Research Record 1603, Transportation Research Board, National Research Council, Washington, D.C., p. 41 - 48.

Pietrzyk, M. C.; Mierzejewski, E. A. [1993]. Electronic Toll and Traffic Management (ETTM) Systems. NCHRP Synthesis of Highway Practice 194, Transportation Research Board, National Research Council, Washington, D.C.

Polus, A.; Reshetnik, I [1997]. A New Concept and a Manual for Toll Plaza Planning. Canadian J ournal of Civil Engineering, v. 24, n. 4, p. 532 - 538. 
Poppe, M. J.; Hook, D. J. P.; Howe, K. M. [1994]. Evaluation of High-Occupancy-Vehicle Lanes in Phoenix, Arizona. Transportation Research Record 1446, Transportation Research Board, National Research Council, Washington, D.C., p. 1 - 7.

Prendergast, J. [1995]. What Price Congestion Management? Civil Engineering, v. 65, n. 4, p. 57 - 59.

Reilly, W. R. [1992]. Operational Aspects of Highway Capacity. In: Pline, J. L. Traffic Engineering Handbook [4a. ed.], Prentice-Hall, Englewood Cliffs, New Jersey, Cap. 5, p. $117-153$.

Samuel, P. [1997]. One Step Forward and Two Steps Back. ITS: Intelligent Transport Systems, n. 8, p. 38 - 40.

Schaufler, A. E. [1997]. Toll Plaza Design. NCHRP Synthesis of Highway Practice 240, Transportation Research Board, National Research Council, Washington, D.C.

Schofer, J. L.; Czepiel, E. J. [2000]. Success Factors and Decision Issues for High Occupancy Vehicle Facilities. Transportation Research Board, $79^{\text {th }}$ Annual Meeting, National Research Council, Washington, D.C.

Setti, J. R. A. [1994]. Introdução àSimulação Discreta de Sistemas. São Carlos. EESC.

Setti, J. R. A. [1997]. Capacidade e Nível de Serviço de Rodovias de Pista Simples. Tese (Livre-Docência), EESC, USP. São Carlos, SP.

Spasovic, L. N.; Zhang, W.; Bladikas, A. K.; Pignataro, L. J.; Niver, E.; Ciszewski, S. [1995]. Primer on Electronic Toll Collection Technologies. Transportation Research Record 1516, Transportation Research Board, National Research Council, Washington, D.C., p. 1 - 10. Spock, L. M. [1998]. Tolling Practices for Highway Facilities. NCHRP Synthesis of Highway Practice 262, Transportation Research Board, National Research Council, Washington, D.C.

Sumner, R. [1999]. Monitoring the Monster. Tolltrans, Traffic Technology International Supplement, out/nov 1999, p. 39 - 43. 
Taylor, M. A. P.; Young, W.; Thompson, R. G. [1989]. Headway and Speed Data Acquisition Using Video. Transportation Research Record 1225, Transportation Research Board, National Research Council, Washington, D.C., p. 130 - 139.

TRB [2000]. Highway Capacity Manual. Transportation Research Board, National Research Council, Washington, D.C., EUA.

Turnbull, K. F.; Hall, K. M.; Ringrose, M. R. [1994]. High-Occupancy-Vehicle Treatments on Toll Facilities. Transportation Research Record 1446, Transportation Research Board, National Research Council, Washington, D.C., p. 14 - 24.

Van Aerde, M. [1995]. A single Regime Speed-Flow-Density Relationship for Congested and Uncongested Highways. Artigo apresentado na $74^{\text {th }}$ TRB Annual Conference, Washington, D.C.

Van Aerde, M. [2000]. Integration Release 2.30 for Windows: User's Guide. V. I e II. Queen's University. Kingston, Ontario, Canadá.

Widmer, J. A.; Iannoni, A.; Funchal, G. [1999]. Sistemática para o Dimensionamento do Número de Canais de Atendimento em Praças de Pedágio. In: XII Congresso de Pesquisa e Ensino em Transportes. Anais. São Carlos, v. 1, p. 585 - 596.

Woo, T. H.; Hoel, L. A. [1991]. Toll Plaza Capacity and Level of Service. Transportation Research Record 1320, Transportation Research Board, Washington, D.C., p. 119 - 127. Yermack, L.; Gallagher, M.; Marshall, K. R. [1995]. ETTM - An Early ITS Winner, ITE J ournal, v. 65, n. 12, p. $42-47$.

Zarrillo, M. L.; Radwan, A. E.; Al-Deek, H. M. [1997]. Modeling Traffic Operations at Electronic Toll Collection and Traffic Management Systems. Computers \& Industrial Engineering, v. 33, n. 3 - 4, p. 857 - 860.

Zarrillo, M. L. [2000]. Capacity Calculations for Two Toll Facilities: Two Experiences in ETC Implementation. Transportation Research Board, $79^{\text {th }}$ Annual Meeting, National Research Council, Washington, D.C.

Zlocchi, G. P. [1990]. Branch Toll Lanes: A Success Story at the Garden State Parkway. ITE J ournal, v. 60, n. 9, p. 21 - 24. 